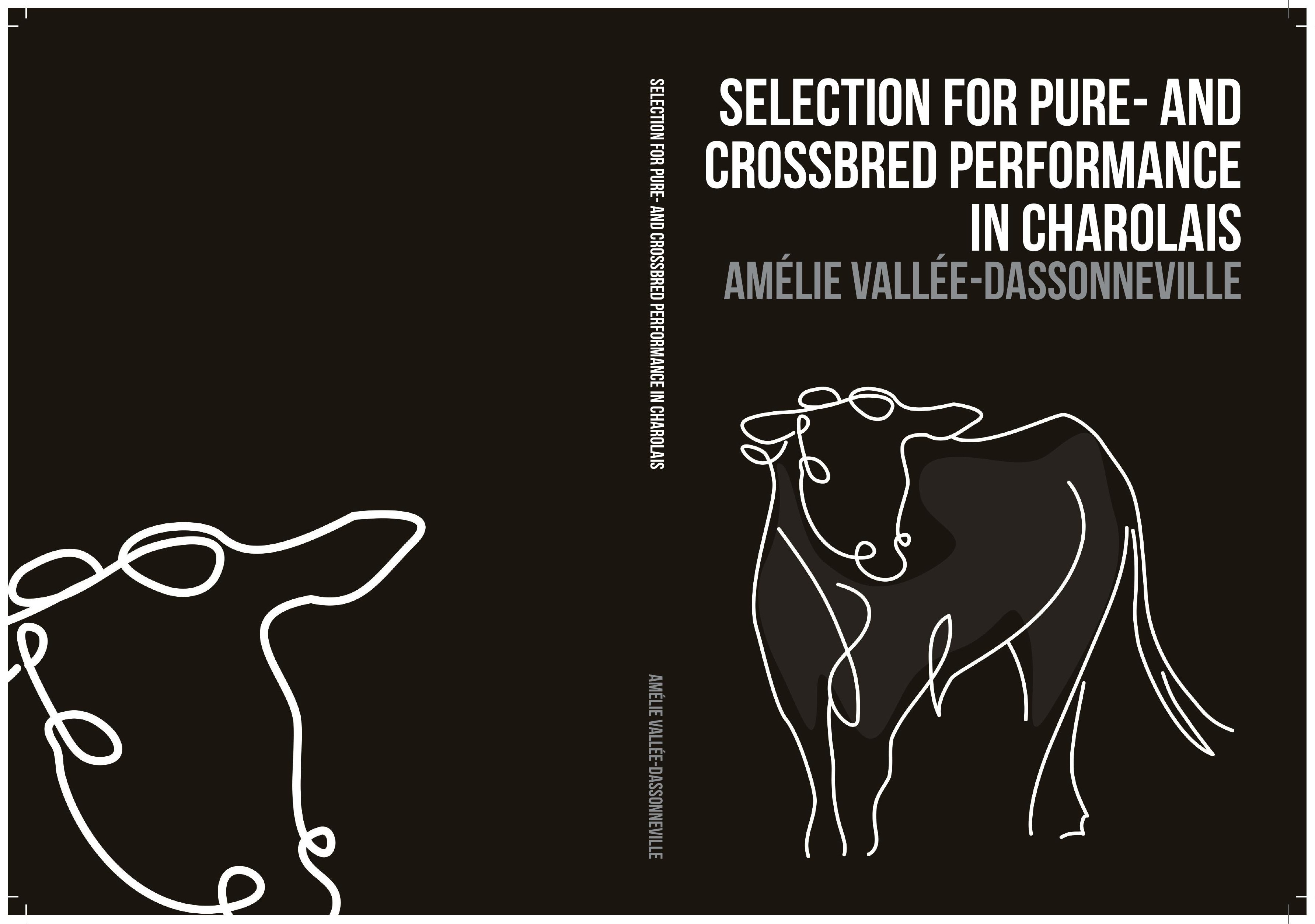




\section{Selection for pure- and crossbred performance in Charolais}

Amélie Vallée-Dassonneville 


\section{Thesis committee}

\section{Promotors}

Prof. Dr Johan A. M. van Arendonk

Professor of Animal Breeding and Genetics

Wageningen University

Prof. Dr Henk Bovenhuis

Personal chair at the Animal Breeding and Genetics Group

Wageningen University

\section{Other members}

Dr Sijne van der Beek, CRV, Arnhem, the Netherlands

Prof. Dr Donagh P. Berry, Teagasc, Cork, Ireland

Prof. Dr Mart C. M. de Jong, Wageningen University

Dr Andrés Legarra, INRA, Castanet-Tolosan, France

This research was conducted under the auspices of the Graduate School of Wageningen Institute of Animal Sciences (WIAS). 


\title{
Selection for pure- and crossbred performance in Charolais
}

\author{
Amélie Vallée-Dassonneville
}

\section{Thesis}

submitted in fulfillment of the requirements for the degree of doctor at Wageningen University

by the authority of the Rector Magnificus

Prof. Dr A. P. J. Mol, in the presence of the

Thesis Committee appointed by the Academic Board to be defended in public on Monday 13 February, 2017 at 1.30 p.m. in the Aula 
Vallée-Dassonneville, A.

Selection for pure- and crossbred performance in Charolais 151 pages.

PhD thesis, Wageningen University, Wageningen, NL (2017) With references and summary in English

ISBN: 978-94-6343-018-0

DOI: $10.18174 / 397975$ 


\begin{abstract}
Vallée-Dassonneville, A. (2017). Selection for pure- and crossbred performance in Charolais. PhD thesis, Wageningen University, Wageningen, NL.
\end{abstract}

Two categories of beef production exist; i.e. (i) purebred animals from a beef sire and a beef dam and (ii) crossbred animals from a beef sire and a dairy dam.

For the purebred beef production, there is a growing interest to include behavior and type traits in the breeding goal. Heritabilities for behavior traits, estimated using subjective data scored by farmers, range from 0.02 to 0.19 . Heritabilities for type traits range from 0.02 to 0.35 . Results show that there are good opportunities to implement selection for behavior traits using a simple on-farm recording system to allow collection of large data set, and for type traits in Charolais. A genome-wide association study detected 16 genomic regions with small effect on behavior and type traits. This suggests that behavior and type traits are influenced by many genes each explaining a small part of genetic variance.

The two main dairy breeds mated to Charolais sires for crossbred beef production in France are Montbéliard and Holstein. The genetic correlation between the same trait measured on Montbéliard x Charolais and on Holstein x Charolais was 0.96 for birth weight, 0.99 for muscular development; and 0.91 for calving difficulty, 0.80 for height, and 0.70 for bone thinness. Thus, for these last three traits, results show evidence for re-ranking of Charolais sires depending on whether they are mated to Montbéliard or Holstein cows. When using genomic prediction, the Montbéliard $x$ Charolais and Holstein x Charolais populations could be combined into a single reference population to increase size and accuracy of genomic prediction. Results indicate that the higher the genetic correlation is between the two crossbred populations, the higher the gain in accuracy is achieved when combining the two populations into a single reference.

The selection of Charolais sires to produce purebred or crossbred animals is made through distinct breeding programs. An alternative could be to combine selection into one breeding program. Decision for combining or keeping breeding programs separate is determined by the correlation between the breeding objectives, the selection intensity, the difference in level of genetic merit, the accuracy of selection, and the recent implementation of genomic evaluation. Considering all parameters and based on estimations for selection on birth weight, I recommend combining both breeding programs because this will lead to higher genetic gain, and might simplify operating organization and reduce associated costs. 



\section{Contents}

\begin{tabular}{|c|c|c|}
\hline & Abstract & \\
\hline Chapter 1 & General introduction & 9 \\
\hline Chapter 2 & $\begin{array}{l}\text { Genetic parameters for large-scale behavior traits and type } \\
\text { traits in Charolais beef cows }\end{array}$ & 25 \\
\hline Chapter 3 & $\begin{array}{l}\text { Genome-wide association study for behavior, type traits, } \\
\text { and muscular development in Charolais beef cattle }\end{array}$ & 45 \\
\hline Chapter 4 & $\begin{array}{l}\text { Genetic parameters for calving and conformation traits in } \\
\text { Charolais x Montbéliard and Charolais x Holstein crossbred } \\
\text { calves }\end{array}$ & 69 \\
\hline Chapter 5 & $\begin{array}{l}\text { Accuracy of genomic prediction when combining two } \\
\text { related crossbred populations }\end{array}$ & 85 \\
\hline Chapter 6 & General discussion & 101 \\
\hline & Summary & 129 \\
\hline & Curriculum vitae & 135 \\
\hline & Acknowledgements & 141 \\
\hline & Remerciements & 145 \\
\hline & Colophon & 149 \\
\hline
\end{tabular}





\section{1}

General introduction 



\subsection{Beef production sector}

Beef is the second most important meat produced in the EU-28 with 7.3 million tonnes, after pork with 21.9 million tonnes (Eurostat, 2013). Beef production of EU28 accounts for about $13 \%$ of total world production of beef. France is the principal beef producer in EU-28 with $19.4 \%$ (or 1.4 million tonnes), followed by Germany (15.2 \%), Italy (11.8\%), the United Kingdom (11.7\%), and Ireland (7.1\%) (Eurostat, 2013). Beef production is an economically important activity in France with a turnover of $€ 7.6$ billion (Eurostat, 2013). One third of the French beef sold originates from purebred animals from beef breeds (Eurostat, 2013). Purebred animals from beef breeds are born to "suckler cows" and raised in specialized beef farms where the primary objective is meat production. The other two thirds of the French beef sold is a by-product of the dairy sector. It includes culled dairy cows, male calves, and surplus female calves not required as dairy herd replacements. A common practice in dairy farms is to inseminate dairy cows not used for replacement of the herd with semen of beef sires to produce crossbred calves. This practice improves the value of calves from dairy herds for fattening. Calves are sold by dairy farmers at young age for fattening. The selling price of crossbred calf from a beef sire and a dairy dam is on average $250 €$ (trade price in July 2016) which is double the price of a purebred dairy calf (France AgriMer, 2016). Crossbred calves from a beef sire and a dairy dam have better meat production performance with $10 \%$ higher growth and $9 \%$ higher carcass weight than purebred dairy calves (Bouyssiere et al., 2013). Some countries, including France, have dedicated beef industries and breeds such as Limousin and Charolais for crossbreeding with dairy cattle. In France, 13.4\% of the calves born in dairy herds are crossbreds from a beef sire and a dairy dam (Bouyssiere et al., 2013). Three quarter of these crossbred calves is fed with a diet consisting of milk only and is slaughtered at five months. The rest of the crossbred calves is fed with cereal and slaughtered at 18 months.

\subsection{Breeding objectives for beef production systems}

For each of the categories of beef production; i.e. (i) purebred animals from a beef sire and a beef dam and (ii) crossbred animals from a beef sire and a dairy dam; distinct breeding programs exist to select the best purebred beef sires. In one breeding program, so-called "purebred breeding program", the objective is to select the best purebred beef sires for purebred performance. In the other 
breeding program, so-called "crossbred breeding program", the objective is to select the best purebred beef sires for crossbred performance.

\subsubsection{Purebred breeding program}

In the breeding program for purebred performance, growth is the most important trait to receive selection emphasis due to its positive association with profit (Phocas et al., 1995). Selecting for feed efficiency is highly desirable, as feed costs comprise a large proportion of variable costs associated with beef production (Arthur et al., 2001). Carcass quality is an increasingly important issue for consumers and thus the meat industry (Bredahl, 2001). Carcass quality includes marbling score, fat thickness, fat percentage, rib eye area, carcass weight, carcass conformation, color, tenderness, juiciness, and flavor (Pariacote et al., 1998; Melucci et al., 2012).

To produce young heifer for the replacement in a beef cattle herd, fertility, calving ease, and maternal ability are important traits to consider into the breeding objective. Fertility minimizes the non-productive period and help to maintain a seasonal calving pattern. Calving ease limits the costs due to the death of the calf or the cow, veterinary fees, and labor to supervise and assist cows during calving. Maternal ability refers to the cow's ability to suckle the calf and is related to the weaning weight of the calf. Gradually, interest has increased to include behavior and type traits into the breeding objective (Forabosco et al. 2007; Vargas et al. 2014). Aggressiveness is important as it is associated with human safety and workability (Le Neindre et al., 2002; Turner et al., 2013). Maternal care is associated with colostrum consumption and colostrum consumption is associated with immunity and calve survival (Frisch, 1982; Hoppe et al., 2008). Udder and teat conformation are functional traits related to calves ability to suckle (Edwards, 1982; Ventorp and Michanek, 1992) and their growth (Goonewardene et al., 2003). Feet and leg conformation and locomotion might be of interest in beef cattle, as in dairy cattle they have been associated with longevity (Larroque and Ducrocq, 2001; Sewalem et al., 2005). Longevity of suckler cows is directly related to farm profit. Increased longevity reduces costs associated with raising or purchasing replacement females, and increases the health and fitness of the animals (Forabosco, 2005). 


\subsubsection{Crossbred breeding program}

In the breeding program for crossbred performance, birth weight, muscularity, and shape are important traits to receive selection emphasis because they determine the selling price of the calves by dairy farmers. Another objective is to limit direct calving difficulty as it is costly. Costs related to calving difficulty are due to loss of the calf, veterinarian intervention, farmer labor (Meijering, 1986; Bekman and van Arendonk, 1993; Dekkers, 1994), delay in rebreeding and lower milk production resulting in increased culling rate (Luo et al., 2002; Hickey et al., 2007). However, increasing weight and conformation tends to conflict with the aim of reducing direct calving difficulties. As the incidence of calving difficulties is lower in mature cows than in heifers, a common practice is to mate mature dairy cows rather than heifers to beef sires. Moreover, if breeding for dairy production is successful and the population genetically improves, dairy heifers are the animals with highest genetic level in the herd and are preferably used for replacement. The selling price of the calves is determined at on average three weeks of age and does not account for growth during fattening and meat production. Therefore, production of calves later in life is not included in the breeding objective.

\subsection{Genetic improvement in beef breeding}

Genetic improvement in beef breeding mainly concerns production traits as they were the first traits to receive selection emphasis. Positive trends for weaning weight (from about 0.2 to $1.1 \mathrm{~kg}$ per annum) and for muscularity have been reported for the major French breeds including Charolais, between 1991 and 1995 (Journaux et al., 1996). Chud et al. (2014) reported annual genetic gain of $0.22 \%$ of the phenotypic mean for birth weight and $0.47 \%$ for weaning weight in Nellore breed between 1998 and 2008. Lower genetic trend $(0.14 \%$ of the phenotypic mean per year) for weaning weight was found in Nellore in the period from 1978 to 2008 (Zuin et al., 2012). For comparison, annual genetic gain for production traits between 1993 and 1997 in US Holsteins was 0.9 \% of phenotypic mean for milk yield and protein yield (Ducrocq and Wiggans, 2015). One reason that might explain the lower genetic improvement in beef cattle than in dairy cattle is the limited use of artificial insemination (AI) for beef cows. For about $11 \%$ of beef cows in France, insemination is by $\mathrm{Al}$, as compared to $70 \%$ for dairy cows (UNCEIA, 2013). The accuracy of breeding values for Al sires is in general considerably higher than for natural service sires. Furthermore, the use of Al allows increasing the selection intensity as fewer sires are needed to inseminate the female population as 
compared to natural service. As a consequence of higher accuracy of selection and higher selection intensity, the rate of genetic gain increases when using Al sires as compared to natural service sires (Harris and Newman, 1994; Betz, 2007). Moreover, the low genetic improvement in beef breeding probably reflects the early setting or the lack of performance and progeny testing programs, use of BLUP methodologies, or availability of national genetic evaluations (Kinghorn et al., 2015).

\subsection{Genomic selection in the beef cattle}

Genetic progress in beef cattle breeding might be increased by the use of genomic selection. Genetic progress $\Delta G$ is defined as:

$$
\Delta G=\frac{i r \sigma_{a}}{L}
$$

where $i$ is the selection intensity, $r$ is the accuracy of selection, $\sigma_{a}$ is the additive genetic standard deviation, and $L$ is the generation interval.

With the use of genomic selection, the generation interval $(L)$ can be shortened as the DNA sample can be collected at birth, so selection candidates can be evaluated at a much younger age, as compared to selection based on own performance or progeny testing. Shortening the generation interval by making use of genomic EBVs is particularly important for carcass traits and maternal traits as records on progeny are available when bulls are 4 years old and 6 years old respectively. With the use of genomic selection, selection intensity (i) might increase, as compared to selection based on own performance recording, as for some traits it is easier to genotyped than to phenotype animals. Consider a trait like feed efficiency which is expensive to record so the number selection candidates that can be recorded and used for selection is limited. Once you have created a reference population, the number of selection candidates with genomic evaluation can easily overcome the number of candidates with phenotypic observations (Miller, 2010). With the use of genomic evaluation, accuracy of selection $(r)$ may increase, as compared to evaluation based on pedigree information, own performance, and progeny testing when the number of progeny is low. Consider farmers selecting bulls for natural mating; the only information available is pedigree information and own performance. With genomic evaluation, farmers have the opportunity to enhance breeding value estimation with genomic information (Swan et al., 2012). 
However, implementation of genomic selection has been slow in beef cattle because of the difficulty to build a reference population of sufficient size to set up genomic prediction with sufficient level of accuracy. As the beef industry does not heavily use $\mathrm{Al}$ (about 11\% of the beef cows inseminated by Al in France; UNCEIA, 2013), few progeny tested sires with accurate EBVs are available for the reference population. Moreover, the beef industry is not dominated by one major breed, such as Holstein in dairy, but consists of various cattle breeds. One option might be to create a multi-breed reference population, however, increase in accuracy by combining different beef breeds for genomic evaluation is low (Bolormaa et al., 2013; Chen et al., 2013; Kachman et al., 2013; Boerner et al., 2014). Therefore, currently reference populations in beef cattle mainly have to rely upon information within a breed.

Recently, efforts in building reference populations for the most numerically important breeds have resulted in the availability of within-breed genomic evaluations. In Australia, genomic evaluation is available for growth traits with relatively high accuracy ranging from 0.52 to 0.73 . However, maximum accuracy for carcass traits is 0.48 ; and 0.33 for female reproduction traits (Johnston et al., 2012). In the US, the main breed associations have developed, in collaboration with national institutes, within-breed genomic evaluations (reviewed by van Eenennaam et al., 2014). Genomic evaluation in Angus has the highest accuracies (between 0.32 and 0.90 ) as it is the major beef breed in the US and therefore has the largest reference population. However, for smaller breeds in the US such as Hereford or Limousin, accuracy is lower and varies between 0.37 and 0.76 . Commercial genomic companies, such as GeneSeek and Zoetis, offer genomic evaluation in Angus. Accuracies range from 0.20 to 0.45 in an Australian validation population (Johnston et al., 2012) and from 0.24 to 0.65 in an American validation population (Northcutt, 2011). In France, genomic evaluations are available for Charolais, Blonde d'Aquitaine, and Limousin. For Charolais, which is the major beef breed in France, accuracy is 0.42 for birth weight, 0.34 for direct calving ease, 0.45 for weaning weight, and ranges from 0.27 to 0.52 for conformation traits (Gunia et al., 2014). 


\subsection{Charolais breed}

Charolais is a specialized beef breed used for the purebred beef production system and for terminal cross with dairy dams. Charolais animals are white in color. Average birth weight of calves is $45 \mathrm{~kg}$ and $93 \%$ of calving occurs without problems (Herd Book Charolais, 2016 a). Charolais are medium to large framed beef cattle with a very deep and broad body. Height at withers of adult cows ranges from 135 to $150 \mathrm{~cm}$, and weight ranges from $700 \mathrm{~kg}$ to 1,200 kg (Herd Book Charolais, 2016 a). Charolais animals are characterized by a high growth potential with an average of $2.2 \mathrm{~kg} /$ day during fattening (Herd Book Charolais, 2016 a). Age at slaughter is 18 months on average and animals have good carcass characteristics with a carcass weight of $438 \mathrm{~kg}$ and 52\% of net average dressing (Herd Book Charolais, $2016 \mathrm{a}$ ).

The breed originates from the east-central part of France. Nowadays, with more than 1.6 million of purebred cows, Charolais breed is the most important beef breed in France and represents $40 \%$ of the total number of beef cows (Herd Book Charolais, 2016 b). Since 1960s, Charolais animals have been exported from France (Bougler et al., 1973; Blackburn and Gollin, 2009). Charolais is the main beef cattle breed in Europe and is principally present in Ireland, Sweden, and in Czech Republic (Simm, 1998). In the US, 6.1\% of the total number of new born beef calves are Charolais and 3.8\% in Australia (Herd Book Charolais, 2016 c).

Charolais breed is widely used for crossbreeding. In France, it is the most common beef breed used for terminal crossing with dairy cows and represents $46 \%$ of crossbred calves born from dairy cows (Herd Book Charolais, 2016 b). In several major beef-producing countries (e.g. the USA, Australia, Brazil) and in tropical regions, there has been strong interest in crossing Charolais with Bos indicus breeds such as Brahman and Zebu to combine growth potential with maternal ability and meat quality (Mourão et al., 2008; Hearnshaw et al., 1998).

\subsection{Aim and outline of this thesis}

This dissertation considers a number of aspects related to selection in Charolais cattle for performance of purebred cows and performance of crossbred calves from dairy cows.

The focus of Charolais breeding for purebred performance has moved to functional traits, i.e. traits that increase the efficiency of the animals by reducing costs of input (Groen et al., 1997; Kühn, 2003). In chapter 2, variance components, 
heritabilities, genetic and phenotypic correlations among behavior and type traits are estimated.

Genomic regions associated with functional traits may be used in genomic selection. To our knowledge, no association studies have been published for behavior and type traits in Charolais. Information on genes involved in these traits might provide valuable insight in the genetic background of these traits and information about genes might be included in the breeding value estimation. In chapter $\mathbf{3}$ a genome-wide association study is performed to investigate if associations between markers and behavior or type traits could be identified.

Charolais sires are selected based on the performance of their crossbred offspring that result from matings with dairy cows. In France, the two main dairy breeds mated to Charolais sires are Montbéliard and Holstein. The estimated breeding value of Charolais sires might differ depending on the dam breed they are mated to. In chapter 4, variance components, heritabilities, genetic and phenotypic correlations are evaluated for Montbéliard $\mathrm{x}$ Charolais and Holstein $\mathrm{x}$ Charolais performances. Genetic correlations between the two crossbred populations are estimated in order to investigate whether the traits observed in Holstein $x$ Charolais and Montbéliard $x$ Charolais populations are genetically the same.

Selection of Charolais bulls for crossbred performance could benefit from genomic selection. One could build a reference population with the Montbéliard $x$ Charolais calves and a reference population with the Holstein $x$ Charolais calves independently. An alternative could be to combine both crossbred populations into a single reference population to increase size and accuracy of prediction. In chapter $\mathbf{5}$, the accuracy of genomic prediction by combining different crossbred populations is explored.

The selection of Charolais sires to produce purebred animals on specialized beef herds and to produce crossbred calves on dairy herds is made through distinct breeding programs. In the general discussion, chapter $\mathbf{6}$, each breeding program is described. The same breeding organization might run one breeding program for purebred and one for crossbred offspring. Combining selection for purebred and crossbred in one breeding program will reduce the cost of selection but might affect genetic progress. Opportunities to combine the two breeding programs are discussed in chapter 6. 


\subsection{References}

Arthur, P. F., J. A. Archer, D. J. Johnston, R. M. Herd, E. C. Richardson, and P. F. Parnell. 2001. Genetic and phenotypic variance and covariance components for feed intake, feed efficiency and other post-weaning traits in Angus cattle. J. Anim. Sci. 79:2805-2811.

Bekman, H., and J. A. M. van Arendonk. 1993. Derivation of economic values for veal, beef and milk production traits using profit equations. Livest. Prod. Sci. 34:35-56.

Betz, G. C. M. 2007. Using the rate of genetic change and the population structure of cattle to better target genetic progress. Proc. $39^{\text {th }}$ Beef Improvement Federation Symp., Fort Collins, USA. p. 103-109.

Blackburn, H., and D. Gollin. 2009. Animal genetic resource trade flows: The utilization of newly imported breeds and the gene flow of imported animals in the United States of America. Livest. Sci. 120:240-247.

Boerner, V., D. J. Johnston, and B. Tier. 2014. Accuracies of genomically estimated breeding values from pure-breed and across-breed predictions in Australian beef cattle. Genet. Sel. Evol. 46:61.

Bolormaa, S., J. E. Pryce, K. Kemper, K. Savin, B. J. Hayes, W. Barendse, Y. Zhang, C. M. Reich, B. A. Mason, R. J. Bunch, B. E. Harrison, A. Reverter, R. M. Herd, B. Tier, H.-U. Graser, and M. E. Goddard. 2013. Accuracy of prediction of genomic breeding values for residual feed intake and carcass and meat quality traits in Bos taurus, Bos indicus, and composite beef cattle. J. Anim. Sci. 91:3088-3104.

Bougler, J., B. Coudurier, J.-M. Duplan, H. Hocde, H. Le Liboux, R. Tondu, and B. Vissac. 1973. Performances de production. La race Charolaise - Résultats français. INRA, Jouy-en-Josas, France. p. 265-339.

Bouyssiere, S., M. Carlier, and B. Lelyon. 2013. Le croisement viande en élevage laitier : état des lieux des pratiques et perspectives. Proc. Renc. Rech. Ruminants, Paris, France. 20:225-228.

Bredahl, L. 2001. Determinants of consumer attitudes and purchase intentions with regard to genetically modified food - Results of a cross-national survey. J. Cons. Policy. 24:23-61. 
Chen, L., F. Schenkel, M. Vinsky, D. Crews, and C. Li. 2013. Accuracy of predicting genomic breeding values for residual feed intake in Angus and Charolais beef cattle. J. Anim. Sci. 91:4669-4678.

Chud, T. C. S., S. L. Caetano, M. E. Buzanskas, D. A. Grossi, D. G. F. Guidolin, G. B. Nascimento, J. O. Rosa, R. B. Lôbo, and D. P. Munari. 2014. Genetic analysis for gestation length, birth weight, weaning weight, and accumulated productivity in Nellore beef cattle. Livest. Sci. 170:16-21.

Dekkers, J. C. M. 1994. Optimal breeding strategies for calving ease. J. Dairy Sci. 77:3441-3453.

Ducrocq, V., and G. Wiggans. 2015. Genetic improvement of dairy cattle. The genetics of cattle, 2 nd edition. p. $371-396$.

Edwards, S. A. 1982. Factors affecting the time to first suckling in dairy calves. Anim. Prod. 34:339.

Eurostat. 2013. Statistiques agricoles au niveau régional. http://ec.europa.eu/eurostat/statisticsexplained/index.php/Agricultural_products/fr (Accessed 16 Septembre 2016).

Falconer, D. 1960. Introduction to quantitative genetics. Ronald Press Co, New York, USA.

Forabosco F., R. Bozzi, P. Boettcher, F. Filippini, P. Bijma, and J. A. M. van Arendonk. 2005. Relationship between profitability, type traits and derivation of economic values in Chianina beef cows. J. Anim. Sci. 83:2043-2051.

Forabosco F., V. Palucci, and W. F. Fikse. 2007. Selecting traits for international beef evaluations: survey results. Interbull Bulletin $37: 168$.

France AgriMer. 2016. Chiffres et bilans http://www.franceagrimer.fr/filiereviandes/Viandes-rouges/Informations-economiques/Chiffres-et-bilans (Accessed 16 Septembre 2016).

Frisch, J. E. 1982. The use of teat-size measurements or calf weaning weight as an aid to selection against teat defects in cattle. Anim. Prod. 32:127-133.

Gunia, M., R. Saintilan, E. Venot, C. Hozé, M.-N. Fouilloux, and F. Phocas. 2014. Genomic prediction in French Charolais beef cattle using high-density single nucleotide polymorphism markers. J Anim Sci. 92:3258-69. 
Goonewardene, L. A., Z. Wang, M. A. Price, R.-C. Yang, R. T. Berg, and M. Makarechian. 2003. Effect of udder type and calving assistance on weaning traits of beef and dairy $x$ beef calves. Livest. Prod. Sci. 81:47-56.

Groen, A. F., T. Steine, J.-J. Colleau, J. Pedersen, J. Pribyl, and N. Reinsch. 1997. Economic values in dairy cattle breeding, with special reference to functional traits. Report of an EAAP-working group. Livest. Prod. Sci. 49:1-21.

Harris, D. L., and S. Newman. 1994. Breeding for profit: synergism between genetic improvement and livestock production (a review). J Anim Sci 72:21782200.

Hearnshaw, H., B. G. Gursansky, B. Gogel, J. M. Thompson, L. R. Fell, P. D. Stephenson, P. F. Arthur, A. F. Egan, W. D. Hoffman, and D. Perry. 1998. Meat quality in cattle of varying Brahman content: the effect of postslaughter processing, growth rate and animal behaviour on tenderness. Proc. Int. Congr. Meat Sci. Technol., Spain. p. 1048-1049.

Herd Book Charolais. 2016 a. Les performances de la race charolaise. http://charolaise.fr/la-charolaise/les-performances-de-la-racecharolaise/ (Accessed 16 Septembre 2016).

Herd Book Charolais. 2016 b. Les chiffres clés de la race charolaise. http://charolaise.fr/la-charolaise/les-chiffres-cles-de-la-race-charolaise/ (Accessed 16 Septembre 2016).

Herd Book Charolais. 2016 c. La Charolaise : Première race allaitante d'Europe très utilisée à l'International. http://charolaise.fr/la-charolaise/la-charolaisea-linternational/ (Accessed 16 Septembre 2016).

Hickey, J. M., M. G. Keane, D. A. Kenny, A. R. Cromie, P. R. Amer, and R. F. Veerkamp. 2007. Heterogeneity of genetic parameters for calving difficulty in Holstein heifers in Ireland. J. Dairy Sci. 90:3900-3908.

Hoppe, S., H. R. Brandt, G. Erhardt, and M. Gauly. 2008. Maternal protective behaviour of German Angus and Simmental beef cattle after parturition and its relation to production traits. Appl. Anim. Behav. Sci. 114:297306.

Johnston, D. J., B. Tier, and H.-U. Graser. 2012. Beef cattle breeding in Australia with genomics: opportunities and needs. Anim. Prod. Sci. 52:100-6. 
Journaux, L., E. Rehben, D. Laloë, and F. Ménissier. 1996. Main results of the genetic evaluation IBOVAL96 for the beef cattle sires. Edition 1996(1). Institut de l'Elevage and INRA, Jouy-en-Josas, France.

Kachman, S. D., M. L. Spangler, G. L. Bennett, K. J. Hanford, L. A. Kuehn, W. M. Snelling, R. M. Thallman, M. Saatchi, D. J Garrick, R. D. Schnabel, J. F. Taylor, and E. J. Pollak. 2013. Comparison of molecular breeding values based on within- and across-breed training in beef cattle. Genet. Sel. Evol. 45: 30.

Kinghorn, B. P., R. G. Banks, and G. Simm. 2015. Genetic improvement of beef cattle. The genetics of cattle, $2^{\text {nd }}$ edition. p. $451-473$.

Kühn, C., J. Bennewitz, N. Reinsch, N. Xu, H. Thomsen, C. Looft, G. A. Brockmann, M. Schwerin, C. Weimann, S. Hiendleder, G. Erhardt, I. Medjugorac, M. Förster, B. Brenig, F. Reinhardt, R. Reents, I. Russ, G. Averdunk, J. Blümel, and E. Kalm. 2003. Quantitative Trait Loci mapping of functional traits in the German Holstein cattle population. J. Dairy Sci. 86:360-368.

Larroque, H., and V. Ducrocq. 2001. Relationships between type and longevity in the Holstein breed. Genet. Sel. Evol. 33:39-59.

Le Neindre, P., L. Gringnard, G. Trillat, A. Boissy, F. Ménissier, F. Sapa, and X. Boivin. 2002. Docile Limousin cows are not poor mothers. Proc. 7th World Congr. Genet. Appl. Livest. Prod., Montpellier, France. p. 59-62.

Luo, M. F., P. J. Boettcher, L. R. Schaeffer, and J. C. M. Dekkers. 2002. Estimation of genetic parameters of calving ease in first and second parities of Canadian Holsteins using Bayesian methods. Livest. Prod. Sci. 74:175184.

Meijering, A. 1986. Dystocia in dairy cattle breeding with special attention to sire evaluation for categorical traits. Ph.D. Diss. Wageningen University, Wageningen, The Netherlands.

Melucci, L. M., M. Panarace, P. Feula, E. L. Villarreal, G. Grigioni, F. Carduza, L. A. Soria, C. A. Mezzadra, M. E. Arceo, J. Papaleo Mazzucco, P. M. Corva, M. Irurueta, A. Rogberg-Muñoz, and M. C. Miquel. 2012. Genetic and management factors affecting beef quality in grazing Hereford steers. Meat Sci. 92:768-774.

Miller, S. 2010. Genetic improvement of beef cattle through opportunities in genomics. R. Bras. Zootec. 39:247-255. 
Mourão, G. B., J. B. Ferraz, J. P. Eler, R. S. Bueno, J. C. Balieiro, E. C. Mattos, and L. G. Figueiredo. 2008. Non-additive genetic effects on weights and performance of a Brazilian Bos taurus x Bos indicus beef composite. J. Genet. Mol. Res. 7:1156-1163.

Northcutt, S. L. 2011. Genomic choices. Available at http://www.angus.org/AGI/GenomicChoiceApril2011.pdf (Accessed 20 September 2016).

Pariacote, F., L. van Vleck, and R. Hunsley. 1998. Genetic and phenotypic parameters for carcass traits of american shorthorn beef cattle. J. Anim. Sci. 76:2584-2588.

Phocas, F., J. J. Colleau, and F. Ménissier. 1995. Expected efficiency of selection for growth in a French beef cattle breeding scheme. I. Multistage selection of bulls used in artificial insemination. Genet. Sel. Evol. 27:149-170.

Sewalem, A., G. J. Kistemaker, and B. J. van Doormaal. 2005. Relationship between type traits and longevity in canadian Jersey and Ayrshires using a Weibull proportional hazards model. J. Dairy Sci. 88:1552-1560.

Simm, G. 1998. Genetic improvement of cattle and sheep. Farming Press. Old Pond Publishing, Ipswich, UK.

Swan, A. A., D. J. Johnston, D. J. Brown, B. Tier, and H.-U. Graser. 2012. Integration of genomic information into beef cattle and sheep genetic evaluations in Australia. Anim. Prod. Sci. 52:126-132.

Turner, S. P., M. C. Jack, and A. B. Lawrence. 2013. Precalving temperament and maternal defensiveness are independent traits but precalving fear may impact calf growth. J. Anim. Sci. 91:4417-4425.

UNCEIA. 2013. Insémination animale en France - Statistique 2013 - Espèce bovine. Méd'ia, Paris, France.

van Eenennaam, A. L., K. A. Weigel, A. E. Young, M. A. Cleveland, and J. C. M. Dekkers. 2014. Applied animal genomics: Results from the field. Annu. Rev. Anim. Biosci. 2:105-39.

Vargas, G., H. H. R. Neves, V. Cardoso, D. P. Munari, and R. Carvalheiro. 2014. Genetic analysis of feet and legs in Nellore cattle. Proc $10^{\text {th }}$ World Congr. Genet. Appl. Livest. Prod., Vancouver, Canada. p. 61. 
Ventorp, M., and P. Michanek. 1992. The importance of udder and teat conformation for teat seeking by the newborn calf. J. Dairy Sci. 75:262268.

Zuin, R. G., M. E. Buzanskas, S. L. Caetano, G. C. Venturini, D. G. F. Guidolin, D. A. Grossi, T. C. S. Chud, C. C. P. Paz, R. B. Lôbo, and D. P. Munari. 2012. Genetic analysis on growth and carcass traits in Nelore cattle. Meat Sci. 91:352-357. 



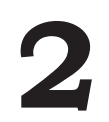

\title{
Genetic parameters for large-scale behavior traits and type traits in Charolais beef cows
}

\author{
A. Vallée ${ }^{1,2}$, I. Breider $^{1}$, J. A. M. van Arendonk ${ }^{1}$, and H. Bovenhuis ${ }^{1}$
}

${ }^{1}$ Animal Breeding and Genomics Centre, Wageningen University, PO Box 338, 6700 $\mathrm{AH}$, Wageningen, the Netherlands; ${ }^{2}$ Gènes Diffusion, 3595 route de Tournai, CS70023, 59501 Douai Cedex, France

Journal of Animal Science (2015) 93(9):4277-4284 


\section{Abstract}

In the last decades, beef cattle breeding mainly focused on improving production and reproduction traits. Nowadays, there is a growing interest to include behavior and type traits in the breeding goal. There is an interest in behavior as it is associated with human safety and workability, and in type traits as they might be associated with longevity of cows. The objective of the current study was to estimate the heritability for behavior and type traits in Charolais, and to estimate the genetic correlations among these traits. Behavior traits, including aggressiveness at parturition, aggressiveness during gestation period, and maternal care, were scored by farmers using an on-farm recording system to enable large scale collection of phenotypes. Type traits, including udder traits $(n=3)$, teat traits (3), feet and leg traits (5), and locomotion (1), were scored by ten trained classifiers. Data was available on 6,649 cows, in parity 1 to 12 and located on 380 herds. Results showed that differences between herds explained up to $23 \%$ of the total phenotypic variance in behavior traits. This might be due to differences in management or to consistent differences in scoring between farmers. Aggressiveness at parturition had higher heritability (0.19) and higher genetic coefficient of variation $\left(\mathrm{CV}_{\mathrm{a}}=11 \%\right)$ than aggressiveness during gestation $\left(\mathrm{h}^{2}=0.06\right.$ and $\left.\mathrm{CV}_{\mathrm{a}}=4 \%\right)$ and maternal care $\left(\mathrm{h}^{2}=0.02\right.$ and $\left.\mathrm{CV}_{\mathrm{a}}=2 \%\right)$. Heritabilities for udder traits $(0.14$ to 0.20$)$ and teat traits $(0.17$ to 0.35$)$ were higher than for feet and leg traits (0.02 to 0.19$)$. Genetic coefficients of variation for udder and teat traits were also higher (up to $21 \%$ ) than for feet and leg traits (up to $11 \%$ ). Strong genetic correlations were found between behavior traits (with absolute values from 0.71 to 0.98). The genetic correlations indicate that it is difficulty to simultaneously improve maternal care and reduce aggressiveness. We concluded that there are good opportunities to implement selection for improved udder and teat traits and against aggressiveness at parturition using a simple on-farm recording system of behavior.

Key words: behavior traits, beef cattle, Charolais, heritability, type traits 


\subsection{Introduction}

In the past decades, breeding goals in beef cattle only included traits directly related with profitability, such as production or reproduction (Phocas et al., 1995; Phocas et al., 1998). Nowadays, there is interest to include behavior and type traits in selection (Forabosco et al. 2007; Vargas et al. 2014). Aggressiveness is important as it is associated with human safety and workability (Le Neindre et al., 2002; Turner et al., 2013). Maternal care is associated with colostrum consumption, immunity, and calve survival (Frisch, 1982; Hoppe et al., 2008). Udder and teat conformation are functional traits interfering with calves ability to suckle (Edwards, 1982; Ventorp and Michanek, 1992) and their growth (Goonewardene et al., 2003). Feet and leg conformation and locomotion might be of interest as in dairy cattle they have been associated with longevity (Larroque and Ducrocq, 2001; Sewalem et al., 2005).

Previous studies on behavior in beef cattle used detailed behavioral characterization collected by trained and experienced classifiers, involving a limited number of records, and therefore limited accuracy of the genetic estimates (Morris et al. 1994; Hoppe et al., 2008; Benhajali et al. 2010; Schmidt at al., 2014). Larger number of records can be obtained by asking farmers to score their animals. A similar system has been successfully implemented in dairy cattle for temperament during milking (e.g. Beard, 1993). Studies estimating heritability and correlation of udder and teat conformation are rare in beef cattle, unlike in dairy (Gutiérrez and Goyache, 2002; Varona et al., 2012). Slightly more studies have been conducted on feet and leg (Mantovani et al. 2010; Jeyaruban et al. 2012), but only one study in Charolais (Norris et al. 2008).

The objective was to estimate heritabilities and genetic correlations for behavior and type traits in Charolais. The estimates will be used to assess the possibilities of selection using on-farm recording system.

\subsection{Materials and Methods}

The guidelines stated in the Guide for the Care and Use of Agricultural Animals in Research and Teaching (FASS, 2010) were followed when collecting information on the animals. 


\subsubsection{Data}

Data from 6,649 cows scored for behavior and type traits were considered, originating from $76 \mathrm{Al}$ sires and 6,080 dams. The number of daughters per sire ranged from 1 to 455 and was on average 87. Twenty five sires had less than 25 daughters, and 25 sires had more than 100 daughters. Cows were born in 380 different herds located in the North-East and West of France. In total, 860 cows moved to another herd during their life, but the herd at scoring could not be traced back so herd of birth was considered for further analysis. Per herd, the maximum number of observations was 125 , and the average was 18 . The minimum number of observations per herd was set to three so observations from 67 cows in 52 herds were initially removed. Forty herds had less than five cows with phenotypes, and fourteen herds had more than 50 cows. The use of Al ensured that sires had daughters on multiple herds: on average a sire had daughters on 50 herds. Twenty seven sires had daughters on less than 20 herds, and 12 sires had daughters on more than 100 herds.

Data collection took place between October 2010 and September 2011. Cows were scored once for each behavior and type trait. The three behavior traits were recorded by the farmers who received instructions on how to score cows but did not follow training session to harmonize scoring. Aggressiveness towards the farmer at parturition and aggressiveness during gestation period were recorded on a scale from 1 representing aggressive behavior to 7 representing docile behavior. Maternal behavior towards the calf was recorded on a scale from 1 representing rejecting behavior to 7 representing attentive maternal behavior. Eleven type traits and locomotion were recorded by ten technicians who had one training session to harmonize scoring of cows. Three traits related to udder conformation (udder volume, udder balance, and udder attachment), three traits related to teat conformation (teat thinness, teat length, and teat shape), and five traits related to feet and leg conformation (front leg, rear leg, foot angle, foot depth, leg angle) were recorded on a scale from 1 to 7 . Depending on the trait, the optimal grade was either 4 or 7 . Locomotion was recorded on a scale from 1 representing lameness to 5 representing no lameness. An explanation of the scale on which the traits were scored is given in Table 2.1. Classifiers scored on average 642 cows on 40 herds. Cows on one herd were classified by the same classifier and were scored during the same visit or during different visits. 


\subsubsection{Statistical analysis}

Genetic analyses were performed using the following linear animal model:

$$
Y_{i j k l}=\mu+\text { Parity }_{i}+\text { BYBS }_{j}+\text { Herd }_{k}+\text { Animal }_{l}+e_{i j k l},
$$

where $Y_{i j k l}$ is the score for behavior and type traits. $\mu$ is the overall mean. Parity $y_{i}$ is the fixed effect of the parity of the cow at time of scoring. Cows were in parity one to twelve. In the statistical analysis, parity six and higher were grouped in one class $(i=1,6)$. BYBS $S_{j}$ is the fixed effect Birth Year by Birth Season which combines the effect of year when the cow was born (between 1997 and 2009) and season when the cow was born defined as two six-months periods starting in October. First class for BYBS $_{j}$ is October-March 1997 and the last class is April-September 2009 ( $j=1$, 26). Herd $d_{k}$ is the random effect of the herd in which the cow was born $(k=1,380)$ and assumed to be distributed as $\mathrm{N}\left(0, I \sigma_{\mathrm{h}}{ }^{2}\right)$ where $\sigma_{\mathrm{h}}{ }^{2}$ is the herd variance and I is the identity matrix. Animal, is the random additive genetic effect of the $I^{\text {th }}$ animal and assumed to be distributed as $N\left(0, A \sigma_{a}{ }^{2}\right)$ where $\sigma_{a}{ }^{2}$ is the additive genetic variance and $A$ is the additive genetic relationship matrix which was constructed based on three generations pedigree. $e_{\mathrm{ijkl}}$ is the random residual effect $\sim \mathrm{N}\left(0, \mathrm{I \sigma}_{\mathrm{e}}{ }^{2}\right)$ where $\sigma_{e}{ }^{2}$ is the residual variance.

Univariate analyses were used to estimate variances for the traits.

The intra-herd heritability was calculated as

$$
\mathrm{h}^{2}=\frac{\sigma_{\mathrm{a}}^{2}}{\sigma_{\mathrm{a}}^{2}+\sigma_{\mathrm{e}}^{2}}
$$

The proportion of variance explained by herd was calculated as

$$
\%_{h e r d}=\frac{\sigma_{\mathrm{h}}^{2}}{\sigma_{\mathrm{a}}^{2}+\sigma_{\mathrm{h}}^{2}+\sigma_{\mathrm{e}}^{2}}
$$

The genetic coefficient of variation gives an indication for the potential response to selection and was calculated as follows (Houle, 1992)

$$
\mathrm{CV}_{\mathrm{a}}=\frac{\sigma_{\mathrm{a}}}{\mu},
$$

where $\mu$ is the phenotypic mean of the trait and $\sigma_{a}$ is the additive genetic standard deviation. 
Phenotypic and genetic correlations were estimated using bivariate analyses. Covariances between animal effects, herd effects, and residual effects were estimated.

Data included observations on cows in parity one to twelve. Traits scored in different parities might not be genetically the same. Therefore, bivariate analyses were used to estimate genetic variances and genetic correlations between the same trait measured in parity 1 and in parity $\geq 4$ cows. There were 2,300 cows in parity 1 and 2,005 cows in parity $\geq 4$. To test if traits are genetically identical, i.e. if genetic correlation is significantly different from 1 , the log-likelihood ratio test was used. The likelihood of the unconstrained model was compared to the likelihood of a constrained model where genetic correlation was fixed at 0.998 . Constraining genetic correlation at a value of exactly 1 is computationally not possible. The loglikelihood ratio test (LRT) equals

$$
\text { LRT }=-2\left[\log _{\mathrm{e}} \operatorname{likelihood}\left(\mathrm{H}_{0}\right)-\log _{\mathrm{e}} \operatorname{likelihood}\left(\mathrm{H}_{\mathrm{a}}\right)\right]
$$

where $\mathrm{H}_{0}$ indicates the constrained model (i.e. traits are genetically the same) and $\mathrm{H}_{\mathrm{a}}$ indicates the unconstrained model. The log-likelihood ratio test follows a $\chi^{2}$ distribution with one degree of freedom.

Variance and covariance components were estimated using ASReml (Gilmour et al., 2009).

\subsection{Results}

\subsubsection{Descriptive statistics}

Number of observations, mean, and standard deviation for each trait are summarized in Table 2.1. Behavior traits had lower number of observations (between 5,881 and 5,954) compared to type traits (between 6,255 and 6,418). Mean for aggressiveness during gestation (5.47) and aggressiveness at parturition (5.03) were closer to the optimum (grade of 7) as compared to the mean for maternal care (4.56). Means for type traits were all close to the intermediate grade of 4 (between 3.43 and 4.73) although 7 is the optimal grade for udder attachment, teat thinness, teat length, and teat shape. Mean for locomotion (4.69) was close to its optimum (grade of 5). Standard deviation for aggressiveness at parturition was higher (SD = 1.33) compared to aggressiveness during gestation (0.89) or maternal care (0.89). The lowest standard deviations were found for udder balance (0.94), front leg (0.67), rear leg (0.92), and leg angle (1.03). Locomotion, which was scored on a 5-point rather than a 7-point scale, had a standard deviation of 0.66 . 


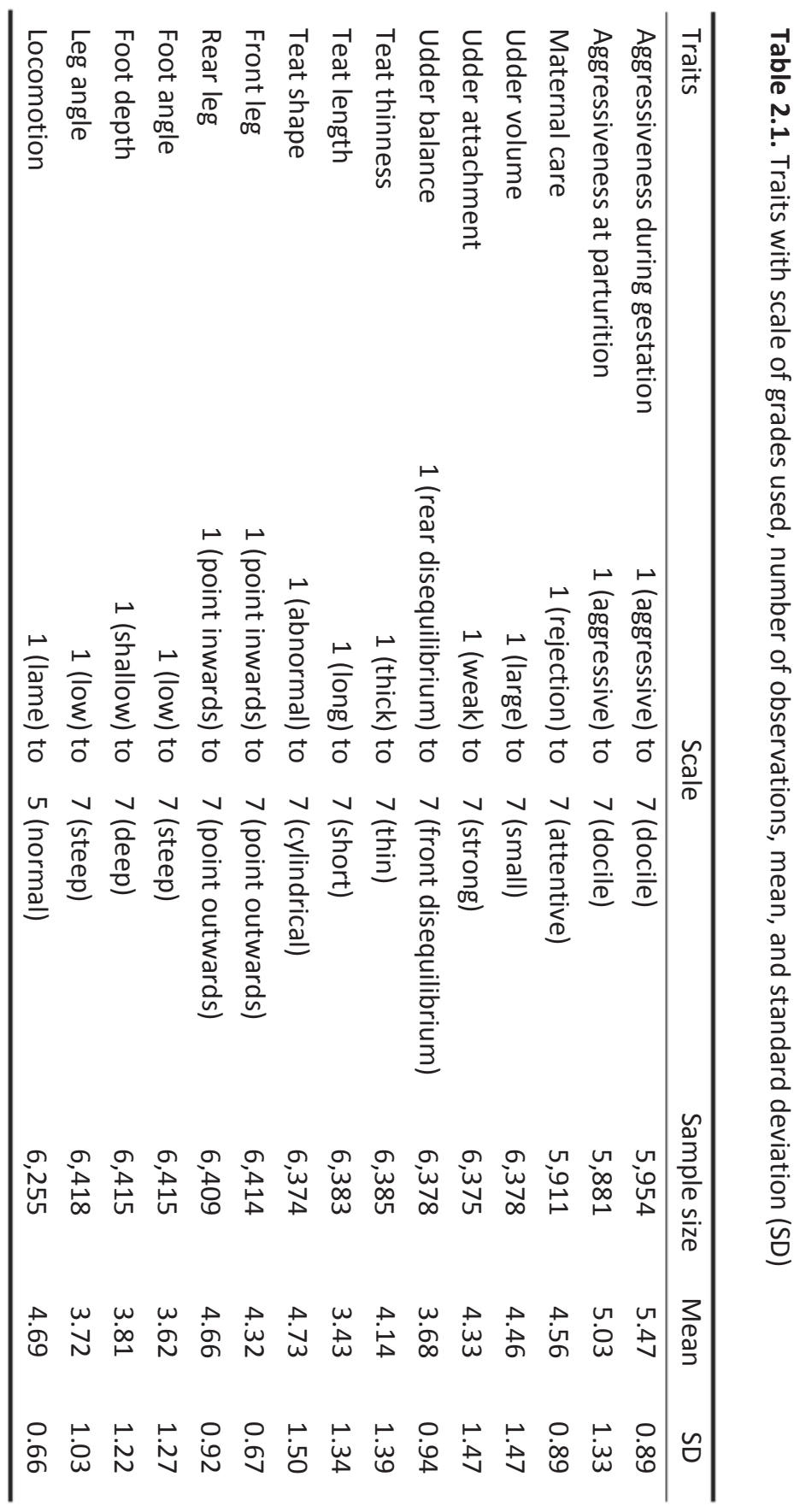




\subsubsection{Variances, heritability, and coefficient of additive genetic variation}

Estimates for variance components, heritabilities, and coefficients of additive genetic variation are shown in Table 2.2. Heritabilities for behavior traits were 0.02 for maternal care, 0.06 for aggressiveness during gestation, and 0.19 for aggressiveness at parturition. For type traits, the highest heritabilities were found for udder traits (between 0.14 and 0.20 ) and teat traits (between 0.17 and 0.35 ) while the lowest values were found for feet and leg traits (between 0.02 and 0.19). High coefficients of additive genetic variation were found for teat length (21\%), teat thinness (17\%), and aggressiveness at parturition (11\%), and the lowest were for locomotion and maternal care (2\%). The proportion of the total phenotypic variance due to differences between herds was high for the three behavior traits (between $19 \%$ and $23 \%$ ), udder volume (29\%), foot angle (22\%), foot depth (19\%), and locomotion (28\%).

Table 2.2. Variance estimates, heritabilities, and genetic coefficients of variation

\begin{tabular}{lccccc}
\hline Trait & $\sigma_{a}^{2}$ & $\sigma_{\mathrm{p}}^{2}$ & $\mathrm{~h}^{2}(\mathrm{SE})$ & $\mathrm{CV}_{\mathrm{a}}(\%)$ & $\%_{\text {herd }}$ \\
\hline Aggressiveness during gestation & 0.04 & 0.79 & $0.06(0.02)$ & 4 & 23 \\
Aggressiveness at parturition & 0.28 & 1.81 & $0.19(0.05)$ & 11 & 19 \\
Maternal care & 0.01 & 0.76 & $0.02(0.01)$ & 2 & 21 \\
Udder volume & 0.27 & 1.88 & $0.20(0.04)$ & 12 & 29 \\
Udder attachment & 0.24 & 1.98 & $0.14(0.03)$ & 11 & 14 \\
Udder balance & 0.16 & 0.89 & $0.19(0.04)$ & 11 & 6 \\
Teat thinness & 0.50 & 1.79 & $0.32(0.05)$ & 17 & 10 \\
Teat length & 0.54 & 1.71 & $0.35(0.05)$ & 21 & 11 \\
Teat shape & 0.32 & 2.27 & $0.17(0.04)$ & 12 & 15 \\
Front leg & 0.03 & 0.45 & $0.07(0.02)$ & 4 & 11 \\
Rear leg & 0.07 & 0.85 & $0.10(0.03)$ & 6 & 16 \\
Foot angle & 0.14 & 1.62 & $0.11(0.03)$ & 10 & 22 \\
Foot depth & 0.08 & 1.49 & $0.07(0.02)$ & 7 & 19 \\
Leg angle & 0.18 & 1.05 & $0.19(0.04)$ & 11 & 9 \\
Locomotion & 0.01 & 0.50 & $0.02(0.01)$ & 2 & 28 \\
\hline$\sigma_{a}^{2}=$ genetic variance, $\sigma_{p}^{2}=$ phenotypic variance, $h^{2}:$ intra-herd heritability \\
(standard errors are in parentheses), CV $V_{a}=$ genetic coefficient of variation, \% herd \\
proportion of variance explained by herd
\end{tabular}




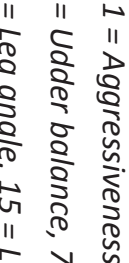

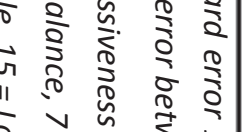

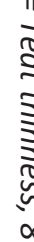
₹ 0 S 2 2 ? $\begin{array}{lll}1 & 0 \\ 0 & 0 & 0 \\ 0 & 0 & 0\end{array}$

$\frac{\sqrt{2}}{\sqrt[2]{3}}$

ก 11

11 $\frac{1}{2}$

ㄱำ

$\frac{1}{2} \frac{1}{5}$

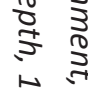

$\begin{array}{ll}\vec{*} & 0\end{array}$

\section{ก) 11}

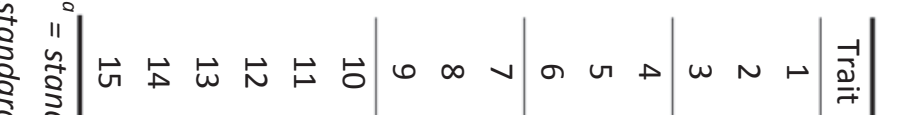

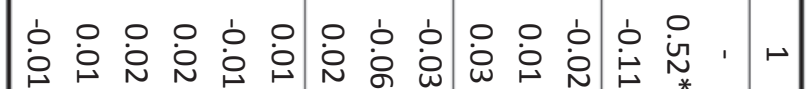

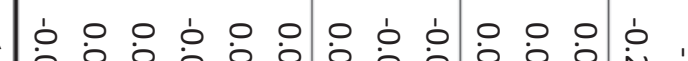

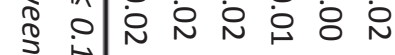

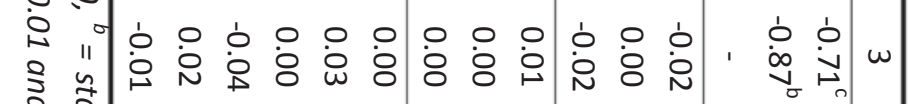
$\sim$ II

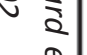
$\begin{array}{llllllllllllllllllll}0 & 0 & 0 & 0 & 0 & 0 & 0 & 0 & 0 & 0 & 0\end{array}$ $\begin{array}{lll}0 & 0 & 0 \\ \text { N } & 0 & 0 \\ 0 & 0 & 0\end{array}$

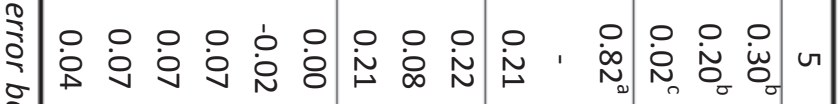

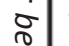
$\begin{array}{lllllllllllllll}0 & 0 & 0 & 0 & 0 & 0 & 0 & 0 & 0 & 0 & 0 & 0 & 0 & 0 & \\ 0 & 0 & 0 & 0 & 0 & 0 & 0 & 0 & 0 & 0 & 0 & 0 & 0 & 0 & 0\end{array}$ 爷 \begin{tabular}{lllllll|llllllllll}
0 & 0 & 0 & 0 & 0 & 0 & 0 & 0 & 0 & 0 & 0 & 0 & 0 & 0 & 0 & 0
\end{tabular} 跑

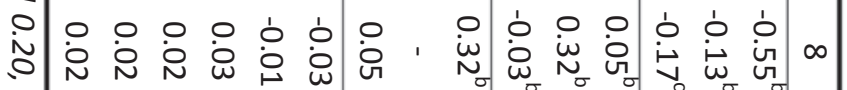

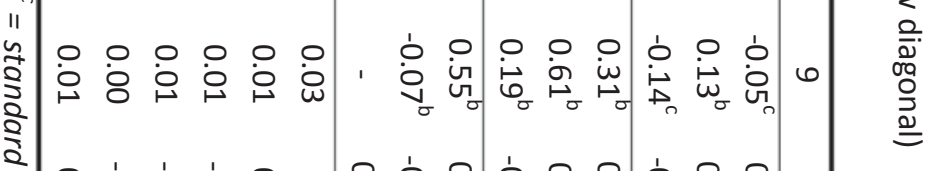

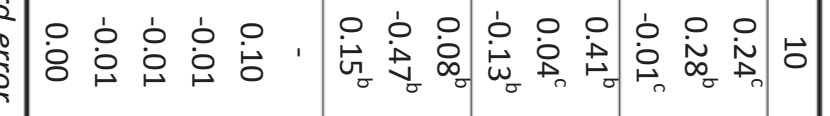
IV *

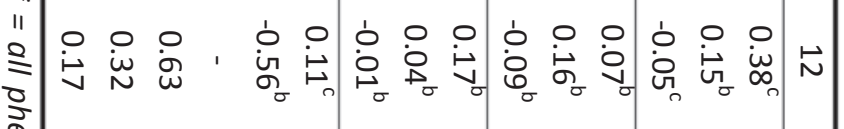

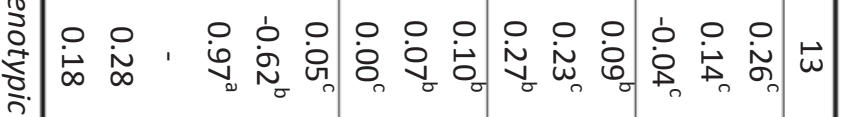

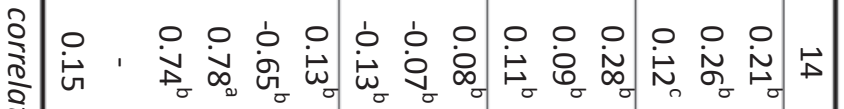

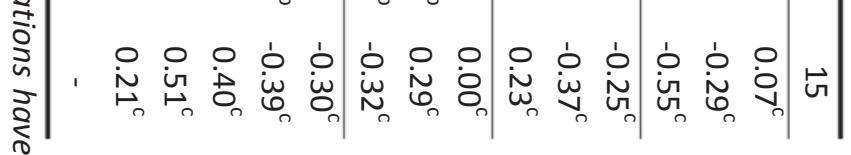




\subsubsection{Phenotypic and genetic correlations between traits}

Phenotypic and genetic correlations between traits are shown in Table 2.3. In general phenotypic correlations were not as strong as genetic correlations. High genetic correlations were found between the three behavior traits (with absolute values from 0.71 to 0.98 ), between udder volume and udder attachment (0.82), and between foot angle, foot depth, and leg angle (between 0.74 and 0.97). Other genetic correlations were weak ( 0.00 between front leg and rear leg) to moderate ( 0.67 between udder attachment and teat thinness).

\subsubsection{Young and old cows}

Table 2.4 shows means, variances, and genetic correlations between the same trait measured in first parity (young) and parity $\geq 4$ (old) cows. Old cows were more attentive towards their calves (mean of 4.77 ) than younger cows (4.37), had a larger udder volume (3.77) than young cows (5.08), weaker udder attachment (3.75) than young cows (4.83), thicker teats (3.67) than young cows (4.55), and longer teats (3.08) than young cows (3.83). With an increase in age we found an increase in phenotypic (from 0.83 to 1.99 ) and genetic variance (from 0.00 to 0.31 ) for aggressiveness at parturition. On the contrary, maternal care showed a slight decrease in phenotypic variance (from 0.68 to 0.56 ) and in genetic variance (from 0.02 to 0.01 ). For type traits, with an increase in age, large decrease in genetic variance was found for udder volume (from 0.35 to 0.20 ) and teat thinness (from 0.68 to 0.51 ). With an increase in age, large increase in genetic variance was found for leg angle (from 0.16 to 0.31 ). Changes in phenotypic variance were limited for type traits except for locomotion with an increase from 0.24 to 0.41 .

For leg angle, the estimated genetic correlation between young and old cows was 0.67 and was significantly different from unity ( $p$-value $=0.03$ ). No other traits had genetic correlation significantly different from 1 . For nine traits, the genetic correlations were equal or higher than 0.80. Behavior traits, front leg, leg angle, and locomotion had genetic correlation smaller than 0.80 but standard errors were large (between 0.20 and 1.45). 


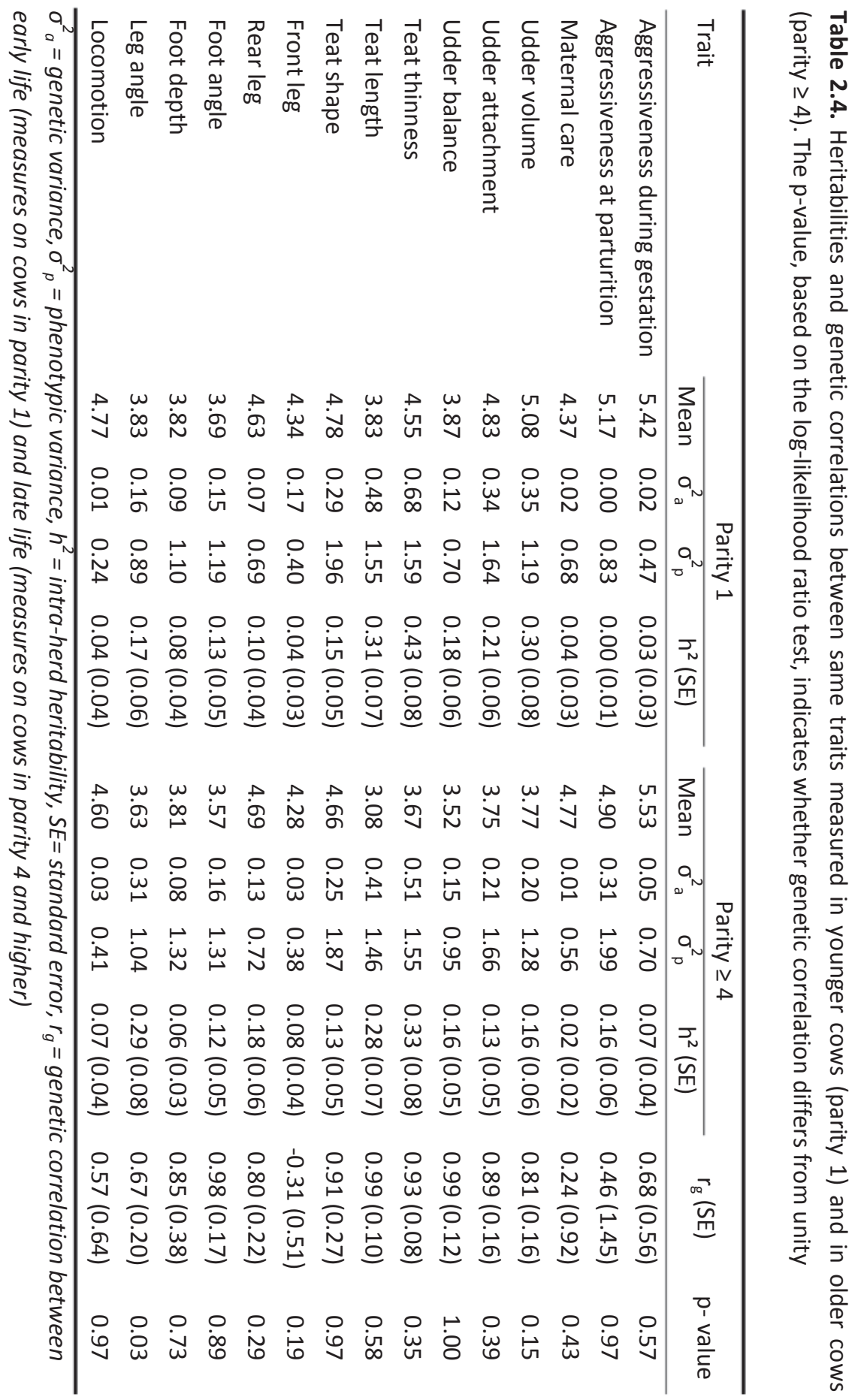




\subsection{Discussion}

\subsubsection{Herd effects}

The effect of herd was substantial for most of the traits. Differences between herds could be due to differences in management. Several studies reported that housing system, and particularly pasture management, have an impact on behavior in beef cattle (Boivin et al., 1994; Le Neindre et al., 1995; Phocas et al., 2006; Hoppe et al., 2008). Animals reared outdoors or under extensive conditions with little human contact were found to be more aggressive towards human than animals raised indoor or under less extensive conditions (Boivin et al., 1994; Becker and Lobato, 1997). Housing system, and particularly floor type and access to pasture, was reported to impact feet and leg traits and locomotion traits (Boelling and Pollott, 1998; Van Dorp et al. 2004; Onyiro and Brotherstone, 2008). Furthermore, behavior traits were scored by the farmers and therefore herd effects for behavior traits could also be caused by differences between farmers in scoring of behavior traits. Several studies on temperament in beef cattle reported significant effect of classifier (Le Neindre et al., 1995; Phocas et al., 2006). Differences between classifiers in scoring type traits may also have contributed to the herd variance as one classifier scored all cows in the same herd and we did not include a classifier effect in the final analysis because herd is nested within classifier. As a check, classifier effect was added in the model and it did not affect the estimates of genetic parameters.

\subsubsection{Difference between young and old cows}

In this study, observations were made on cows of different ages. Difference in age may affect estimates of genetic parameters e.g. because a trait can be genetically different between parities, because old cows consist of a selected group of individuals, and because the length of observation period for behavior trait differs with the age of cows.

In literature, several traits were reported to be genetically different between parities such as calving difficulty in Charolais (Eriksson et al. 2004) or fertility in dairy cattle (Jamrozik et al. 2005). In the present study, a significant genetic difference between young cows and old cows was found for leg angle. For this trait we also observed a higher heritability in older cows as compared to younger cows. For other traits no significant evidence for genetic differences between traits measured in old and young cows was detected.

Older cows consist of a selected group of animals as the majority of voluntary culling occurs between first and second calving. Therefore, cows with unfavorable 
behavior and type are more likely to be culled. This type of selection might result in a reduced phenotypic and genetic variance for cows in parities $\geq 4$ as compared cows in parity 1 . A reduced phenotypic variance was observed for maternal care and several type traits. The effect of selection on estimation of genetic parameters has been highlighted before (e.g. Pryce et al., 2000; Gutiérrez et al., 2002).

Behavior was scored by farmers based on their experiences in handling the cows. Thus, farmers had to base their behavior score for younger cows on a shorter time span compared to older cows for which farmers have a better knowledge of their behavior through experiences during multiple calvings. Farmers may therefore have used a smaller range of scores for younger cows compared to older cows. This could contribute to the lower phenotypic variances for aggressiveness in younger cows. In addition, observation for older cows might be more accurate compared to younger cows. This could contribute to the higher genetic variances and heritabilities for aggressiveness in older cows.

\subsubsection{Heritabilities}

Heritabilities of behavior traits in the current study were lower than most heritabilities reported in literature. This might be due to our scoring system which is subjective. Other studies used objective measurements such as licking time and found a heritability of $0.32 \pm 0.23$ (Le Neindre et al., 2002), running time (with heritability up to $0.23 \pm 0.04$ ), or number of escape (with heritability up to $0.26 \pm$ 0.04) (Phocas et al, 2006). Furthermore, heritability of handling behavior was reported to decline with habituation to human contact, going from 0.39 at weaning to 0.29 at 18 months of age for the speed at which an animal leaves the crush (Burrow and Corbet, 2000). This decline in heritability with habituation to human contact probably affected our heritability estimates; cows in our study were used to be handled, as compared to literature where in general younger animals were used (Benhajali et al. 2010; Hoppe et al. 2010). Aggressiveness at parturition had higher standard deviation and heritability than aggressiveness during gestation. One reason might be that farmers had less handling experience with cows during gestation than during parturition, causing the use of a reduced range of score, and consequently reduced variance.

Maternal effects, if present and not accounted for in the model, can affect the heritability estimates. Maternal genetic effect for behavior traits, although limited, have been reported and maternal heritabilities ranged up to 0.05 (Prayaga and Henshall, 2005; Beckman et al., 2007). In this study, the structure of the dataset prohibited including a maternal effect (both genetic and environmental) in the model. In case maternal effects play a role in the variability of some of the traits, 
they will be confounded with direct genetic effects, causing an overestimation of the heritability. Calf behavior was also reported to have an effect on the dam behavior at parturition (Pérez-Torres et al. 2014). Similarly, not taking into account calf effect may have caused an overestimation of the heritability.

A few studies estimated heritabilities in beef cattle on similar type traits than in this study. To our knowledge, only one study was conducted in Charolais (Norris et al. 2008) which found similar heritability for front leg conformation but higher heritability for rear leg conformation ( 0.21 vs. 0.10 in the present study). Varona et al. (2012) found similar heritabilities for teat thinness and front leg but slightly lower heritabilities for teat length ( 0.29 vs. 0.35 in the present study) and higher heritability for rear leg ( 0.17 vs. 0.10 in the present study) in Pirenaica breed. Gutiérrez and Goyache (2002) found a lower heritability for udder volume (0.12 vs. 0.20 in the present study) in Asturiana de los Valles cattle. More research has been conducted on type traits in dairy cattle (Vollema and Groen, 1997; DeGroot et al., 2002, Vukasinovic et al.; 2002; Wiggans et al., 2006; Onyiro and Brotherstone, 2008). In dairy cattle, a wide range of heritabilities are found and heritabilities tend to be higher than in the present study. Higher heritability in dairy might be caused by a more uniform scoring resulting from better trained and experienced classifiers.

\subsubsection{Genetic correlations}

A strong genetic correlation was found between maternal care and aggressiveness at parturition and to a lesser extend aggressiveness during gestation. This is in line with other studies although their estimates were lower (Morris et al., 1994; Le Neindre et al.,2002; Phocas et al. 2006). These finding suggests that higher aggressiveness at parturition is part of better maternal care. The strong genetic correlation indicates that it is difficult to improve maternal care and reduce aggressiveness simultaneously through selection.

Strong genetic correlations were found between udder volume and udder attachment, between foot angle and foot depth, between foot angle and leg angle, and between leg angle and foot depth. These genetic correlations were stronger than the ones found in previous studies (Kirschten et al., 2001; Jeyaruban et al. 2012). Foot angle and foot depth also showed a strong phenotypic correlation, suggesting that classifiers had difficulties to distinguish between both traits and consequently gave similar scores for the traits. This underlines the need for clear definitions of traits and training of classifiers.

The genetic correlations between teat length and teat shape, and between front leg and rear leg were very weak, unlike reported by previous studies (Vukasinovic et al. 1997; Norris et al. 2008). 


\subsubsection{Opportunity for selection}

Opportunity for genetic improvement as assessed by the coefficient of genetic variation was high for most of the traits, such as aggressiveness at parturition or teat thinness, especially as compared to the coefficient of genetic variation of $5 \%$ found for body weight in Charolais (Mujibi and Crews, 2009; Phocas, 2009). On the other hand, traits such as maternal care or front leg had low coefficient of genetic variation and low heritability indicating that selection for these traits is more difficult. This study shows that there are interesting opportunities to progeny test bulls for behavior traits based on data collected by farmers.

\subsection{Acknowledgements}

This study was funded by Gènes Diffusion. The authors thank the technicians and farmers from Apis Diffusion, Ain Génétique Service, CECNA, CIA Gènes Diffusion, COOPELIA, COOPEL, and ELVA NOVIA for their efforts in collecting and making available the data. 


\subsection{References}

Beard, K. 1993. Genetic evaluation for milking speed, temperament, likability and survival in Australia. Interbull Bulletin 8:4.

Becker, B., and J. F. P. Lobato. 1997. Effect of gentle handling on the reactivity of zebu crossed calves to humans. Appl. Anim. Behav. Sci. 53:219-224.

Beckman, D. W., R. M. Enns, S. E. Speidel, B. W. Brigham, and D. J. Garrick. 2007. Maternal effects on docility in Limousin cattle. J. Anim. Sci. 85:650-657.

Benhajali, H., X. Boivin, J. Sapa, P. Pellegrini, P. Boulesteix, and P. Lajudie. 2010. Assessment of different on-farm measures of beef cattle temperament for using genetic evaluation. J. Anim. Sci. 88:3529-3537.

Boelling, D., and G. E Pollott. 1998. Locomotion, lameness, hoof and leg traits in cattle I.: Phenotypic influences and relationships. Livest. Prod. Sci. 54(3):193-203.

Boivin, X., P. Le Neindre, J. P. Garel, and J. M. Chupin. 1994. Influence of breed and rearing management on cattle reactions during human handling. Appl. Anim. Behav. Sci. 39(2):115-122.

Burrow, H. M., and N. J. Corbet. 2000. Genetic and environmental factors affecting temperament of zebu and zebu-derived beef cattle grazed at pasture in the tropics. Aust. J. Exp. Agr. 51:155-162.

De Groot, B. J., J. F. Keown, L. D. Van Vleck, and E. L. Marotz. 2002. Genetic parameters and responses of linear type, yield traits, and somatic cell scores to divergent selection for predicted transmitting ability for type in Holsteins. J. Dairy Sci. 85:1578-1585.

Edwards, S. A. 1982. Factors affecting the time to first suckling in dairy calves. Anim. Prod. 34:339.

Eriksson, S., A. Näsholm, K. Johansson, and J. Philipsson. 2004. Genetic parameters for calving difficulty, stillbirth, and birth weight for Hereford and Charolais at first and later parities. J. Anim. Sci. 82:375-383.

FASS. 2010. Guide for the care and use of agricultural animals in research and teaching. http://www.fass.org/docs/agguide3rd/Ag_Guide_3rd_ed.pdf.

Forabosco F., V. Palucci, and W. F. Fikse. 2007. Selecting traits for international beef evaluations: survey results. Interbull Bulletin 40:82-86. 
Frisch, J. E. 1982. The use of teat-size measurements or calf weaning weight as an aid to selection against teat defects in cattle. Anim. Prod. 32: 127-133.

Gilmour, A. R., B. J. Gogel, B. R. Cullis, and R. Thomson. 2009. ASREML Software Release 3. VSN International Ltd., Hemel Hempstead, UK.

Goonewardene, L. A., Z. Wang, M. A. Price, R.-C. Yang, R. T. Berg, and M. Makarechian. 2003. Effect of udder type and calving assistance on weaning traits of beef and dairy $x$ beef calves. Livest. Prod. Sci. 81:47-56.

Gutierrez, J. P., I. Alvarez, I. Fernandez, L. J. Royo, J. Dıez, and F. Goyache. 2002. Genetic relationships between calving date, calving interval, age at first calving and type traits in beef cattle. Livest. Prod. Sci. 78: 215-222.

Gutierrez, J. P., and F. Goyache. 2002. Estimation of genetic parameters of type traits in Asturiana de los Vales beef cattle breed. J. Anim. Breed. Genet. 119:93-100.

Houle, D. 1992. Comparing evolvability and variability of quantitative traits. Genetics 130:195-204.

Hoppe, S., H. R. Brandt, G. Erhardt, and M. Gauly. 2008. Maternal protective behaviour of German Angus and Simmental beef cattle after parturition and its relation to production traits. Appl. Anim. Behav. Sci. 114:297306.

Hoppe, S., H. R. Brandt, S. Konig, G. Erhardt, and M. Gauly. 2010. Temperament traits of beef calves measured under field conditions and their relationships to performance. J. Anim. Sci. 88:1982-1989.

Jamrozik, J., J. Fatehi, G.J. Kistemaker, and L. R. Schaeffer. 2005. Estimates of Genetic Parameters for Canadian Holstein Female Reproduction Traits. J. Dairy Sci. 88:2199-2208.

Jeyaruban, G., B. Tier, D. Johnston, and H. Graser. 2012. Genetic analysis of feet and leg traits of Australian Angus cattle using linear and threshold models. Anim. Prod. Sci. 52:1-10.

Kirschten, D. P., D. D. Kress, M. W. Tess, and K. L. Davis. 2001. Estimating genetic parameters of a linear type scoring method in beef cattle. Proc. Am. Soc. Anim. Sci., West. Sect. 52:1-4.

Larroque, H., and V. Ducrocq. 2001. Relationships between type and longevity in the Holstein breed. Genet. Sel. Evol. 33:39-59. 
Le Neindre, P., G. Trillat, J. Sapa, F. Ménissier, J. N. Bonnet, and J. M. Chupin. 1995. Individual differences in docility in Limousin cattle. J. Anim. Sci. 73:22492253.

Le Neindre, P., L. Gringnard, G. Trillat, A. Boissy, F. Ménissier, F. Sapa, and X. Boivin. 2002. Docile Limousin cows are not poor mothers. Proc. 7th World Congr. Genet. Appl. Livest. Prod., Montpellier, France. p. 59-62.

Mantovani, R., M. Cassandro, B. Contiero, A. Albera, and G. Bittante. 2010. Genetic evaluation of type traits in hypertrophic Piemontese cows. J. Anim. Sci. 88:3504-3512.

Morris, C. A., N. G. Cullen, R. Kilgour, and K. J. Bremner. 1994. Some genetic factors affecting temperament in Bos Taurus cattle. N.Z. J. Agric. Res. 37:167175.

Mujibi, F. D. N., and D. H. Crews Jr. 2009. Genetic parameters for calving ease, gestation length, and birth weight in Charolais cattle. J. Anim. Sci. 87:2759-2766.

Norris, D., N. W. Serape, C. B. Bang, and J. W. Ngami. 2008. Estimation of (co)variance components for type traits in Charolais cattle. J. Biol. Sci. 8:229-232.

Onyiro, O. M., and S. Brotherstone. 2008. Genetic analysis of locomotion and associated conformation traits of Holstein-Friesian dairy cows managed in different housing systems. J. Dairy Sci. 91:322-328.

Pérez-Torres, L., A. Orihuela, M. Corro, I. Rubio, A. Cohen, and C. S. Galina. 2014. Maternal protective behavior of zebu type cattle (Bos indicus) and its association with temperament. J. Anim. Sci. 92:4694-4700.

Phocas, F., J. J. Colleau, and F. Ménissier. 1995. Expected efficiency of selection for growth in a French beef cattle breeding scheme. I. Multistage selection of bulls used in artificial insemination. Genet. Sel. Evol. 27(2):149-170.

Phocas, F., C. Bloch, P. Chapelle, F. Bécherel, G. Renand, and F. Ménissier. 1998. Developing a breeding objective for a French purebred beef cattle selection programme. Livest. Prod. Sci. 57(1):49-65.

Phocas, F., X. Boivin, J. Sapa, G. Trillat, A. Boissy, and P. Le Neindre. 2006. Genetic correlations between temperament and breeding traits in Limousin heifers. Anim. Sci. 82:805-811. 
Phocas, F. 2009. Genetic analysis of breeding traits in a Charolais cattle population segregating an inactive myostatin allele. J. Anim. Sci. 87(6): 1865-1871.

Prayaga, K. C., and J. M. Henshall. 2005. Adaptability in tropical beef cattle: genetic parameters of growth, adaptive and temperament traits in a crossbred population. Aust. J. Exp. Agr. 45:971-983.

Pryce, J. E., M. P. Coffey, and S. Brotherstone. 2000. The genetic relationship between calving interval, body condition score and linear type and management traits in registered Holsteins. J. Dairy Sci. 83:2664-2671.

Schmidt, S. E., D. A. Neuendorff, D. G. Riley, R. C. Vann, S. T. Willard, T. H. Welsh Jr., and R. D. Randel. 2014. Genetic parameters of three methods of temperament evaluation of Brahman calves. J. Anim. Sci. 92:3082-3087.

Sewalem, A., G. J. Kistemaker, and B. J. Van Doormaal. 2005. Relationship between type traits and longevity in Canadian Jersey and Ayrshires using a Weibull proportional hazards model. J. Dairy Sci. 88:1552-1560.

Turner, S. P., M. C. Jack, and A. B. Lawrence. 2013. Precalving temperament and maternal defensiveness are independent traits but precalving fear may impact calf growth. J. Anim. Sci. 91:4417-4425.

Van Dorp, T. E., P. Boettcher, and L. R. Schaeffer. 2004. Genetics of locomotion. Livest. Prod. Sci. 90:247-253.

Vargas, G., H. H. R. Neves, V. Cardoso, D. P. Munari, and R. Carvalheiro. 2014. Genetic analysis of feet and legs in Nellore cattle. Proc 10th World Congr. Genet. Appl. Livest. Prod., Vancouver, Canada. p. 61.

Varona, L., C. Moreno, and J. Altarriba. 2012. Genetic correlation of longevity with growth, post-mortem, docility and some morphological traits in the Pirenaica beef cattle breed. Animal. 6(6):873-879.

Ventorp, M. and P. Michanek. 1992. The importance of udder and teat conformation for teat seeking by the newborn calf. J. Dairy Sci. 75:262268.

Vollema, A. R., and A. F. Groen. 1997. Genetic correlations between longevity and conformation traits in an upgrading dairy cattle population. J. Dairy Sci. 80:3006-3014. 
Vukasinovic, N., J. Moll, and N. Künzi. 1997. Factor analysis for evaluating relationships between herd life and type traits in Swiss Brown cattle. Livest. Prod. Sci. 49: 227-234.

Vukasinovic, N, Y. Schleppi, and N. Künzi. 2002. Using conformation traits to improve reliability of genetic evaluation for herd life based on survival analysis. J. Dairy Sci. 85:1556-1562.

Wiggans, G. R., L. L. M. Thornton, R. R. Neitzel, and N. Gengler. 2006. Genetic parameters and evaluation of rear legs (rear view) for Brown Swiss and Guernseys. J. Dairy Sci. 89:4895-4900. 


\section{3 \\ Genome-wide association study for behavior, type traits, and muscular development in Charolais beef cattle}

A. Vallée ${ }^{1,2}$, J. Daures ${ }^{2}$, J. A. M. van Arendonk ${ }^{1}$, and H. Bovenhuis ${ }^{1}$

${ }^{1}$ Animal Breeding and Genomics Centre, Wageningen University, PO Box 338, 6700 $\mathrm{AH}$, Wageningen, the Netherlands; ${ }^{2}$ Gènes Diffusion, 3595 route de Tournai, CS70023, 59501 Douai Cedex, France Journal of Animal Science (2016) 94(6):2307-2316 


\begin{abstract}
Behavior, type traits and muscular development are of interest for beef cattle breeding. Genome-wide association studies (GWAS) enable the identification of candidate genes which enables gene based selection and provides insight in the genetic architecture of these traits. The objective of the current study was to perform a GWAS for three behavior traits, twelve type traits, and muscular development in Charolais cattle. Behavior traits, including aggressiveness at parturition, aggressiveness during gestation period, and maternal care, were scored by farmers. Type traits, including udder conformation, teat, feet and legs, and locomotion, were scored by trained classifiers. Data used in the GWAS consisted of 3,274 cows with phenotypic records and genotyping information for 44,930 Single Nucleotide Polymorphism (SNP). When SNP had a false discovery rate (FDR) smaller than 0.05, they were referred as significant. When SNP had a FDR between 0.05 and 0.20 , they were referred as suggestive. Four significant and 12 suggestive regions were detected for aggressiveness during gestation, maternal care, udder balance, teat thinness, teat length, foot angle, foot depth, and locomotion. These 4 significant and 12 suggestive regions were not supported by other significant SNP in close proximity. No SNP with major effects were detected for behavior and type traits and SNP associations for these traits were spread across the genome suggesting that behavior and type traits were influenced by many genes each explaining a small part of genetic variance. The GWAS identified one region on chromosome 2 significantly associated with muscular development, which included the myostatin gene (GDF8) which is known to affect muscularity. No other regions associated with muscular development were found. Results showed that the myostatin region associated with muscular development had pleiotropic effects on udder volume, teat thinness, rear leg, and leg angle.
\end{abstract}

Key words: association study, beef cattle, behavior traits, Charolais, muscular development, type traits 


\subsection{Introduction}

In beef cattle, there is a growing interest to include in the breeding goal not only traits directly related to profitability such as muscular development (Martinez et al., 2010), but also traits related to behavior and type (Forabosco et al. 2007; Vargas et al. 2014). Aggressiveness has been associated with human safety and workability (Le Neindre et al., 2002; Turner et al., 2013). Maternal care of cows to neonatal calves has been associated with colostrum consumption, immunity, and calve survival (Frisch, 1982; Hoppe et al., 2008). Udder, teat, and feet and leg conformation are important functional traits and in dairy cattle these traits have been associated with longevity (Larroque and Ducrocq, 2001; Sewalem et al., 2005).

A genome-wide association study (GWAS) enables the detection of quantitative trait loci (QTL) associated with a particular trait (e.g. Weller, 2009). Finding candidate genes and the causal mutation will lead to a better understanding of the biology underlying the trait (Moser et al., 2010). Behavior in beef cattle has been reported to be influenced by QTL at several locations (Gutierrez-Gil et al., 2008; Hulsman Hanna et al., 2014). To our knowledge, QTL detection studies for type traits have not been performed previously in beef cattle but information is available on dairy cattle (e.g. Schrooten et al. 2000; Wu et al., 2013). Several studies indicated that muscular development is influenced by the myostatin gene GDF8 in cattle (Grobet et al., 1998; McPherron and Lee, 1997) including Charolais (Allais et al., 2010). However, to our knowledge no GWAS has been performed for muscular development in beef cattle which could provide valuable information on other regions affecting muscular development. Moreover, potential pleiotropic effects of the myostatin polymorphism on behavior and type traits have not been investigated.

The aim of this study was to perform a GWAS for behavior, type traits, and muscular development in Charolais.

\subsection{Materials and Methods}

The guidelines stated in the Guide for the Care and Use of Agricultural Animals in Research and Teaching (Federation of Animal Science Societies, 2010) were followed when collecting phenotypes and blood sample on the animals. 


\subsubsection{Population structure}

Data was available for 3,274 cows originating from $51 \mathrm{Al}$ sires and 3,204 dams. The number of daughters per sire ranged from 20 to 127, with an average of 66. Cows were born in 316 different herds located in the North-East and West of France. In total, 471 cows moved to another herd during their life. For these cows the herd at scoring could not be traced back and herd of birth was considered in the statistical analyses. The average number of cows per herd was 11. In total there were 104 cows in the data set on herds with less than five cows with phenotypic observations and 256 cows from herds with more than 25 cows with phenotypic observations. The use of Al ensured that sires had daughters on multiple herds; sires had daughters in 16 to 115 different herds and in an average of 51 different herds.

\subsubsection{Traits}

Data collection for behavior and type traits took place between October 2010 and September 2011. Cows were scored once and could be in parity one to parity twelve at the moment of scoring. The three behavior traits were recorded by the farmers who received instructions prior the October 2010 on how to score cows. Aggressiveness towards the farmer at parturition and aggressiveness during gestation period were recorded on a scale from 1, representing aggressive behavior, to 7, representing docile behavior. Maternal care towards the calf was recorded on a scale from 1 , representing rejecting behavior to 7 , representing attentive maternal behavior. Twelve type traits were recorded by ten technicians. A joint training session was organized to ensure consistent scoring of cows by technicians. One technician scored on average 337 cows on 33 herds. Cows on one herd were scored by the same technician, either during the same visit or during different visits. Three traits related to udder conformation (udder volume, udder balance, and udder attachment), three traits related to teat conformation (teat thinness, teat length, and teat shape), and five traits related to feet and leg conformation (front leg, rear leg, foot angle, foot depth, leg angle) were recorded on a scale from 1 to 7 (see Table 3.1). Depending on the trait, the optimal grade was either 4 or 7 . Locomotion was recorded on a scale from 1 representing lameness to 5 representing no lameness. More details on data collection are available in Vallée et al. (2015).

From the 3,274 cows scored for behavior and type traits, 3,064 cows were also scored for muscular development as a part of the national recording scheme. Cows were scored once for muscular development, before their first calving at an average age of 33 months. Muscular development was recorded by trained and 
experienced classifiers who scored all cows from the same herd. Muscular development was evaluated based on five visual inspections of shoulders, back, and rump. For each observation, the score ranged from 1 to 10 where 1 corresponded to light muscular development and 10 to heavy muscular development. The overall score for muscular development was obtained by adding each of the five scores and expressing the sum on a scale from 10 to 100.

Table 3.1. Traits with scale of grades used, number of cows with phenotype and genotype available $(n)$, phenotypic mean $(\mu)$, and heritability $\left(h^{2}\right)$. Heritabilities are given by Vallée et al. (2015), except for muscular development. Standard errors are in parentheses

\begin{tabular}{lrlrrr}
\hline Traits & \multicolumn{2}{c}{ Scale } & $\mathrm{n}$ & $\mu$ & $\mathrm{h}^{2}$ \\
\hline Aggres. gest. & 1 (aggressive) to & 7 (docile) & 3,274 & 5.48 & $0.06(0.02)$ \\
Aggres. part. & 1 (aggressive) to & 7 (docile) & 3,274 & 5.02 & $0.19(0.05)$ \\
Maternal care & 1 (rejection) to & 7 (attentive) & 3,274 & 4.59 & $0.02(0.01)$ \\
Udder volume & 1 (big) to & 7 (small) & 3,269 & 4.40 & $0.20(0.04)$ \\
Udder att. & 1 (weak) to & 7 (strong) & 3,267 & 4.34 & $0.14(0.03)$ \\
Udder balance & 1 (rear diseq.) to & 7 (front diseq.) & 3,269 & 3.66 & $0.19(0.04)$ \\
Teat thinness & 1 (thick) to & 7 (thin) & 3,273 & 4.16 & $0.32(0.05)$ \\
Teat length & 1 (long) to & 7 (short) & 3,273 & 3.42 & $0.35(0.05)$ \\
Teat shape & 1 (abnormal) to & 7 (cylindrical) & 3,268 & 4.80 & $0.17(0.04)$ \\
Front leg & 1 (pt. in.) to & 7 (pt. out.) & 3,271 & 4.32 & $0.07(0.02)$ \\
Rear leg & 1 (pt. in.) to & 7 (pt. out.) & 3,268 & 4.65 & $0.10(0.03)$ \\
Foot angle & 1 (low) to & 7 (steep) & 3,271 & 3.62 & $0.11(0.03)$ \\
Foot depth & 1 (shallow) to & 7 (deep) & 3,269 & 3.79 & $0.07(0.02)$ \\
Leg angle & 1 (low) to & 7 (steep) & 3,274 & 3.71 & $0.19(0.04)$ \\
Locomotion & 1 (lame) to & 5 (normal) & 3,223 & 4.67 & $0.02(0.01)$ \\
Musc. dev. & 10 (light) to & 100 (heavy) & 3,064 & 59.2 & $0.20(0.04)$ \\
\hline
\end{tabular}

Aggres. gest. $=$ aggressiveness during gestation, Aggres. part. $=$ aggressiveness at parturition, Udder att. = udder attachment, Musc. dev.= muscular development, diseq. $=$ disequilibrium, $p t$. in. $=$ point inwards, pt. out. $=$ point outwards 


\subsubsection{Genotypes}

All the 3,274 cows were genotyped with the Illumina BovineSNP50 Beadchip (Illumina Inc., San Diego, CA, USA). Genotypes were analysed using the Illumina GenomeStudio software (v 1.9.4; Illumina Inc., San Diego, CA, USA). SNP positions were based on the UMD 3.1 map (ftp.ccb.jhu.edu/pub/ data/assembly/Bos_taurus/Bos_taurus_UMD_3.1/, accessed March 1, 2015). SNP with a call rate smaller than $95 \%$, with a minor allele frequency (MAF) lower than $2 \%$, and with a difference between frequency of heterozygotes from that expected under Hardy-Weinberg equilibrium higher than 0.15 (Wiggans et al., 2009) were removed. Based on these criteria 9,678 SNP were removed and after quality control 44,930 SNP were available for the GWAS.

\subsubsection{Statistical analysis}

GWAS was performed using the following linear animal model:

$$
Y_{\text {hijkl }}=\mu+\text { Parity }_{h}+\text { BYBS }_{i}+\text { SNP }_{j}+\text { Herd }_{k}+\text { Animal }_{l}+e_{h i j k l}
$$

where $Y_{\text {hijk }}$ is the score for behavior, type, or muscular development. $\mu$ is the overall mean. Parity $y_{h}$ is the fixed effect of the parity of the cow at time of scoring $(h=1,6)$. For behavior and type traits, cows were in parity one to twelve. Parity six and higher were combined in one class. For muscular development, no parity effect was included in the model as all animals were scored before their first calving. BYBS ${ }_{i}$ is the fixed effect Birth Year by Birth Season which combines the effect of year (between 1997 and 2009) and season when the cow was born (two six-months periods). First class for BYBS $_{i}$ is October-March 1997 and the last class is AprilSeptember $2009(i=1,26)$. SNP $j$ is the fixed SNP effect $(j=1,3)$. If less than three animals were available for one genotypic class then genotypes for these animals were set to missing. Herd $d_{k}$ is the random effect of the $k^{\text {th }}$ herd in which the cow was born $(k=1,316)$ and assumed to be distributed as $N\left(0, I \sigma_{h}{ }^{2}\right)$ where $\sigma_{h}{ }^{2}$ is the herd variance and $\mathrm{I}$ is the identity matrix. Animal, is the random additive genetic effect of the $I^{\text {th }}$ animal and assumed to be distributed as $N\left(0, A \sigma_{a}{ }^{2}\right)$ where $\sigma_{a}{ }^{2}$ is the additive genetic variance and $A$ is the additive genetic relationship matrix constructed based on three generations pedigree of the cows with observations. $e_{i j k l}$ is the random residual effect $\sim N\left(0, \sigma_{e}{ }^{2}\right)$ where $\sigma_{e}^{2}$ is the residual variance. In the GWAS analysis, variance components were fixed at values estimated from a larger data set described in Vallée et al. (2015). Analyses were performed using ASReml (Gilmour et al., 2009). 
For all traits residuals were normally distributed except for locomotion. Based on the analysis of the residuals for locomotion 55 outliers were removed. The significance threshold for a SNP was adjusted for multiple testing using the false discovery rate (FDR). The "qvalue" package in R statistical software (Storey and Tibshirani, 2003) was used to obtain the FDR. A FDR lower than 0.05 will be referred to as significant and a FDR between 0.05 and 0.20 as suggestive in our study.

The minimum number of records per SNP genotype was set to 3 . For significant and suggestive SNP with a small number of observations in one of the genotype classes, a sensitivity analysis was performed. The sensitivity analysis consisted of removing records of animals in genotype classes with 5 or less records. After removing these records the significance of the SNP effect was re-evaluated and if the SNP was not significant ( $p>0.05)$ after removal of these records, the SNP was removed from the list of significant or suggestive SNP.

To determine if a SNP had a significant additive effect, dominance effect, or both, the option !CONTRAST in ASReml (Gilmour et al., 2009) was used. Additive effect was defined as the difference between the effects of the two homozygous genotypes. Dominance effect was defined as the difference between the effects of heterozygous genotype and the average of the two homozygous genotypes. It was tested if the additive or dominance effect differed significantly $(p<0.05)$ from 0.

\subsection{Results}

\subsubsection{SNP associated with behavior and type traits}

In total, 7 significant and 21 suggestive SNP were associated with behavior and type traits. Three of the significant (FDR $\leq 0.05$ ) SNP and 7 of the suggestive (FDR $\leq 0.20$ ) SNP had 5 or less observations for one of the genotypic classes. For these SNP a sensitivity analysis was performed. After removing records of animals in genotype classes with 5 or less observations, none of these SNP were significant. Therefore these SNP were removed from the list of significant or suggestive SNP and 4 significant and 14 suggestive SNP remained and these will be discussed in more detail (Figure 3.1; Table 3.2).

SNP were associated with aggressiveness during gestation ( 2 significant and 5 suggestive), with maternal care (1 significant and 1 suggestive), udder balance (1 suggestive), teat thinness ( 1 suggestive), teat length (3 suggestive), foot angle (1 significant), foot depth ( 2 suggestive), and locomotion (1 suggestive). The -log10( $p$ - 
values) ranged from 4.18 to 6.72 and the SNP were located on various chromosomes. Results for the significant and suggestive SNP were not supported by other significant SNP in close proximity. The MAF for significant and suggestive SNP ranged between 0.03 and 0.44 and two SNP had a MAF lower than 0.10. Absolute differences between effects of homozygous genotypes ranged between 0.05 and 0.83 points on a 7-point scale. SNP explained between $0.37 \%$ and $30.9 \%$ of the total additive genetic variance. Two significant and 3 suggestive SNP associated with aggressiveness during gestation and maternal care explained more than $10 \%$ of the total additive genetic variance. Three of these SNP had a limited number of records (between 8 and 33) in the genotype class with the lowest frequency. Seventeen of the significant or suggestive SNP showed additive effects and fifteen showed dominance effects $(p<0.05)$.

No suggestive or significant SNP were detected for aggressiveness at parturition, udder volume, udder attachment, teat shape, front leg, rear leg, and leg angle.

a. Behavior traits
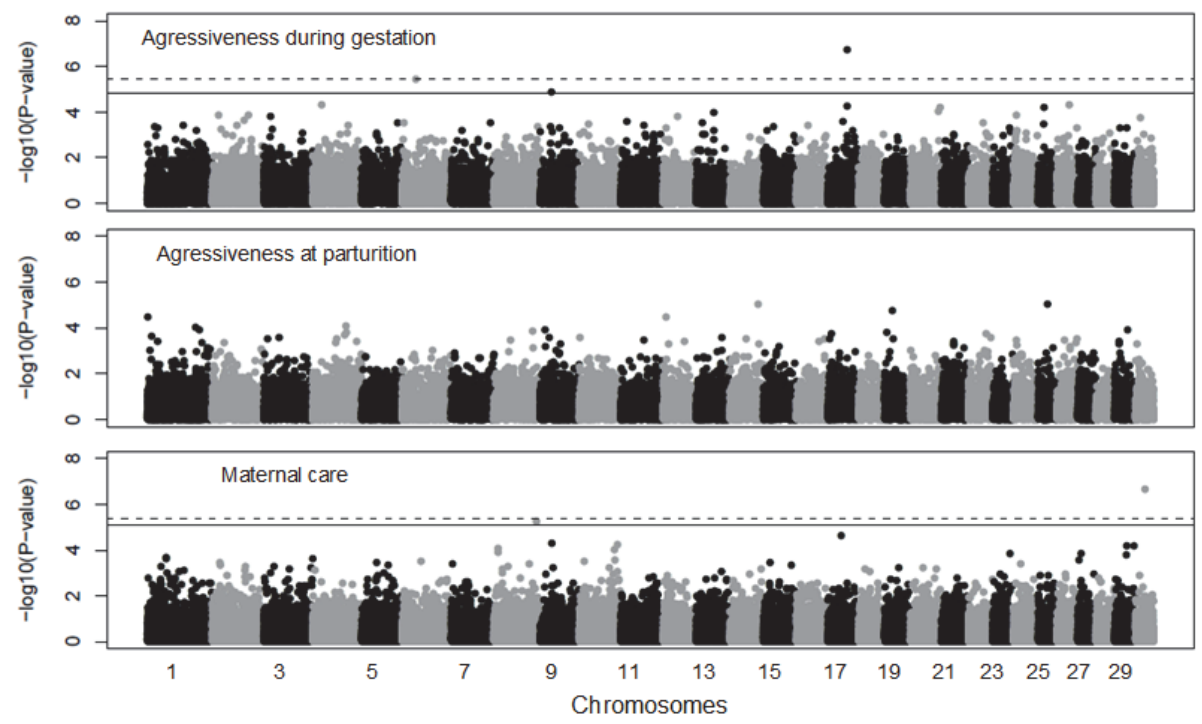
b. Udder type traits
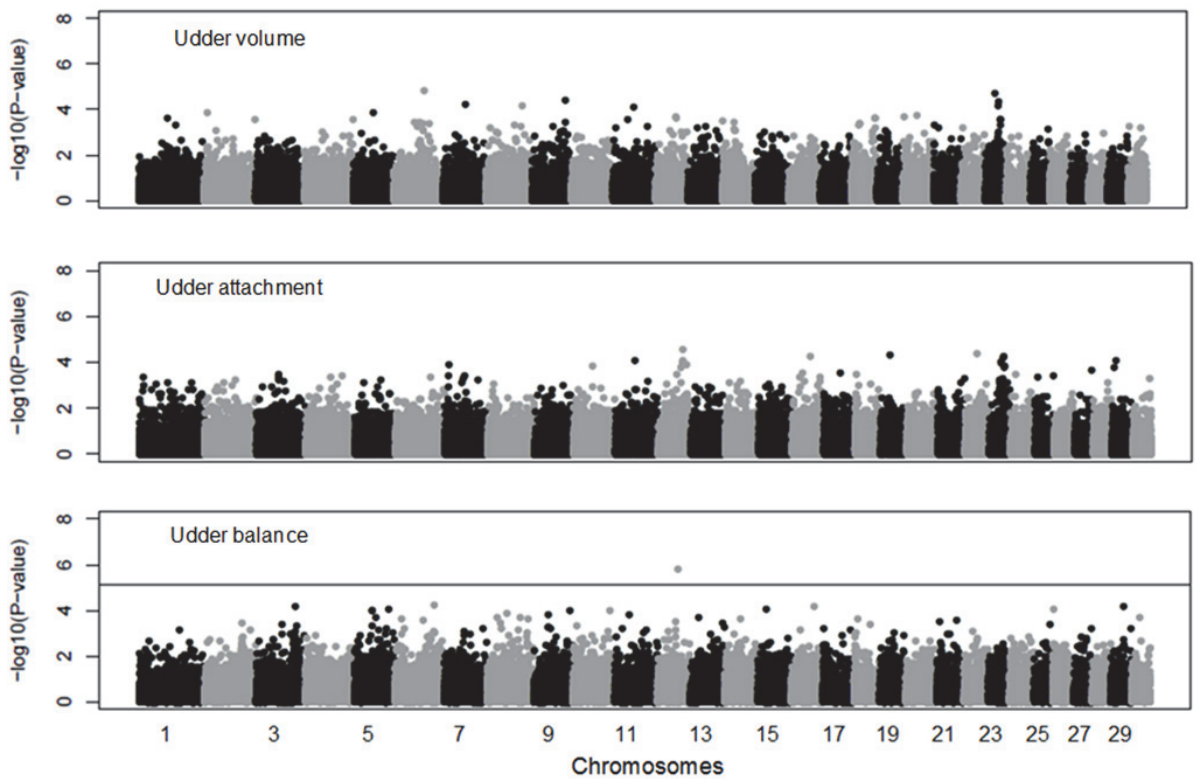

c. Teat type traits
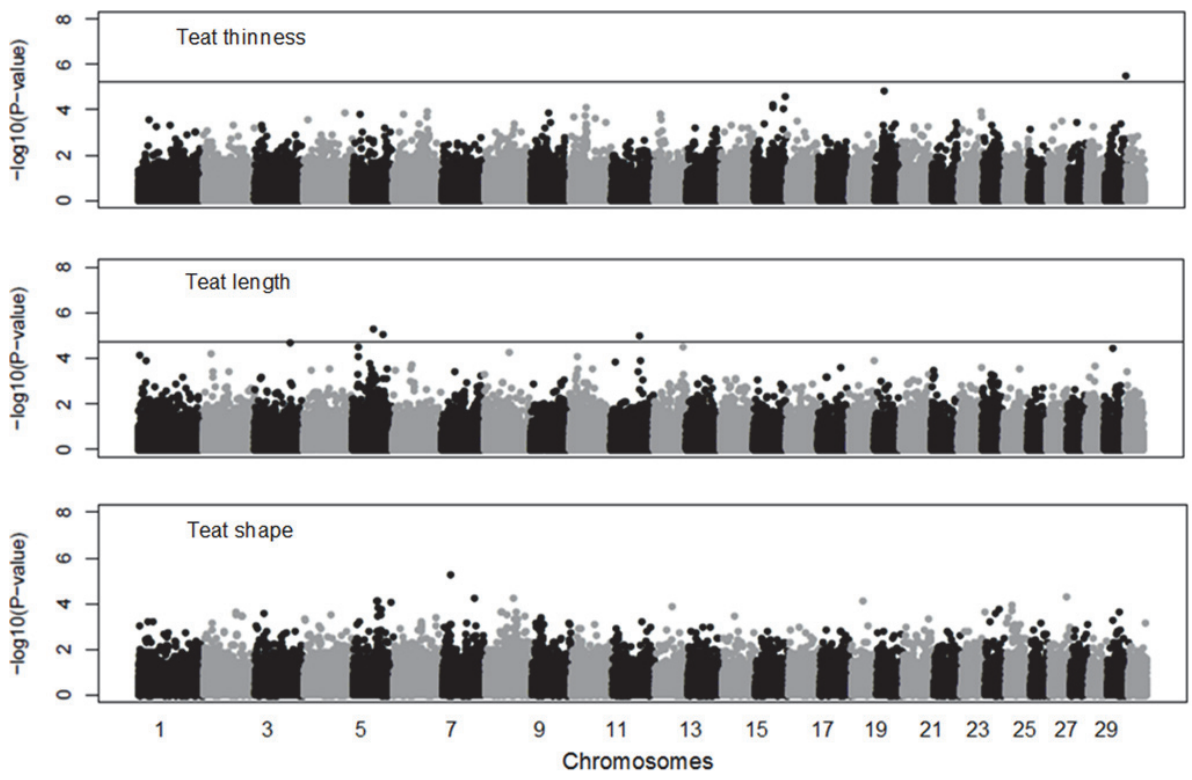
d. Feet and leg type traits and locomotion
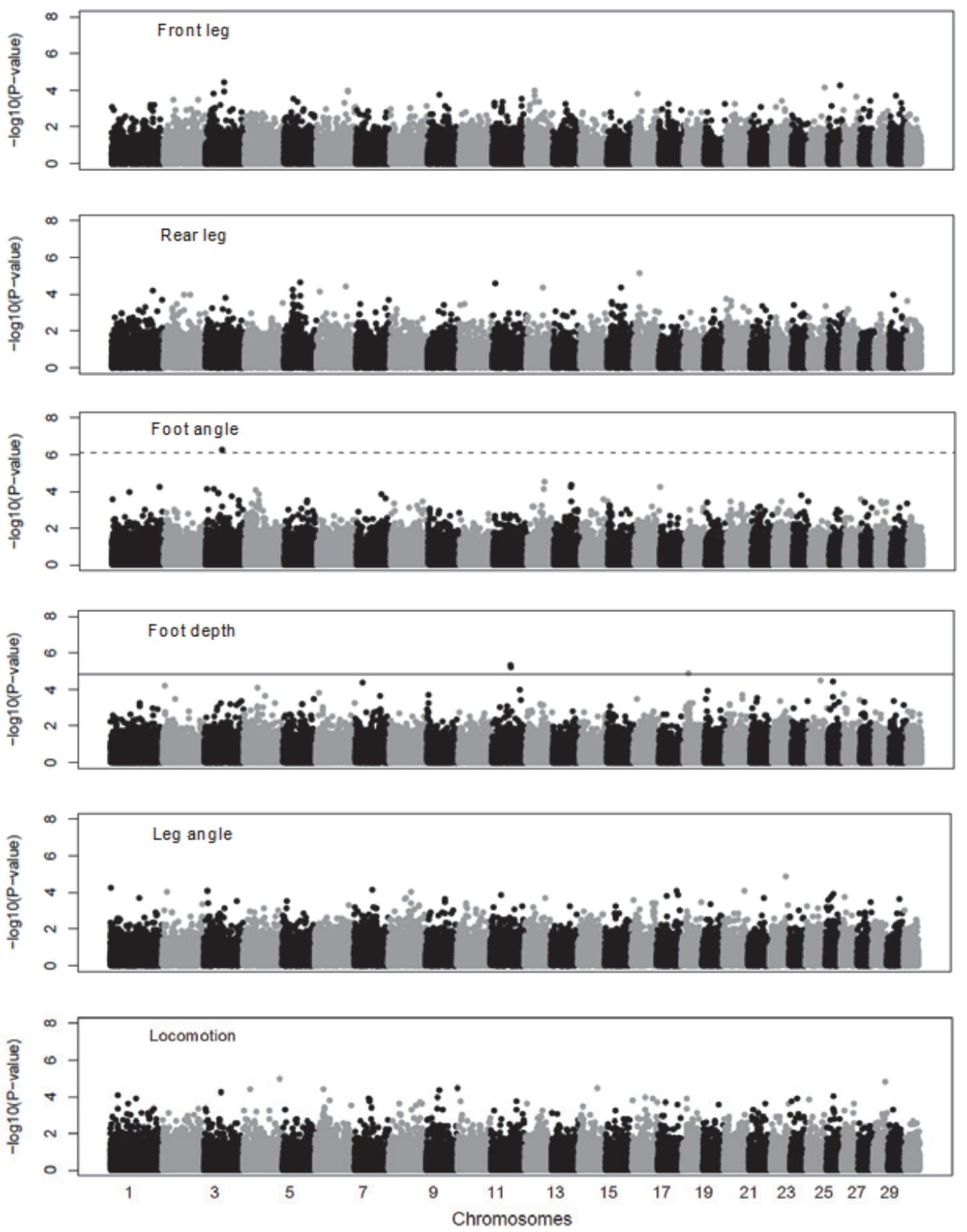

Figure 3.1. GWAS for behavior and type traits. The false discovery rate was set at 0.05 for significant SNP (dashed line) and 0.20 for suggestive SNP (solid line) 


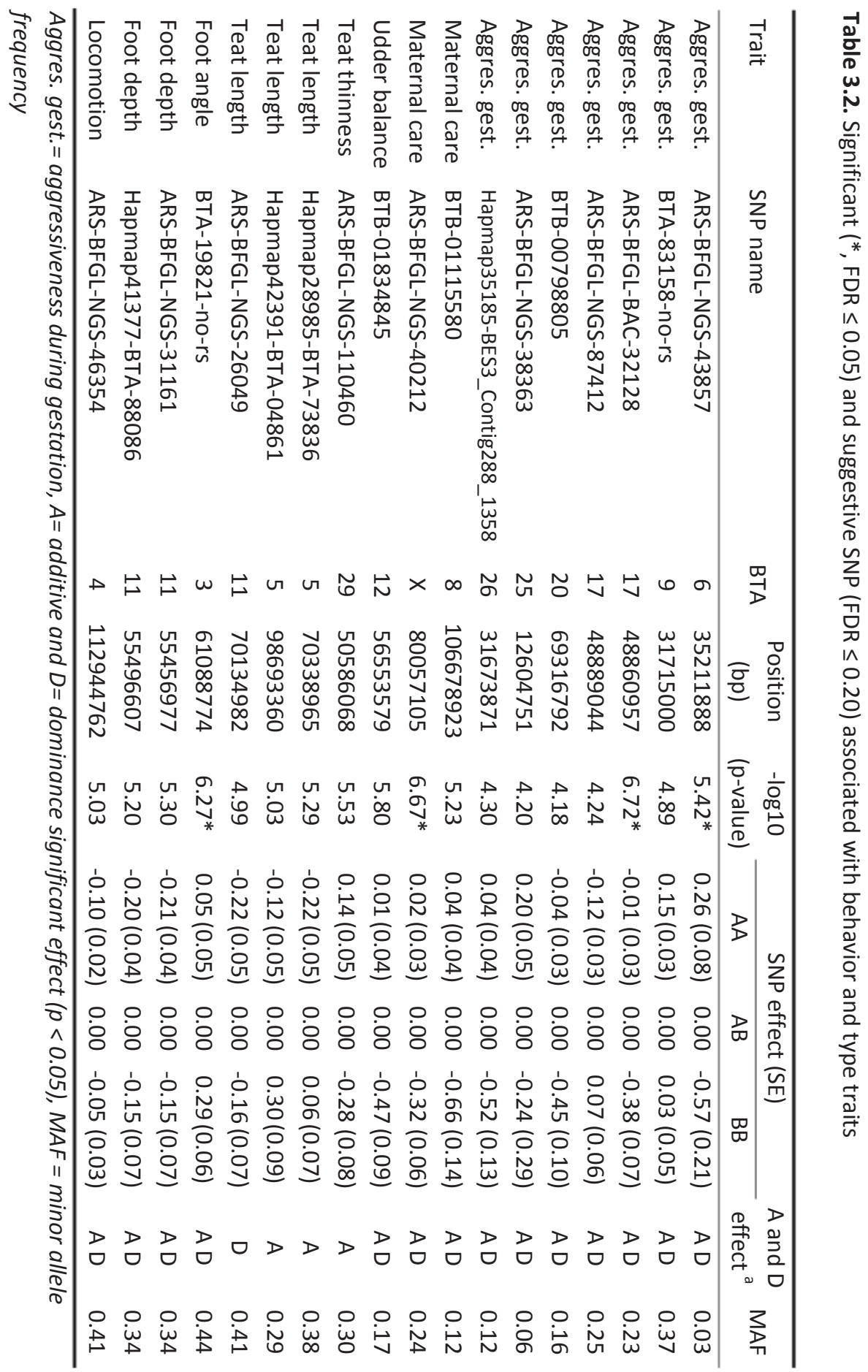




\subsubsection{SNP associated with muscular development}

Thirty five significant SNP located on chromosome 2 were associated with muscular development (Figure 3.2). Twenty two SNP were grouped in a $4 \mathrm{Mbp}$ region which included the myostatin gene GDF8, reported to influence muscular development (Grobet et al., 1998; McPherron and Lee, 1997; Allais et al., 2010). The most significant SNP ARS-BFGL-NGS-101125 (-log10 p-value of 33.6) was located at 676 Mbp from the GDF8 gene (Table 3.3). ARS-BFGL-NGS-101125 had a MAF of 0.11 and 21 cows were homozygous for the favourable muscular development allele. ARS-BFGL-NGS-101125 explained $34 \%$ of the additive genetic variance. ARS-BFGLNGS-101125 showed a significant additive effect $(p<0.01)$ and significant dominance effect $(p<0.01)$ on muscular development. The favourable homozygous genotype had an effect of +7.9 on the muscular development score (on a scale from 10 to 100) compared to the other homozygous genotype.

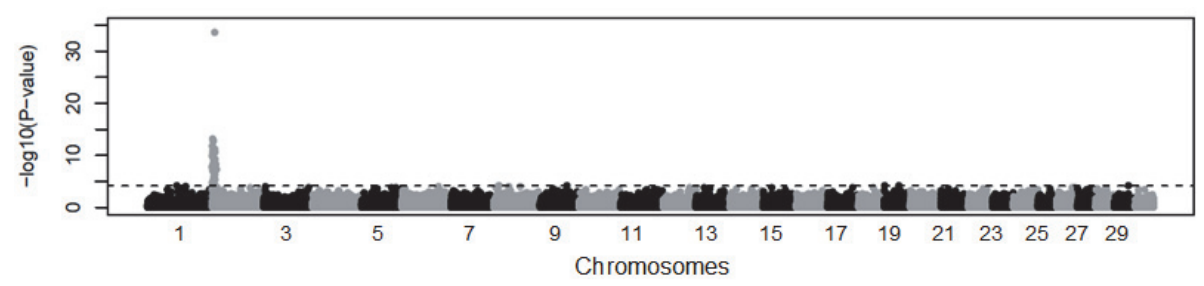

Figure 3.2. GWAS for muscular development. The false discovery rate was set at 0.05 for significant SNP (dashed line)

\subsubsection{Effect of the myostatin region on behavior and type traits}

The allele of ARS-BFGL-NGS-101125 associated with a favourable muscular development was significantly associated with smaller udder volume $(p=0.02)$, thicker teats $(p=0.04)$, rear leg pointing outwards $(p=0.02)$, and lower leg angle ( $p$ $<0.01$ ) (Table 3.3). A significant additive effect of ARS-BFGL-NGS-101125 was found for udder volume $(p<0.01)$, rear leg $(p<0.01)$, and leg angle $(p=0.01)$. A significant dominance effect of ARS-BFGL-NGS-101125 was found for udder volume $(p<0.01)$, teat thinness $(p=0.01)$, rear leg $(p<0.01)$, and leg angle $(p<0.01)$. 
Table 3.3. Effect of ARS-BFGL-NGS-101125 on muscular development (Musc. dev.) and on the behavior and type traits. Standard errors are in parentheses

\begin{tabular}{|c|c|c|c|c|c|c|}
\hline \multirow{2}{*}{ Trait } & \multirow{2}{*}{$\mathrm{p}$-value } & \multicolumn{3}{|c|}{ SNP effect } & \multirow{2}{*}{$\begin{array}{l}\text { Additive } \\
\text { effect }^{a}\end{array}$} & \multirow{2}{*}{$\begin{array}{c}\text { Dominance } \\
\text { effect }^{a}\end{array}$} \\
\hline & & $\mathrm{AA}(\mathrm{SE})$ & $A B$ & $\mathrm{BB}(\mathrm{SE})$ & & \\
\hline Musc. dev. & $<0.01$ & $-6.33(0.50)$ & 0.00 & $1.53(1.74)$ & $A$ & $\mathrm{D}$ \\
\hline Aggres. gest. & 0.30 & $0.05(0.04)$ & 0.00 & $0.18(0.18)$ & & \\
\hline Aggres. part. & 0.25 & $-0.01(0.06)$ & 0.00 & $0.45(0.28)$ & & \\
\hline Maternal care & 0.63 & $0.03(0.04)$ & 0.00 & $0.09(0.18)$ & & \\
\hline Udder volume & 0.02 & $-0.15(0.05)$ & 0.00 & $-0.07(0.25)$ & $A$ & D \\
\hline Udder att. & 0.11 & $0.05(0.06)$ & 0.00 & $-0.55(0.29)$ & & \\
\hline Udder balance & 0.84 & $-0.01(0.04)$ & 0.00 & $0.07(0.20)$ & & \\
\hline Teat thinness & 0.04 & $-0.13(0.06)$ & 0.00 & $-0.40(0.27)$ & NS & $\mathrm{D}$ \\
\hline Teat length & 0.61 & $-0.04(0.06)$ & 0.00 & $-0.11(0.27)$ & & \\
\hline Teat shape & 0.08 & 0.09 (0.07) & 0.00 & $-0.49(0.31)$ & & \\
\hline Front leg & 0.80 & $-0.01(0.03)$ & 0.00 & $0.08(0.14)$ & & \\
\hline Rear leg & 0.02 & $0.00(0.04)$ & 0.00 & $0.52(0.19)$ & $A$ & $\mathrm{D}$ \\
\hline Foot angle & 0.31 & $0.07(0.05)$ & 0.00 & $-0.18(0.25)$ & & \\
\hline Foot depth & 0.25 & $0.07(0.05)$ & 0.00 & $-0.18(0.25)$ & & \\
\hline Leg angle & $<0.01$ & $0.14(0.05)$ & 0.00 & $-0.41(0.22)$ & $A$ & $\mathrm{D}$ \\
\hline Locomotion & 0.15 & $0.02(0.03)$ & 0.00 & $-0.25(0.14)$ & & \\
\hline
\end{tabular}

${ }^{a}=$ additive and dominance effects were evaluated for traits with significant $(p<0.05)$ effect of ARS-BFGL-NGS-101125, $A=$ significant $(p<0.05)$ additive effect and $D=$ significant $(p<0.05)$ dominance effect, $N S=$ non-significant

Aggres. gest. $=$ aggressiveness during gestation, Aggres. part.= aggressiveness at parturition, Udder att. $=$ udder attachment 


\subsection{Discussion}

\subsubsection{Association with behavior and type traits}

\subsubsection{Genetic architecture}

In total, the GWAS identified a limited number of significant (4) and suggestive (14) SNP associated with behavior and type traits. We performed calculations to determine the power of detection for our study using the function "luo.ld.power" (Luo 1998) from the package "IdDesign" for the statistical software R. We assumed allele frequencies of 0.5 for both the marker and the QTL, a $r^{2}$ between the marker and the QTL of 0.3, a Type I error of 0.001 and additive gene action. Based on 3,274 genotyped cows, the power of detecting a QTL explaining 3\% of the phenotypic variance is equal to $97 \%$. The detection power of the current study drops to $80 \%$ for a QTL explaining 2\% of the phenotypic variance and to 33\% for a QTL explaining $1 \%$. This indicates that our study has a high power to detect QTL explaining more than $3 \%$ of the total phenotypic variance and probably does not detect QTL explaining less than $1 \%$ of the total phenotypic variance. The power of our study was further illustrated by the significance of SNP closely located to the GDF8 gene which is known to be associated with muscular development in Charolais (Allais et al., 2010). Therefore, the limited number of QTL detected in the current study suggests that behavior and type traits are influenced by many genes each explaining a small part of genetic variance. This agrees with studies on temperament in Holstein x Charolais (Gutierrez-Gil et al., 2008) and behavior traits in mice (Flint, 2003).

Several studies suggested substantial dominance variance for behavior traits (Meffert et al.; 2002; Gutierrez-Gil et al., 2008) and type traits (Mitzal et al. 1997, Ertl et al., 2014). This study detected 15 SNP with significant dominance effects out of 18 in total. A dominance mode of inheritance could be another reason for the low number of significant SNP effects found in the current study. The power of detecting a QTL explaining 3\% of the phenotypic variance drops from $97 \%$ for a SNP with a dominance ratio of 0 to $88 \%$ with a dominance ratio of 1 .

The SNP associated with behavior and type traits were not supported by other SNP in the region, like the 22 SNP close to the myostatin gene that affected muscular development. The SNP found to be significantly associated were expected to be accompanied by other significant SNP in the region which are also in linkage disequilibrium (LD) with the causal mutation. However, there was no evidence suggesting that these significant or suggestive SNP were artefacts e.g. due to low number of observations for one genotype class or confounding of genotypes with systematic environmental effects such as effects of classifier. The SNP removed 
after quality control were not located in the neighbouring region of significant or suggestive SNP. An explanation for observing only a single significant SNP associated with a trait could be that the SNP is misplaced in the bovine genome map (Snelling et al., 2007). However this is unlikely to be the case for all 18 SNP. Two SNP detected as significant or suggestive had low MAF (lower than 0.10 ) and their maximum LD $\left(r^{2}\right)$ with other SNP was 0.65 . Difficulty to identify supporting SNP could be because SNP on the Illumina BovineSNP50 Beadchip have been selected against low MAF (ascertainment bias). Therefore, significant SNP with low MAF in the current study might have a limited number of SNP in high LD. One SNP found to be significantly associated with maternal care is located on chromosome $X$, a region covered by a limited number of SNP. This results in a low LD between SNP in this region, and could explain why the single significant association could not be confirmed by neighbouring SNP.

Two significant and 3 suggestive SNP associated with aggressiveness during gestation and maternal care explained a large proportion of the total additive genetic variance. This might be explained by a high standard error due to limited number of animals from one homozygous genotype class, so the SNP variance is not estimated very accurately. Furthermore the SNP effects are likely to be overestimated due to the Beavis effect (Beavis, 1998).

\subsubsection{Literature}

The significant SNP ARS-BFGL-NGS-43857 associated with aggressiveness during gestation was at $0.3 \mathrm{Mbp}$ from a marker reported to be associated with sociality behavior in Holstein x Charolais (Gutierrez-Gil et al., 2008). The suggestive SNP BTA-83158-no-rs and BTB-00798805 were associated with aggressiveness during gestation and were at 6.5 and $7.3 \mathrm{Mbp}$ from markers reported to be associated with vocalization during social separation and fearfulness behavior (Gutierrez-Gil et al., 2008). No other confirmation was found for significant or suggestive results for behavior from the current study and other QTL mapping studies on behavior in beef cattle (Schmutz et al., 2001; Esmailizadeh et al., 2008), nor QTL mapping studies on temperament during milking in dairy cattle (Spelman et al. 1999; Schrooten et al. 2000; Hiendleder et al. 2003). The SNP ARS-BFGL-NGS-40212 significantly associated with maternal care was located on chromosome X. In pigs, two studies found QTL located on chromosome $X$ and associated with extreme form of failure of maternal behavior, i.e. sow maternal aggression to their own new-born piglets (Quilter et al., 2007; Chen et al., 2009).

To our knowledge, the present study is the first GWAS for type traits in beef cattle. No SNP identified in the present study were close to QTL reported for type traits in 
dairy cattle (Spelman et al., 1999; Schrooten et al., 2000; Hiendleder et al., 2003; Ashwell et al., 2005). One reason might be that QTL for type traits segregating in Holstein differ from those segregating in Charolais (Thaller et al., 2003; Wientjes et al., 2015).

\subsubsection{Candidate genes}

Genes were considered candidates if located within a $200 \mathrm{Kbp}$ window of the significant or suggestive SNP. Three genes were potential candidates for aggressiveness during gestation. CCSER1 located on chromosome 6, was associated with attention-deficit and hyperactivity disorder in Human (reviewed by Li et al. 2014). TMEM132D located on chromosome 17, was associated with panic disorder, fear and anxiety in Human and in mice (Erhardt et al., 2010; Landgraf et al., 2007; Gregersen et al. 2014). ADRA2A located on chromosome 26, was associated with stress-coping behavior in Human, rat, and mice (Domes et al., 2004; Stamatakis et al., 2008; Laarakker et al. 2010). One gene was potential candidate for maternal care. ATRX located on chromosome $\mathrm{X}$, was associated with licking and grooming in rats (Weaver et al. 2006).

\subsubsection{Association with muscular development and pleiotropic effects}

In total, 54 significant SNP were associated with muscular development of which 35 were located on chromosome 2, and 19 were located on chromosomes 1, 3, 5, 6, 7, $8,9,10,18,19,23,25,26$ and 27. The false discovery test used assumes independent tests, but this assumption is violated as many SNP on e.g. chromosome 2 are in LD. Therefore, we chose to recalculate FDR after excluding chromosome 2. Results showed that none of the SNP located outside chromosome 2 was still detected as significant and therefore this study did not identify additional regions associated with muscular development. The GWAS identified one region on chromosome 2 associated with muscular development, which included the myostatin gene GDF8. This study confirms previous results reporting that the myostatin region is responsible for double muscling in several cattle breeds (Dunner et al., 2003; Grobet et al., 1998), including Charolais (Allais et al. 2010).

The frequency of the minor allele $(0.11)$ for the most significant SNP (ARS-BFGLNGS-101125) was similar to the frequency of causal mutation Q204X in the GDF8 gene observed in the Charolais population (Allais et al., 2010). Muscularity is included in the breeding goal and therefore one might expect a higher frequency of the favourable allele for double muscling. The low frequency of the double muscling allele (0.11) is explained by the adverse effects of the Q204X mutation on 
fitness traits including fertility, calf viability, stress susceptibility (Arthur et al. 1988) and dystocia (Arthur et al. 1989). Therefore breeding is aimed at limiting the number of animals homozygous for the Q204X mutation but maximizing the number of heterozygotes (Allais et al., 2010).

Unlike in some other studies (Phocas, 2009; Allais et al., 2010), in our study observations for all three genotypic classes of ARS-BFGL-NGS-101125 were available, allowing testing for dominance effects. Results showed a significant dominance effect ( $p$-value < 0.01) of ARS-BFGL-NGS-101125 on muscular development. These results could not be compared to other studies where the dominance effects of the Q204X allele on muscular development was not assessed due to the absence of animals homozygous for the Q204X mutation (Phocas, 2009; Allais et al., 2010).

Results confirm that the myostatin region is significantly associated with muscular development and has pleiotropic effects on some type traits, i.e. udder volume, teat thinness, rear leg, and leg angle. The effects on high muscular development and low leg angle are likely to be due to analogous scores for these two traits rather than to a shared biological mechanism. The effect was significantly dominant for udder volume, teat thinness, rear leg, and leg angle ( $p$-value $\leq 0.01$ ). No effect of the myostatin region on aggressiveness and maternal care was found. To our knowledge, the effect of the myostatin region on behavior and type traits has never been studied.

\subsection{Acknowledgements}

This study was funded by Gènes Diffusion. The authors thank the technicians and farmers for their efforts in collecting the data and samples, and Apis Diffusion, Ain Génétique Service, CECNA, CIA Gènes Diffusion, COOPELIA, COOPEL, and ELVA NOVIA for making the data and samples available. Matthieu Duban and Sophie Merlin are acknowledged for their work in providing the genotype data. 


\subsection{References}

Allais, S., H. Levéziel, N. Payet-Duprat, J. F. Hocquette, J. Lepetit, S. Rousset, C. Denoyelle, C. Bernard-Capel, L. Journaux, A. Bonnot, and G. Renand. 2010. The two mutations Q204X and nt821 of the myostatin gene affect carcass and meat quality in heterozygous young bulls of French beef breeds. J. Anim. Sci. 88:446-454.

Arthur, P. F., M. Makarechian, and M. A. Price. 1988. Incidence of dystocia and perinatal calf mortality resulting from reciprocal crossing of doublemuscled and normal cattle. Can. Vet. J. 29(2):163-167.

Arthur, P. F., M. Makarechian, M. A. Price, and R. T. Berg. 1989. Heterosis, maternal and direct effects in double-muscled and normal cattle: I. Reproduction and growth traits. J. Anim. Sci. 67:902-910.

Ashwell, M. S., D. W. Heyen, J. I. Weller, M. Ron, T. S. Sonstegard, C. P. Van Tassell, and H. A. Lewin. 2005. Detection of quantitative trait loci influencing conformation traits and calving ease in Holstein-Friesian cattle. J. Dairy Sci. 88(11):4111-4119.

Beavis, W. D. 1998. QTL analyses: power precision and accuracy. Molecular dissection of complex traits. A. H. Paterson ed. CRC Press, Boca Raton, FL. p 145-162.

Chen, C., Y. Guo, G. Yang, Z. Yang, Z. Zhang, B. Yang, X. Yan, M. Perez-Enciso, J. Ma, Y. Duan, B. Brenig, and L. Huang. 2009. A genome wide detection of quantitative trait loci on pig maternal infanticide behavior in a large scale White Duroc x Erhualian resource population. Behav. Genet. 39(2):213219.

Domes, G., M. Heinrichs, U. Rimmele, U. Reichwald, and M. Hautzinger. 2004. Acute stress impairs recognition for positive words - Association with stress-induced cortisol secretion. Stress 7(3):173-181.

Dunner, S., M. E. Miranda, Y. Amigues, J. Canon, M. Georges, R. Hanset, J. Williams, and F. Menissier. 2003. Haplotype diversity of the myostatin gene among beef cattle breeds. Genet. Sel. Evol. 35:103-118.

Erhardt, A., L. Czibere, D. Roeske, S. Lucae, P. G. Unschuld, S. Ripke, M. Specht, M. A. Kohli, S. Kloiber, M. Ising, A. Heck, H. Pfister, P. Zimmermann, R. Lieb, B. Putz, M. Uhr, P. Weber, J. M. Deussing, M. Gonik, M. Bunck, M. S. 
Kebler, E. Frank, C. Hohoff, K. Domschke, P. Krakowitzky, W. Maier, B. Bandelow, C. Jacob, J. Deckert, S. Schreiber, J. Strohmaier, M. Nothen, S. Cichon, M. Rietschel, T. Bettecken, M. E. Keck, R. Landgraf, B. MullerMyhsok, F. Holsboer, and E. B. Binder. 2010. TMEM132D, a new candidate for anxiety phenotypes: Evidence from human and mouse studies. Mol. Psychiatry 16:647-663.

Ertl, J., A. Legarra, Z. G. Vitezica, L. Varona, C. Edel, R. Emmerling, and K. U. Götz. 2014. Genomic analysis of dominance effects on milk production and conformation traits in Fleckvieh cattle. Genet. Sel. Evol. 46(40).

Esmailizadeh, A. K., C. D. Bottema, G. S. Sellick, A. P. Verbyla, C. A. Morris, N. G. Cullen., and W. S. Pitchford. 2008. Effects of the myostatin F49L substitution on beef traits. J. Anim. Sci. 86(5):1038-1046.

Federation of Animal Science Societies. 2010. Guide for the care and use of agricultural animals in research and teaching. FASS Ag Guide, Champaign, IL.

Flint, J. 2003. Analysis of quantitative trait loci that influence animal behavior. J. Neurobiol. 54:46-77.

Forabosco, F., V. Palucci, and W. F. Fikse. 2007. Selecting traits for international beef evaluations: survey results. Interbull Bull. 37:16-18.

Frisch, J. E. 1982. The use of teat-size measurements or calf weaning weight as an aid to selection against teat defects in cattle. Anim. Prod. 32: 127-133.

Gilmour, A. R., B. J. Gogel, B. R. Cullis, and R. Thompson. 2009. ASReml User Guide Release 3.0. VSN International Ltd. Hemel Hempstead, HP1 1ES, UK.

Gregersen, N. O., H. N. Buttenschon, A. Hedemand, H. A. Dahl, A. S. Kristensen, B. Clementsen, D. P. Woldbye, P. Koefoed, A. Erhardt, T. A. Kruse, A. G. Wang, A. D. Børglum, and O. Mors. 2014. Are TMEM genes potential candidate genes for panic disorder? Psychiatr. Genet. 24:37-41.

Grobet, L., D. Poncelet, L. J. Royo, B. Brouwers, D. Pirottin, C. Michaux, F. Menissier, M. Zanotti, S. Dunner, and M. Georges. 1998. Molecular definition of an allelic series of mutations disrupting the myostatin function and causing double-muscling in cattle. Mamm. Genome 9:210-213. 
Gutiérrez-Gil, B., N. Ball, D. Burton, M. Haskell, J. L. Williams, and P. Wiener. 2008. Identification of quantitative trait loci affecting cattle temperament. J. Hered. 99(6):629-638.

Hiendleder, S., H. Thomsen, N. Reinsch, J. Bennewitz, B. Leyhe-Horn, C. Looft, N. Xu, I. Medjugorac, I. Russ, C. Kühn, G. A. Brockmann, J. Blümel, B. Brenig, F. Reinhardt, R. Reents, G. Averdunk, M. Schwerin, M. Förster, E. Kalm, and G. Erhardt. 2003. Mapping of QTL for body conformation and behavior in cattle. J. Hered. 94(6):496-506.

Hoppe, S., H. R. Brandt, G. Erhardt, and M. Gauly. 2008. Maternal protective behaviour of German Angus and Simmental beef cattle after parturition and its relation to production traits. Appl. Anim. Behav. Sci. 114:297306.

Hulsman Hanna, L. L., D. J. Garrick, C. A. Gill, A. D. Herring, P. K. Riggs, R. K. Miller, J. O. Sanders, and D. G. Riley. 2014. Genome-wide association study of temperament and tenderness using Bayesian approaches in a NelloreAngus crossbred population. Livest. Sci. 161:17-27.

Laarakker, M. C., J. R. van Raai, H. A. van Lith, and F. Ohl. 2010. The role of the alpha 2A-adrenoceptor in mouse stress-coping behaviour. 2010. Psycho neuro endocrinology 35(4):490-502.

Landgraf, R., M. S. Kessler, M. Bunck, C. Murgatroyd, D. Spengler, M. Zimbelmann, M. Nussbaumer, L. Czibere, C. W. Turck, N. Singewald, D. Rujescu, and E. Frank. 2007. Candidate genes of anxiety-related behavior in HAB/LAB rats and mice: Focus on vasopressin and glyoxalase-I. Neurosci. Biobehav. Rev. 31(1):89-102.

Larroque, H., and V. Ducrocq. 2001. Relationships between type and longevity in the Holstein breed. Genet. Sel. Evol. 33(1):39-59.

Le Neindre, P., L. Gringnard, G. Trillat, A. Boissy, F. Ménissier, F. Sapa, and X. Boivin. 2002. Docile Limousin cows are not poor mothers. Proc. 7th World Congr. Genet. Appl. Livest. Prod., Montpellier, France. p. 59-62.

Li, Z., S. H. Chang, L. Y. Zhang, L. Gao, and J. Wang. 2014. Molecular genetic studies of ADHD and its candidate genes: a review. Psychiatry Research 219(1):10-24.

Luo, Z. W. 1998. Detecting linkage disequilibrium between a polymorphic marker locus and a trait locus in natural populations. Heredity. 80:198-208. 
Martinez, A., N. Aldai, R. Celaya, and K. Osoro. 2010. Effect of breed body size and the muscular hypertrophy gene in the production and carcass traits of concentrate-finished yearling bulls. J. Anim. Sci. 2010. 88:1229-1239.

McPherron, A. C., and S. J. Lee. 1997. Double-muscling in cattle due to mutations in the myostatin gene. Proc. Natl. Acad. Sci. USA 94(23):12457-12461.

Meffert, L. M., S. K. Hicks, and J. L. Regan. 2002. Nonadditive genetic effects in animal behavior. Am. Nat. 160(6):198-213.

Misztal, I., T. J. Lawlor, and N. Gengler. 1997. Relationships among estimates of inbreeding depression, dominance and additive variance for linear traits in Holsteins. Genet. Sel. Evol. 29:319-326.

Moser, G., M. S. Khatkar, B. J. Hayes, and H. W. Raadsma. 2010. Accuracy of direct genomic values in Holstein bulls and cows using subsets of SNP markers. Genet. Sel. Evol. 42:37.

Phocas, F. 2009. Genetic analysis of breeding traits in a Charolais cattle population segregating an inactive myostatin allele. J. Anim. Sci. 87(6):1865-1871.

Quilter, C. R., S. C. Blott, A. E. Wilson, M. R. Bagga, C. A. Sargent, G. L. Oliver, O. I. Southwood, C. L. Gilbert, A. Mileham, and N. A. Affara. 2007. Porcine maternal infanticide as a model for puerperal psychosis. Am. J. Med. Genet. Neuropsychiatr. Genet. 144(7):862-868.

Schmutz, S. M., J. M. Stookey, D. C. Winkelman-Sim, C. S. Waltz, Y. Plante, and F. C. Buchanan. 2001. A QTL study of cattle behavioral traits in embryo transfer families. J. Hered. 92(3):290-292.

Schrooten, C., H. Bovenhuis, W. Coppieters, and J. A. M. van Arendonk. 2000. Whole genome scan to detect quantitative trait loci for conformation and functional traits in dairy cattle. J. Dairy Sci. 83:795-806.

Sewalem, A., G. J. Kistemaker, and B. J. Van Doormaal. 2005. Relationship between type traits and longevity in Canadian Jersey and Ayrshires using a Weibull proportional hazards model. J. Dairy Sci. 88:1552-1560.

Snelling, W. M., R. Chiu, J. E. Schein, M. Hobbs, C. A. Abbey, D. L. Adelson, J. Aerts, G. L. Bennett, I. E. Bosdet, M. Boussaha, R. Brauning, A. R. Caetano, M. M. Costa, A. M. Crawford, B. P. Dalrymple, A. Eggen, A. Everts-van der Wind, S. Floriot, M. Gautier, C. A. Gill, R. D. Green, R. Hol., O. Jann, S. J. M. Jones, S. M. Kappes, J. W. Keele, P. J. de Jong, D. M. 
Larkin, H. A. Lewin, J. C. McEwan, S. McKay, M. A. Marra, C. A. Mathewson, L. K. Matukumalli, S. S. Moore, B. Murdoch, F. W. Nicholas, K. Osoegawa, A. Roy, H. Salih, L. Schibler, R. D. Schnabel, L. Silveri, L. C. Skow, T. P. L. Smith, T. S. Sonstegard, J. F. Taylor, R. Tellam, C. P. Van Tassell, J. L. Williams, J. E. Womack, N. H. Wye, G. Yang, S. Zhao, and the International Bovine BAC Mapping Consortium. 2007. A physical map of the bovine genome. Genome Biol. 8(8):165.

Spelman, R. J., A. E. Huisman, S. R. Singireddy, W. Coppieters, J. Arranz, M. Georges, and D. J. Garrick. 1999. Short communication: quantitative trait loci analysis on 17 non production traits in the New Zealand dairy population. J. Dairy Sci. 82:2514-2516.

Stamatakis, A., S. Pondiki, E. Kitraki, A. Diamantopoulou, T. Panagiotaropoulos, A. Raftogianni, and F. Stylianopoulou. 2008. Effect of neonatal handling on adult rat spatial learning and memory following acute stress. Stress 11:148-159.

Storey, J. D., and R. Tibshirani. 2003. Statistical significance for genome-wide studies. PNAS. 100(16):9440-9445.

Thaller, G., W. Krämer, A. Winter, B. Kaupe, G. Erhardt, and R. Fries. 2003. Effects of DGAT1 variants on milk production traits in German cattle breeds. J Anim. Sci. 81:1911-1918.

Turner, S. P., M. C. Jack, and A. B. Lawrence. 2013. Precalving temperament and maternal defensiveness are independent traits but precalving fear may impact calf growth. J. Anim. Sci. 91:4417-4425.

Vallée, A., I. Breider, J. A. van Arendonk, and H. Bovenhuis. 2015. Genetic parameters for large-scale behavior traits and type traits in Charolais beef cows. J. Anim. Sci. 93(9):4277-4284.

Vargas, G., H. H. R. Neves, V. Cardoso, D. P. Munari, and R. Carvalheiro. 2014. Genetic analysis of feet and legs in Nellore cattle. Proc 10th World Congr. Genet. Appl. Livest. Prod., Vancouver, Canada.

Weaver, I. C., M. J. Meaney, and M. Szyf. 2006. Maternal care effects on the hippocampal transcriptome and anxiety-mediated behaviors in the offspring that are reversible in adulthood. Proc. Natl. Acad. Sci. U S A. 103(9):3480-3485. 
Wientjes, Y. C. J., R. F. Veerkamp, P. Bijma, H. Bovenhuis, C. Schrooten, and M. P. L. Calus. 2015. Empirical and deterministic accuracies of across population genomic prediction. Genet. Sel. Evol. 47:5.

Wiggans, G. R., T. S. Sonstegard, P. M. VanRaden, L. K. Matukumalli, R. D. Schnabel, J. F. Taylor, F. S. Schenkel, and C. P. Van Tassell. 2009. Selection of singlenucleotide polymorphisms and quality of genotypes used in genomic evaluation of dairy cattle in the United States and Canada. J. Dairy Sci. 92(7):3431-3436.

Wu, X., M. Fang, L. Liu, S. Wang, J. Liu, X. Ding, S. Zhang, Q. Zhang, Y. Zhang, L. Qiao, M. S. Lund, G. Su, and D. Sun. 2013. Genome wide association studies for body conformation traits in the Chinese Holstein cattle population. BMC Genomics. 14:897.

Weller, J. I. 2009. Quantitative Trait Loci Analysis in Animals. $2^{\text {nd }}$ ed CABI, Wallingford, Oxford. 



\title{
4
}

\section{Genetic parameters for calving and conformation traits in Charolais $x$ Montbéliard and Charolais x Holstein crossbred calves}

\author{
A. Vallée $e^{1,2}$, J. A. M. van Arendonk ${ }^{1}$, and H. Bovenhuis ${ }^{1}$
}

\footnotetext{
${ }^{1}$ Animal Breeding and Genomics Centre, Wageningen University, PO Box 338, 6700 $\mathrm{AH}$, Wageningen, the Netherlands; ${ }^{2}$ Gènes Diffusion, 3595 route de Tournai, CS70023, 59501 Douai Cedex, France Journal of Animal Science (2013) 91:5582-5588
} 


\begin{abstract}
Charolais sires can be mated to Montbéliard or Holstein dairy cows to produce crossbred calves sold for meat production. Heritabilities and correlations between traits can differ when they are calculated within Charolais $x$ Montbéliard or within Charolais $x$ Holstein population. Moreover, the genetic correlation between the same trait measured on Charolais $x$ Montbéliard and on Charolais $x$ Holstein crossbred calves is not necessarily unity. First objective of this study was to estimate heritability and genetic correlation between traits within Charolais $\mathrm{x}$ Montbéliard and within Charolais $x$ Holstein population. Second objective was to investigate if those traits are genetically identical between crossbred populations. Traits studied were calving difficulty, birth weight, height, bone thinness, and muscular development. Data included 22,852 Charolais x Montbéliard and 16,012 Charolais x Holstein crossbred calves from 391 Charolais sires. Heritabilities estimated separately within each crossbred population were similar. Stronger genetic correlations were observed in Charolais $x$ Holstein population compared with Charolais $x$ Montbéliard between calving difficulty and height ( 0.67 vs. 0.54 ), calving difficulty and bone thinness ( 0.42 vs. 0.27 ), birth weight and bone thinness (0.52 vs. 0.20), and between birth weight and muscular development (0.41 vs. 0.18). Bivariate analysis considering observations on Charolais $x$ Montbéliard and on Charolais $x$ Holstein as different traits showed that genetic variances and heritabilities were similar for all traits except height. Birth weight and muscular development were genetically identical traits in each crossbred populations, with genetic correlations of 0.96 and 0.99 . Genetic correlations were 0.91 for calving difficulty, 0.80 for height, and 0.70 for bone thinness and Log-Likelihood Ratio tests indicated that they were significantly different from 1 ( $p \leq 0.01$ ). Results show evidence for re-ranking of Charolais sires for calving difficulty, height, and bone thinness depending on whether they are mated to Montbéliard or Holstein cows.
\end{abstract}

Key words: calf, crossbred, genetic correlation, maternal environment 


\subsection{Introduction}

To manage the replacement of their dairy cattle herds, farmers can choose to inseminate dairy cows having low milk production potential with semen of beef sires. Calves produced are sold at about three weeks of age for beef production. Economic value of these crossbred calves is directly linked to their conformation and indirectly linked to calving difficulty (Luo et al., 2002; Hickey et al., 2007). In France, where the data were collected, the two main dairy cow breeds mated to Charolais sires are Holstein and Montbéliard.

In various species, prenatal environment provided by the mother was shown to have consequences on progeny (Nicholas, 1996). Allen et al. (2004) employed embryo transfer between larger Thoroughbred and smaller Pony mares and determined a difference of $15 \%$ for growth at birth. Studies in pigs or poultry have compared genetic parameters of the parental purebred lines to their terminal crossbred lines (Lutaaya et al., 2001). Zumbach et al. (2007) found genetic correlations lower than 1 for same production traits observed in purebred lines and in their reciprocal crosses which was partly attributed to different environment conditions.

In bovines, differences in performances and economic impact between crossbred and purebred calves have been reported by few studies (Wolfova et al., 2007; Dal Zotto et al., 2009). Interaction between sire and maternal breed was one explanation, among others, for low to medium correlations (from 0.01 to +0.46) between breeding values of beef sires for growth traits estimated on purebred and on crossbred progeny (Tilsch et al., 1989). However, to our knowledge, no genetic parameters have been estimated within different crossbred populations. In addition, information is lacking on genetic correlations for the same trait between different crossbred populations.

The study will focus on traits measured on Charolais $x$ Montbéliard and Charolais $x$ Holstein crossbred calves including calving difficulty, birth weight, height, bone thinness, and muscular development. Traits observed in Charolais x Holstein and Charolais $x$ Montbéliard populations might be genetically different. Therefore, the first objective is to estimate heritabilities and genetic correlations among traits in each crossbred population separately. Further, the second objective is to estimate genetic correlations between the same trait measured in Charolais $\mathrm{x}$ Holstein and Charolais x Montbéliard populations. 


\subsection{Materials and Methods}

Animal Care and Use Committee approval was not obtained for this study because data used is routinely collected as part of the breeding program and collecting these phenotypes does not violate the integrity of the animals.

\subsubsection{Population structure}

Data were from 38,864 crossbred calves originating from 391 purebred Charolais Al sires mated to dams from Montbéliard or Holstein breeds. Number of males was 20,168 (51.9\%) and 18,696 (48.1\%) for females. Number of Charolais x Montbéliard calves was 22,852 (58.8\%) and 16,012 (41.2\%) for Charolais x Holstein calves. Number of sires with offspring in both crossbred populations was 367 . Number of sires with more than 30 calves in each crossbred population was 204 . Sires had on average 99 offspring.

\subsubsection{Traits}

Traits included in this study were calving difficulty, birth weight, height, bone thinness, and muscular development. Data were collected through the national progeny testing program on calves born between 1986 and 2012. Herds were located in the mideastern part of France.

Calving difficulty was recorded by farmers and was evaluated on a scale from 1 to 5 where 1 corresponded to a calving process without difficulty nor assistance and 5 corresponded to particular difficult circumstances where the calf died during calving. Birth weight was estimated by farmers immediately after calving and expressed in kilograms. Conformation traits of calves were recorded on average at 22 days of age and included height, bone thinness, and muscular development. These conformation traits were scored by 19 qualified classifiers who followed regular training sessions in order to score the traits in a consistent way. Classifiers scored both crossbred calves using the same trait definition. Height at withers was scored on a scale from 1 to 5 where 1 corresponded to shortest calves; bone thinness was also scored on a scale from 1 to 5 where 1 corresponded to thinnest bone structure. Muscular development was evaluated based on visual inspection of shoulders, back, and rump. Each location was scored on a scale from 1 to 9 where 1 corresponded to light muscular development. The overall score for muscular development was obtained by averaging the scores for shoulders, back, and rump. 


\subsubsection{Statistical analysis}

Data were analyzed using the following animal model:

$$
Y_{i j k l m n}=\mu+S_{i}+C_{j}+B Y_{B} S_{k}+\text { Animal }_{l}+e_{i j k l}
$$

where $Y_{i j k l m n}$ was the observation, $\mu$ was the overall mean, $S_{i}$ was the fixed effect of sex i (2 classes), $C_{j}$ was the fixed effect of classifier $\mathrm{j}$ (19 classes), $\mathrm{BYBS}_{\mathrm{k}}$ was the fixed effect of the combination between the birth year (from 1986 to 2012) and the birth season defined as four classes where three-month periods were defined starting in December (104 classes). Animal, was the random additive genetic effect of the $\mathrm{I}^{\text {th }}$ calf $\sim \mathrm{N}\left(0, A \sigma_{\mathrm{a}}{ }^{2}\right)$ where $A$ corresponded to additive genetic relationship matrix and $\sigma^{2}$ a corresponded to the additive genetic variance. $\mathrm{e}_{\mathrm{ijk}}$ was the random residual effect $\sim \mathrm{N}\left(0,1 \sigma_{\mathrm{e}}{ }^{2}\right)$ where I corresponded to the identity matrix and $\sigma^{2}$ e corresponded to residual variance.

Only relations on the paternal side were used to construct the additive genetic relationship matrix. Pedigree information on the paternal side was traced back with a minimum of three generations. At first, univariate analyses were used to estimate heritabilities and bivariate analyses to estimate genetic correlations between different traits measured within the same crossbred population. Secondly, bivariate analyses were used to estimate heritabilities and genetic correlations between the same trait measured in the two different crossbred populations, as follow:

$$
\left[\begin{array}{l}
y_{1} \\
y_{2}
\end{array}\right]=\left[\begin{array}{cc}
X_{1} & 0 \\
0 & X_{2}
\end{array}\right]\left[\begin{array}{l}
b_{1} \\
b_{2}
\end{array}\right]+\left[\begin{array}{cc}
Z_{1} & 0 \\
0 & Z_{2}
\end{array}\right]\left[\begin{array}{l}
u_{1} \\
u_{2}
\end{array}\right]+\left[\begin{array}{l}
e_{1} \\
e_{2}
\end{array}\right]
$$

Where $y_{1}$ represents traits measured on Montbéliard $x$ Charolais crossbreds and $y_{2}$ on Holstein $\mathrm{x}$ Charolais. $X_{1}$ and $X_{2}$ are the incidence matrices for fixed effects $b_{1}$ and $b_{2} . Z_{1}$ and $Z_{2}$ are the incidence matrices for random genetic effects $u_{1}$ and $u_{2}$. $e_{1}$ and $e_{2}$ are the error terms. Covariances between $e_{1}$ and $e_{2}$ were 0 as traits were measured on different individuals. To test if genetic correlation was significantly different from 1, the Log-Likelihood Ratio test was used. The likelihoods used were of the unconstrained model and of the model where genetic correlation was fixed at 0.998 . Constraining genetic correlation at a value of exactly 1 is computationally not possible. Significance levels were obtained from a chi-square distribution with 1 degree of freedom. Breeding values of the 204 sires with a minimum of 30 calves in each crossbred population were estimated, using a univariate model in Charolais $\mathrm{x}$ Montbéliard and in Charolais x Holstein separately. 
Genetic parameters were estimated using ASREML (Gilmour et al., 2009).

\subsection{Results}

\subsubsection{Descriptive statistics}

Number of observations, means and standard deviations are given for each crossbred population in Table 4.1. Charolais x Montbéliard and Charolais x Holstein populations had similar means for calving difficulty and height. Calves from Montbéliard dams had 600 grams heavier estimated weights compared with calves from Holstein dams, had 0.17 point higher bone thinness scores and had 0.35 point higher muscular development scores. Standard deviations were similar in both crossbred populations for all traits.

Table 4.1. Traits description with number of observations ( $n$ ), phenotypic means $(\mu)$ and standard deviations (SD) for Charolais $x$ Montbéliard (Montb.) and Charolais $x$ Holstein (Hol.)

\begin{tabular}{|c|c|c|c|c|c|c|c|}
\hline \multirow{2}{*}{ Trait } & \multirow{2}{*}{ Scale } & \multicolumn{3}{|c|}{ Charolais x Montb. } & \multicolumn{3}{|c|}{ Charolais $x$ Hol. } \\
\hline & & $\mathrm{n}$ & $\mu$ & SD & $\mathrm{n}$ & $\mu$ & SD \\
\hline Calving dif. & 1 (easy) to 5 (difficult) & 20,806 & 1.67 & 0.69 & 15,580 & 1.74 & 0.70 \\
\hline Birth w. & $\mathrm{Kg}$ & 20,064 & 45.1 & 8.0 & 15,029 & 44.5 & 7.9 \\
\hline Height & 1 (short) to 5 (tall) & 18,759 & 3.15 & 0.85 & 12,641 & 3.11 & 0.92 \\
\hline Bone thin. & 1 (thin) to 5 (thick) & 18,772 & 2.65 & 0.85 & 12,647 & 2.48 & 0.85 \\
\hline Musc. dev. & 1 (light) to 9 (heavy) & 18,882 & 5.30 & 1.42 & 12,788 & 4.95 & 1.48 \\
\hline
\end{tabular}

Calving dif.= calving difficulty, Birth $w .=$ birth weight, Bone thin.= bone thinness, Musc. dev. = muscular development

\subsubsection{Heritability and correlation within crossbred population}

Heritabilities, phenotypic and genetic correlations among birth and conformation traits for Charolais $x$ Montbéliard population are presented in Table 4.2 and for Charolais $x$ Holstein population in Table 4.3. Estimated heritabilities and phenotypic correlations were similar in both crossbred populations. Calving difficulty and birth weight had similar genetic correlation in Charolais $x$ Montbéliard population (0.86) and in Charolais $x$ Holstein population (0.87). Muscular development had in both populations genetic correlations of approximately zero with height and bone thinness (from -0.10 to 0.01 ). Stronger genetic correlations were observed in 
Charolais $\mathrm{x}$ Holstein population compared with Charolais $\mathrm{x}$ Montbéliard between calving difficulty and height ( 0.67 vs. 0.54$)$, calving difficulty and bone thinness ( 0.42 vs. 0.27 ), birth weight and bone thinness ( 0.52 vs. 0.20$)$, and between birth weight and muscular development (0.41 vs. 0.18).

Table 4.2 Heritability, phenotypic and genetic correlation for traits measured in Charolais x Montbéliard calves. Phenotypic correlations are presented above the diagonal and genetic correlations below. Heritabilities on diagonal (in italics) and genetic variances $\left(\sigma^{2}{ }_{a}\right)$ were estimated on univariate analysis. Standard errors are between parentheses.

\begin{tabular}{lccccc}
\hline & Calving dif. & Birth weight & Height & Bone thin. & Musc. dev. \\
\hline Calving dif. & $0.16(0.02)$ & $0.41(0.01)$ & $0.21(0.01)$ & $0.18(0.01)$ & $0.17(0.01)$ \\
Birth w. & $0.86(0.03)$ & $0.26(0.03)$ & $0.48(0.01)$ & $0.36(0.01)$ & $0.27(0.01)$ \\
Height & $0.54(0.06)$ & $0.71(0.04)$ & $0.33(0.03)$ & $0.35(0.01)$ & $0.13(0.01)$ \\
Bone thin. & $0.27(0.07)$ & $0.20(0.07)$ & $0.44(0.06)$ & $0.32(0.03)$ & $0.11(0.01)$ \\
Musc. dev. & $0.47(0.07)$ & $0.18(0.07)$ & $-0.10(0.07)$ & $0.01(0.07)$ & $0.35(0.03)$ \\
$\sigma^{2}{ }_{a}$ & 0.07 & 15.7 & 0.22 & 0.18 & 0.60 \\
\hline
\end{tabular}

Calving dif.= calving difficulty, Birth $w .=$ birth weight, Bone thin.= bone thinness, Musc. dev. = muscular development

Table 4.3. Heritability, phenotypic and genetic correlation for traits measured in Charolais $x$ Holstein calves. Phenotypic correlations are presented above the diagonal and genetic correlations below. Heritabilities on diagonal (in italics) and genetic variances $\left(\sigma^{2}{ }_{a}\right)$ were estimated on univariate analysis. Standard errors are between parentheses.

\begin{tabular}{lccccc}
\hline & Calving dif. & Birth weight & Height & Bone thin. & Musc. dev. \\
\hline Calving dif. & $0.12(0.02)$ & $0.40(0.01)$ & $0.23(0.01)$ & $0.17(0.01)$ & $0.15(0.01)$ \\
Birth w. & $0.87(0.04)$ & $0.20(0.02)$ & $0.51(0.01)$ & $0.39(0.01)$ & $0.28(0.01)$ \\
Height & $0.67(0.06)$ & $0.68(0.05)$ & $0.36(0.04)$ & $0.33(0.01)$ & $0.10(0.01)$ \\
Bone thin. & $0.42(0.08)$ & $0.52(0.06)$ & $0.45(0.07)$ & $0.30(0.03)$ & $0.13(0.01)$ \\
Musc. dev. & $0.49(0.08)$ & $0.41(0.07)$ & $0.01(0.08)$ & $-0.02(0.08)$ & $0.30(0.03)$ \\
$\sigma^{2}{ }_{a}$ & 0.06 & 11.3 & 0.26 & 0.17 & 0.49 \\
\hline
\end{tabular}

Calving dif.= calving difficulty, Birth $w .=$ birth weight, Bone thin.= bone thinness, Musc. dev. = muscular development 


\subsubsection{Heritability and genetic correlation between crossbred populations}

Table 4.4 shows heritabilities and genetic correlations between the same trait measured in Charolais $\times$ Montbéliard and in Charolais $x$ Holstein populations. Heritabilities estimates based on bivariate analysis were similar for Charolais $x$ Montbéliard and Charolais $x$ Holstein for all traits except for height where heritability was lower in Charolais x Montbéliard (0.34) than in Charolais x Holstein (0.55) populations. This difference is mainly due to a lower additive genetic variance in Charolais $x$ Montbéliard (0.23) as compared to Charolais $x$ Holstein (0.44) populations. This difference in heritability and in additive genetic variance was not as pronounced when estimating heritabilities on univariate analysis within population (Table 4.2 and 4.3 ).

Genetic correlations between crossbred populations for birth weight and for muscular development were not significantly different from 1 ( $p=0.05$ and 0.75 ). Genetic correlation between crossbred populations was 0.91 for calving difficulty, 0.80 for height, and 0.70 for bone thinness and all were significantly different from 1 ( $p \leq 0.01)$.

Table 4.4. Heritabilities $\left(h^{2}\right)$ and genetic correlations $\left(r_{g}\right)$ between same traits measured in Charolais $x$ Montbéliard (Montb.) and in Charolais $x$ Holstein populations. $p$-value is based on the Log-Likelihood ratio test and indicates if genetic correlation differs from unity. Standard errors are between parentheses.

\begin{tabular}{|c|c|c|c|c|c|c|c|c|}
\hline & \multicolumn{3}{|c|}{ Charolais x Montb. } & \multicolumn{3}{|c|}{ Charolais $x$ Holstein } & \multirow{2}{*}{$r_{g}$} & \multirow{2}{*}{$\begin{array}{l}p- \\
\text { value }\end{array}$} \\
\hline & $\sigma_{a}^{2}$ & $\sigma_{p}^{2}$ & $h^{2}$ & $\sigma_{a}^{2}$ & $\sigma_{p}^{2}$ & $h^{2}$ & & \\
\hline Calving dif. & 0.08 & 0.46 & $0.17(0.02)$ & 0.07 & 0.47 & $0.14(0.02)$ & $0.91(0.04)$ & 0.01 \\
\hline Birth w. & 17.8 & 60.8 & $0.29(0.03)$ & 13.1 & 58.1 & $0.23(0.03)$ & $0.96(0.02)$ & 0.05 \\
\hline Height & 0.23 & 0.67 & $0.34(0.03)$ & 0.44 & 0.79 & $0.55(0.05)$ & $0.80(0.04)$ & $<0.001$ \\
\hline Bone thin. & 0.19 & 0.59 & $0.32(0.03)$ & 0.17 & 0.55 & $0.31(0.03)$ & $0.70(0.05)$ & $<0.001$ \\
\hline Musc. dev. & 0.61 & 1.69 & $0.36(0.03)$ & 0.58 & 1.65 & $0.35(0.03)$ & $0.99(0.02)$ & 0.75 \\
\hline
\end{tabular}

Calving dif. $=$ calving difficulty, Birth $w .=$ birth weight, Bone thin $=$ bone thinness, Musc. dev. = muscular development, $\sigma_{a}^{2}=$ genetic variance, $\sigma_{p}^{2}=$ phenotypic variance 


\subsubsection{Comparison of breeding values estimated within crossbred population}

Breeding values of sires estimated on either their Charolais x Montbéliard or their Charolais $x$ Holstein crossbred offspring are shown in Figure 4.1. Traits reported in Figure 1 are bone thinness and muscular development, i.e. a situation where the genetic correlation is significantly different from 1 (bone thinness) and a situation where the genetic correlation is not significantly different from 1 (muscular development).

Bone thinness

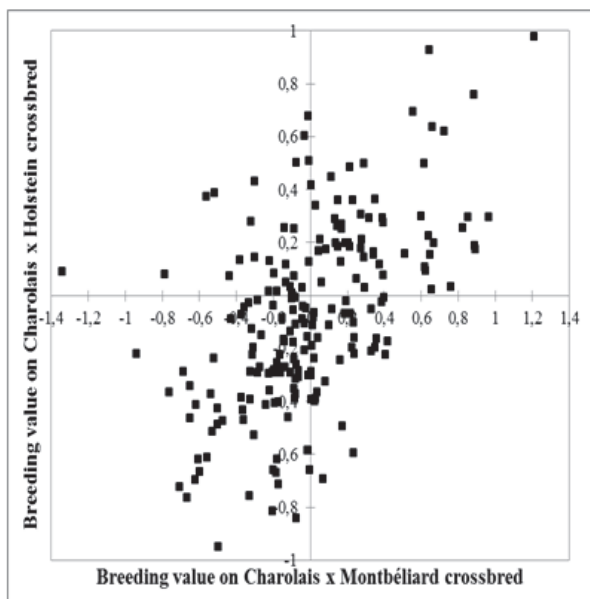

Muscular development

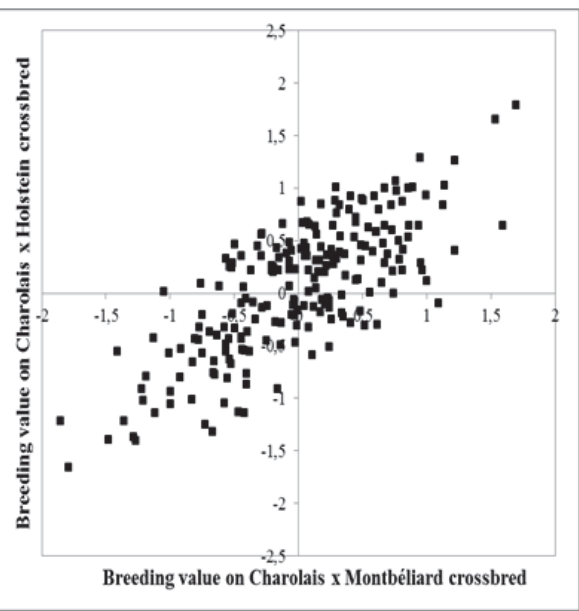

Figure 4.1. Breeding values of 204 sires originating from univariate analysis for bone thinness and muscular development estimated either on Charolais $\mathrm{x}$ Montbéliard or on Charolais x Holstein crossbred calves 


\subsection{Discussion}

\subsubsection{Trait means for Charolais $\mathrm{x}$ Montbéliard and Charolais $\mathrm{x}$ Holstein populations}

Calves from crosses between Charolais sires and Montbéliard dams have on average higher birth weight, thicker bones and higher grades for muscular development. This difference between Charolais $x$ Montbéliard and Charolais $x$ Holstein calves might be due to (maternal) genetic differences between Montbéliard and Holstein dams. However, as Holstein and Montbéliard cows are generally raised in different herds, we cannot exclude specific effects of Montbéliard and Holstein herds such as age at calving or criteria to select females used for terminal cross. In the present study, no information was available on specific farm conditions but Montbéliard and Holstein herds were located in the same region and we are not aware of any systematic differences in management between Montbéliard and Holstein herds. Therefore we expect that (maternal) genetic differences between Montbéliard and Holstein dams are the main reason for differences in mean values between both crossbred populations.

\subsubsection{Heritabilities}

Estimates of heritability obtained for calving difficulty are similar to that reported by Mujibi and Crews (2009) on purebred Charolais who analysed scores transformed to a continuous scale. Heritability of birth weight is slightly lower than previous studies on purebred Charolais (Phocas and Laloe, 2003; Mujibi and Crews, 2009).

Little information is available on genetic parameters for conformation traits of young calves because most studies considered post-weaning traits. Heritability of bone thinness for Piemontese cows was 0.12 (Mantovani et al., 2010) which is lower than the present results. Heritability of muscularity at weaning for purebred Blonde d'Aquitaine and Limousin animals (Bouquet et al., 2010) was similar than results in the current study. Afolayan et al. (2007) analyzed height and muscularity from weaning to 600-days and estimated heritabilities from 0.42 to 0.60 for height and from 0.19 to 0.44 for muscularity. Heritability estimates for height tend to be higher than results of the current study which might be due to the objective measurement of this trait in centimeters.

Pre-weaning traits in beef cattle are affected by maternal effects (Manfredi et al.; 1991, Brandt et al.; 2010; McHugh et al., 2011). Therefore most national cattle evaluation programs use statistical models accounting for direct genetic, maternal genetic, and maternal permanent environmental effects (Crews and Wang, 2007). 
Models used in the present study did not include a maternal (genetic) effect because interest is in genetic parameters for Charolais breed and maternal (genetic) effects would relate to the Holstein or Montbéliard breeds. Present heritabilities are comparable with other studies considering a maternal effect (Phocas and Laloe, 2003; Eriksson et al., 2004). In the current data set herd information was missing for two thirds of the data and therefore the effect of herd was not included in the model. However, as farmers recorded calving traits, difference in trait values between herds might exist due to the subjective nature of recording. In addition, differences in management between herds might exist which could affect the traits. Therefore, additional analyses were performed based on observations for which herd information was available. Herd variance explained between $1 \%$ (for bone thinness) and $23 \%$ (for birth weight) of the phenotypic variance. Herd variance was especially important for traits recorded by the farmer. Adjusting for herd effects led to similar estimates of genetic variance as those from the analysis when not including herd effects. Adjusting for herd effects does lead to a reduction of the residual variance for most traits and therefore might affect heritability estimates. This underlines the importance of herd identification and adjusting for herd effects.

\subsubsection{Genetic correlations between traits within crossbred population}

Calving difficulty and birth weight have high genetic correlations in both Charolais $\mathrm{x}$ Montbéliard and Charolais $x$ Holstein populations (0.86 and 0.87 ). This is in agreement with estimates in purebred Charolais (Mujibi and Crews, 2009). These genetic antagonisms indicate the difficulty to improve simultaneously calving difficulty and birth weight, traits which are both of interest for the terminal cross. Calving difficulty is moderately correlated with height, bone thinness, and muscular development. Afolayan et al. (2007) reported similar genetic correlations between weight and height and between weight and muscle percentage at 400 days. Height and bone thinness are not correlated with muscular development which offers opportunities to improve these traits independently. Results agree with correlations between height and muscular development in Normande dairy breed (Colleau et al. 1989).

\subsubsection{Genetic correlations between crossbred populations}

Calving difficulty ( $r_{\mathrm{g}}$ of 0.91$)$, bone thinness $\left(r_{\mathrm{g}}\right.$ of 0.70$)$ and height $\left(r_{\mathrm{g}}\right.$ of 0.80 ) should be considered as genetically different traits depending upon the breed of the dam. To our knowledge no similar study has been conducted in cattle. In pig breeding, different purebred populations are mated to produce terminal crossbred 
animals and this allows estimating genetic correlations between different crosses. Zumbach et al. (2007) presented a range of genetic correlations for production traits between purebreds and their reciprocal crosses with lowest value of 0.53 for growth. Although they concluded that low genetic correlations were due to difference in environment between populations, epistatic interaction could also have played a role.

Genetic differences between traits measured in Charolais $\mathrm{x}$ Montbéliard and Charolais $x$ Holstein, as quantified by genetic correlation, could be supported by differences in genetic variance in case of height. Further, genetic correlations of calving difficulty, height and bone thinness with other traits differ when evaluated in Charolais $x$ Montbéliard or in Charolais $x$ Holstein. As consequence of these genetic differences, re-ranking of sires evaluated in each crossbred population was observed. Tilsch et al. (1989) evaluated breeding values of beef sires though the performance of minimum six of their purebred and crossbred progeny for various growth traits. The low correlations between breeding values (from 0.01 to +0.46 ) also suggest genetic differences between sires depending upon the dam breeds they were mated to. In the context of pig breeding, even though purebred and crossbred populations are kept in different environments, several studies showed the influence of the breed of the population used for evaluation on the breeding value of purebred sires (Lo et al., 1993; Dekkers, 2007; Zumbach et al., 2007), and concluded on important reranking (Ibanez-Escriche et al., 2011).

\subsubsection{Influence of maternal breed}

Genetic differences between traits measured in Charolais $\mathrm{x}$ Montbéliard and Charolais $x$ Holstein might originate from several factors, one being differences in maternal environment, i.e. environment before (and closely after) birth (e.g. Banos et al. 2007). E.g. due to differences in morphology, Montbéliard and Holstein dams might provide different uterine conditions to their offspring which might result in genotype by (uterine) environment interaction. Studies using embryo transfer and crossfostering in mice resulted in significant uterine and nursing effects on tail length, body weight and growth rate (Cowley et al., 1989; Rhees et al., 1999). Studies in human also showed effect of pre- and post-natal maternal environment on obesity or diabetes phenotypes (Barker, 1998).

Alternatively, epistatic interactions might explain genetic differences between traits measured in Charolais x Montbéliard and Charolais x Holstein. Indeed, the effect of alleles from the Charolais sire might differ depending upon the presence of alleles from either Montbéliard or from Holstein breed. In addition, interaction between the maternal genotype and the genotype of the offspring might play a 
role. This hypothesis is confirmed by observations in mice using embryo-transfer, where various responses of the offspring genotypes on body weight were noticed depending on the kind of mother they developed in (Maestripieri and Mateo, 2009).

\subsubsection{Implications}

Calving difficulty, height, and bone thinness show significant genetic differences when measured in Charolais $x$ Montbéliard or in Charolais $x$ Holstein calves ( $p$-value from 0.01 to $<0.001$ ). Genetic difference for calving difficulty is smaller; however, this trait is of great interest for farmers. Consequently, selection of Charolais sires depends upon the dam breed. Separated genetic evaluations for Charolais $\mathrm{x}$ Montbéliard and Charolais $x$ Holstein crossbreds should be considered. This would offer breeding companies the possibility to label their commercial sires depending on their performance with a certain dam breed. Farmers would have the opportunity to make optimal choice when buying sires straws to inseminate their Holstein or Montbéliard females.

\subsection{Acknowledgements}

This study was funded by Gènes Diffusion. The authors thank Institut de l'Elevage for making data available, Weijia Gong for his helpful support and all members of Gènes Diffusion's staff involved in the project. 


\subsection{References}

Afolayan, R. A., W. S. Pitchford, M. P. B. Delanda, and W. A. McKiernan. 2007. Breed variation and genetic parameters for growth and body development in diverse beef cattle genotypes. Animal. 1: 13-20.

Allen, W. R., S. Wilsher, C. Tiplady and R. M. Butterfield. 2004. The influence of maternal size on pre- and postnatal growth in the horse: III Postnatal growth. Reproduction, 2004: 127 67-77.

Banos, G., S. Brotherstone, and M.P. Coffey. 2007. Prenatal Maternal Effects on Body Condition Score, Female Fertility, and Milk Yield of Dairy Cows. J. Dairy Sci. 90:3490-3499.

Barker, D. J. P. 1998. Mothers, Babies, and Health in Later Life. 2nd edition. Churchill Livingstone, Edinburgh, UK.

Bouquet, A., M.-N. Fouilloux, G. Renand, and F. Phocas. 2010. Genetic parameters for growth, muscularity, feed efficiency and carcass traits of young beef bulls. Livest. Prod. 129: 38-48.

Brandt, H., A. Müllenhoff, C. Lambertz, G. Erhardt, and M. Gauly. 2010. Estimation of genetic and crossbreeding parameters for preweaning traits in German Angus and Simmental beef cattle and the reciprocal crosses. J. Anim. Sci. 88:80-86.

Colleau, J. J., C. Beaumont, and D. Regaldo. 1989. Restricted maximum likelihood (REML) estimation of genetic parameters for type traits in Normande cattle breed. Livest. Prod. Sci. 23:47-66.

Cowley, D. E., D. Pomp, W. R. Atchley, E. J. Eisen, and D. Hawkins-Brown. 1989. The impact of maternal uterine genotype on postnatal growth and adult body size in mice. Genetics. 122:193-203.

Crews, Jr. D. H., and Z. Wang. 2007. Illustration of the maternal animal model used for genetic evaluation of beef cattle1. J. Anim. Sci. 85:1842-1848.

Dal Zotto, R., M. Penasa, M. De Marchi, M. Cassandro, N. Lòpez-Villalobos, and G. Bittante. 2009. Use of crossbreeding with beef bulls in dairy herds: Effect on age, body weight, price, and market value of calves sold at livestock auctions. J. Anim. Sci. 87:3053-3059.

Dekkers, J. C. M. 2007. Marker-assisted selection for commercial crossbred performance. J. Anim. Sci. 85:2104-2114. 
Eriksson, S., A. Näsholm, K. Johansson, and J. Philipsson. 2004. Genetic parameters for calving difficulty, stillbirth, and birth weight for Hereford and Charolais at first and later parities. J. Anim. Sci. 82:375-383.

Gilmour, A. R., B. J.Gogel, B. R. Cullis, and R. Thomson. 2009. ASREML Software Release 3.

Hickey, J. M., M. G. Keane, D. A. Kenny, A. R. Cromie, P. R. Amer, and R. F. Veerkamp. 2007. Heterogeneity of genetic parameters for calving difficulty in Holstein heifers in Ireland. J. Dairy Sci. 90:3900-3908.

McHugh, N., R. D. Evans, P. R. Amer, A. G. Fahey, and D. P. Berry. 2011. Genetic parameters for cattle price and body weight from routinely collected data at livestock auctions and commercial farms. J. Anim. Sci. 89:29-39.

Ibáñez-Escriche, N., J. Reixach, N. Lleonart, and J. L. Noguera. 2011. Genetic evaluation combining purebred and crossbred data in a pig breeding scheme1. J. Anim. Sci. 89:3881-3889.

Lo, L. L., R. L. Fernando, and M. Grossman. 1993. Covariance between relatives in multibreed populations: Additive model. Theor. Appl. Genet. 87:423430.

Luo, M. F., P. J. Boettcher, L. R. Schaeffer, and J. C. M. Dekkers. 2002. Estimation of genetic parameters of calving ease in first and second parities of Canadian Holsteins using Bayesian methods. Livest. Prod. Sci. 74:175184.

Lutaaya, E., I. Misztal, J. W. Mabry, T. Short, H. H. Timm, and R. Holzbauer. 2001. Genetic parameter estimates from joint evaluation of purebreds and crossbreds in swine using the crossbred model1. J. Anim. Sci. 79:30023007.

Maestripieri, D., and J. M. Mateo. 2009. Maternal effects in mammals. University of Chicago Press.

Manfredi, E. J., M. San Cristobal, and J. L. Foulley. 1991. Some factors affecting the estimation of genetic parameters for cattle dystocia under a threshold model. Anim. Prod. 53:151-156.

Mantovani, R., M. Cassandro, B. Contiero, A. Albera, and G. Bittante. 2010. Genetic evaluation of type traits in hypertrophic Piemontese cows. J. Anim. Sci. 88:3504-3512. 
Mujibi, F. D. N., and D. H. Crews Jr. 2009. Genetic parameters for calving ease, gestation length, and birth weight in Charolais cattle. J Anim Sci. 87:2759-2766.

Nicholas, F. W. 1996. Introduction to Veterinary Genetics. Oxford University Press, Oxford.

Phocas, F., and D. Laloe. 2003. Evaluation models and genetic parameters for calving difficulty in beef cattle. J. Anim. Sci. 81:933-938.

Rhees, B. K., C. A. Ernst, C. H. Miao, and W. R. Atchley. 1999. Uterine and postnatal maternal effects in mice selected for differential rate of early development. Genetics. 153:905-917.

Tilsch, K., J. Wollert, and A. Baumung. 1989. Relationship between breeding values for growth of beef sires in purebreeding and crossbreeding. Livest. Prod. Sci. 21: 275-285.

Wolfova, M., J. Wolf, J. Kvapilık, and J. Kica. 2007. Selection for Profit in Cattle: II. Economic Weights for Dairy and Beef Sires in Crossbreeding Systems. J. Dairy Sci. 90:2456-2467.

Zumbach, B., I. Misztal, S. Tsuruta, J. Holl, W. Herring, and T. Long. 2007. Genetic correlations between two strains of Durocs and crossbreds from differing production environments for slaughter traits. J. Anim. Sci. 85:901-908. 


\section{Accuracy of genomic prediction when combining two related crossbred populations}

A. Vallée $e^{1,2}$, J. A. M. van Arendonk ${ }^{1}$, and H. Bovenhuis ${ }^{1}$

${ }^{1}$ Animal Breeding and Genomics Centre, Wageningen University, PO Box 338, 6700 $\mathrm{AH}$, Wageningen, the Netherlands; ${ }^{2}$ Gènes Diffusion, 3595 route de Tournai, CS70023, 59501 Douai Cedex, France

Journal of Animal Science (2014) 92(10):4342-4348 


\section{Abstract}

Charolais bulls are selected for their crossbreed performance when mated to Montbéliard or Holstein dams. To implement genomic prediction, one could build a reference population for each crossbred population independently. An alternative could be to combine both crossbred populations into a single reference population to increase size and accuracy of prediction. The objective of this study was to investigate the accuracy of genomic prediction by combining different crossbred populations. Three scenarios were considered: (1) using one crossbred population as reference to predict phenotype of animals from the same crossbred population, (2) combining the two crossbred populations into one reference to predict phenotype of animals from one crossbred population, and (3) using one crossbred population as reference to predict phenotype of animals from the other crossbred population. Traits studied were bone thinness, height and muscular development. Phenotypes and 45,117 SNP genotypes were available for 1,764 Montbéliard $x$ Charolais calves and 447 Holstein $x$ Charolais calves. The population was randomly spilt into ten subgroups which were assigned to the validation one by one. To allow fair comparison between scenarios, size of the reference population was kept constant for all scenarios. Breeding values were estimated with BLUP and genomic BLUP (GBLUP). Accuracy of prediction was calculated as the correlation between the estimated breeding values and the phenotypic values of the calves in the validation divided by the square root of the heritability. GBLUP showed higher accuracies (between 0.281 and 0.473) than BLUP (between 0.197 and 0.452). Accuracies tended to be highest when prediction was within one crossbred population, intermediate when populations were combined into the reference population, and lowest when prediction was across populations. Decrease in accuracy from a prediction within one population to a prediction across populations was more pronounced for bone thinness (-27\%) and height $(-29 \%)$ than for muscular development (-14\%). Genetic correlation between the two crossbred populations was estimated using pedigree relationships. It was 0.70 for bone thinness, 0.80 for height and 0.99 for muscular development. Genetic correlation indicates the expected gain in accuracy of prediction when combining different populations into one reference population. The larger the genetic correlation is, the larger the benefit is to combine populations for genomic prediction.

Keywords: beef cattle, crossbred, genetic correlation, genomic selection 


\subsection{Introduction}

Dairy cows not used for the replacement of the herds can be inseminated with semen of beef sires to produce calves sold at about three weeks of age for beef production. In France, the two main dairy cattle breeds mated to Charolais sires are Holstein and Montbéliard. For this purpose, purebred Charolais sires are selected based on the performances of their crossbred offspring, i.e. a phenotype not expressed in the purebred Charolais. Selection based on genomic prediction could result in abandoning progeny testing and reducing costs associated with data collection. To implement genomic prediction for selecting Charolais bulls for crossbreeding, one could decide to build independently a reference population with the Montbéliard $x$ Charolais calves and a reference population with the Holstein $x$ Charolais calves. However, as the size of reference population is directly related to the accuracy (Daetwyler et al. 2008; Goddard, 2009; Meuwissen, 2009), combining both crossbred populations would lead in a single larger reference population and could increase accuracy of genomic prediction. Combining genetically different reference populations has been investigated in purebreds and results showed no or limited benefits in terms of accuracy of the genomic prediction (Pryce et al., 2011, Chen et al., 2013). Accuracy of genomic prediction based on a reference population consisting of two crossbred types has been rarely discussed. Results might be different than ones observed in combining purebreds as both crossbreds contain genes from a common breed which is the breed of interest (i.e. Charolais). This situation also occurs in pig, poultry, and sheep breeding schemes. The objective of this study was to investigate the accuracy of genomic prediction by combining different crossbred populations, using real data. Three scenarios which differ with respect to the contribution of both crossbreds to the reference and the validation population were tested.

\subsection{Materials and Methods}

The guidelines stated in the Guide for the Care and Use of Agricultural Animals in Research and Teaching (FASS, 2010) were followed when caring for the animals.

\subsubsection{Data}

Phenotypes were collected on 2,211 crossbred calves from which 1,111 were males and 1,100 were females. Calves originated from 88 purebred Charolais Al sires mated to dams from Montbéliard or Holstein breed. Out of the 88 sires, 69 sires 
had offspring in both crossbred populations. Number of Montbéliard $x$ Charolais calves was $1,764(79.8 \%)$ and number of Holstein $x$ Charolais calves was 447 (20.2\%). Traits included in this study were bone thinness, height, and muscular development. All traits were scored on calves at three weeks of age on average. Height at withers was scored on a scale from 1 to 5 where 1 corresponded to shortest calves and 5 corresponded to taller calves. Bone thinness was also scored on a scale from 1 to 5 where 1 corresponded to thinnest bone structure and 5 corresponded to thicker bone structure. Muscular development was evaluated based on visual inspection of shoulders, back, and rump. Muscular development was scored on a scale from 1 to 9 where 1 corresponded to light muscular development and 9 corresponded to important muscular development. Data were collected between 2010 and 2012 by two qualified classifiers who followed regular training sessions in order to score the traits in a consistent way. One classifier scored 925 Montbéliard x Charolais calves and 241 Holstein x Charolais calves. The other classifier scored 839 Montbéliard x Charolais calves and 206 Holstein $x$ Charolais calves. More details on traits and data collection can be found in Vallée et al. (2013).

All 2,211 calves and their 88 Charolais purebred sires were genotyped with the Illumina BovineSNP50 Beadchip (Illumina Inc., San Diego, CA, USA). Quality control was performed using preGSf90 program (Misztal et al., 2002). All animals had call rates greater than $90 \%$. SNPs with a call rate smaller than $95 \%$ were removed (1,497 SNPs). The minor allele frequency was estimated based on the complete genotyping data, including genotypes from Montbéliard $x$ Charolais calves, Holstein $x$ Charolais calves and purebred Charolais sires. SNPs with a minor allele frequency smaller than $2 \%$ were removed (8,263 SNPs). Monomorphic SNPs were removed (5,363 SNPs). After quality control, 45,117 SNPs were left and included in further analysis.

\subsubsection{Estimation of breeding values}

Each trait was analyzed using the following linear animal model:

$$
Y_{i j k l m}=\mu+S_{i}+C_{j}+D_{k}+\text { BYBS }_{I}+\text { Animal }_{m}+e_{i j k l m},
$$

where $Y_{i j k l m}$ is the observation, $\mu$ is the overall mean, $S_{i}$ is the fixed effect of sex $i$ ( 2 classes), $C_{j}$ is the fixed effect of classifier $j$ (2 classes), $D_{k}$ is the dam breed ( 2 classes), BYBS, is the fixed effect of the combination between the birth year and the birth season defined as classes of three-month periods starting in December 2010 (8 classes). Animal $\mathrm{I}_{\mathrm{m}}$ is the random additive genetic effect of the $\mathrm{m}^{\text {th }}$ calf. $\mathrm{e}_{\mathrm{ijk} / \mathrm{m}}$ is the 
random residual effect $\sim N\left(0,1 \sigma_{\mathrm{e}}{ }^{2}\right)$ where I corresponds to the identity matrix and $\sigma^{2}{ }_{e}$ corresponds to residual variance.

Regular BLUP breeding values were calculated using pedigree information based on paternal relationships. Pedigree information on the sire was traced back with a minimum of three generations. It was assumed that the effect Animal $m$ was distributed as $\mathrm{N}\left(0, \mathbf{A} \sigma_{\mathrm{a}}{ }^{2}\right)$ where $\mathrm{A}$ is the additive genetic relationship matrix and $\sigma^{2}{ }_{a}$ corresponded to the additive genetic variance.

Genomic breeding values were calculated using genomic BLUP (GBLUP; VanRaden, 2008) where A was replaced by the marker-based genomic relationship matrix $G$. The additive genetic relationship matrix and the genomic relationship matrix were calculated using BLUPF90 package (Misztal et al., 2002).

Allele frequencies used to construct $G$ were estimated from the observed genotypes of all animals, including the Montbéliard x Charolais, Holstein x Charolais and the purebred Charolais animals.

Variance components used in BLUP and GBLUP were fixed at values estimated from a larger data set described in Vallée et al. (2013) where calves from both crossbred populations were included and traits were assumed genetically similar between populations. Genetic variance and residual variance were 0.121 and 0.407 for bone thinness, 0.198 and 0.391 for height, and 0.661 and 1.025 for muscular development, respectively. Analysis was performed using BLUPF90 package (Misztal et al., 2002).

\subsubsection{Scenarios for reference and validation populations}

Accuracy and bias were calculated based on ten replicates. For this purpose, the population was randomly split into ten subgroups which were assigned to the validation one by one. In each replicate, $90 \%$ of the calves belonged to the reference population and $10 \%$ of the calves belonged to the validation population. To allow fair comparison between scenarios, size of the reference population was kept constant for all scenarios. In the first scenario, Montbéliard x Charolais calves $(n=1,588)$ were used to predict phenotype of calves $(n=176)$ from the same crossbred type. In scenario 2, Montbéliard x Charolais calves $(n=1,185)$ and Holstein $x$ Charolais calves $(n=402)$ were combined and used as reference population. Phenotypes of Montbéliard $x$ Charolais crossbreds ( $n=176$ ) (scenario 2a) and Holstein x Charolais crossbreds ( $n=45)$ (scenario $2 b$ ) were predicted. In scenario 3 , Montbéliard $x$ Charolais calves $(n=1,588)$ were used as reference population to predict phenotypes of Holstein $x$ Charolais $(n=45)$. In each replicate, calves in the reference population were the same for scenario 1 and scenario 3 . In each replicates, calves in the validation population were the same for scenario 1 and 
scenario 2a. Similarly, calves in the validation population were the same for scenario $2 \mathrm{~b}$ and scenario 3 . A scenario with only Holstein $\mathrm{x}$ Charolais calves in the reference population was not tested as the number of available calves for the reference population was limited $(n=447)$. Number of calves and type of crossbred used in each scenario are summarized in Table 5.1.

In each scenario, breeding values were estimated using BLUP and GBLUP to allow comparison of results between the two methods. Accuracy of prediction was calculated as the correlation between the estimated breeding values and the phenotypic values of the calves in the validation divided by the square root of the heritability (Hayes et al., 2010). Heritabilities used to calculate the accuracy were estimated from a larger data set described in Vallée et al. (2013). They were 0.229 for bone thinness, 0.336 for height and 0.392 for muscular development. Standard error of accuracy was calculated as the standard deviation of the correlations between the estimated breeding values and the phenotypic values based on ten replicates, divided by the square root of the number of replicates. Bias of breeding values was assessed by the regression of phenotypes on the estimated breeding values. Accuracy and bias were calculated for each of the ten replicates and then averaged.

Table 5.1. Description of number and crossbred type of calves used in each scenario in the 10 -fold cross-validation

\begin{tabular}{|c|c|c|}
\hline Scenario & Reference population & Validation population \\
\hline 1 & Montbéliard x Charolais $(n=1,588)$ & Montbéliard $x$ Charolais $(n=176)$ \\
\hline $2 a$ & $\begin{array}{l}\text { Montbéliard x Charolais }(n=1,185) \\
\text { and Holstein } \times \text { Charolais }(n=402)\end{array}$ & Montbéliard x Charolais $(n=176)$ \\
\hline $2 b$ & $\begin{array}{l}\text { Montbéliard x Charolais }(n=1,185) \\
\text { and Holstein } \times \text { Charolais }(n=402)\end{array}$ & Holstein $\times$ Charolais $(n=45)$ \\
\hline 3 & Montbéliard x Charolais $(n=1,588)$ & Holstein $\times$ Charolais $(n=45)$ \\
\hline
\end{tabular}




\subsection{Results}

\subsubsection{Difference in allele frequencies}

Figure 5.1 shows the distribution of the difference in allele frequency at each locus between the Montbéliard $x$ Charolais calves and Holstein x Charolais calves. Consequently, these results also showed difference in allele frequencies between dam breeds. The maximum range would be from -0.500 to 0.500 if one allele is fixed in Montbéliard and the other allele is fixed in Holstein. Difference observed in allele frequency ranged from -0.490 to 0.407 . The number of loci with an absolute difference in allele frequency larger than 0.10 ranged $35.3 \%$. Montbéliard $x$ Charolais calves had lower average number of heterozygote SNPs $(16,067)$ than Holstein x Charolais $(16,819)$.

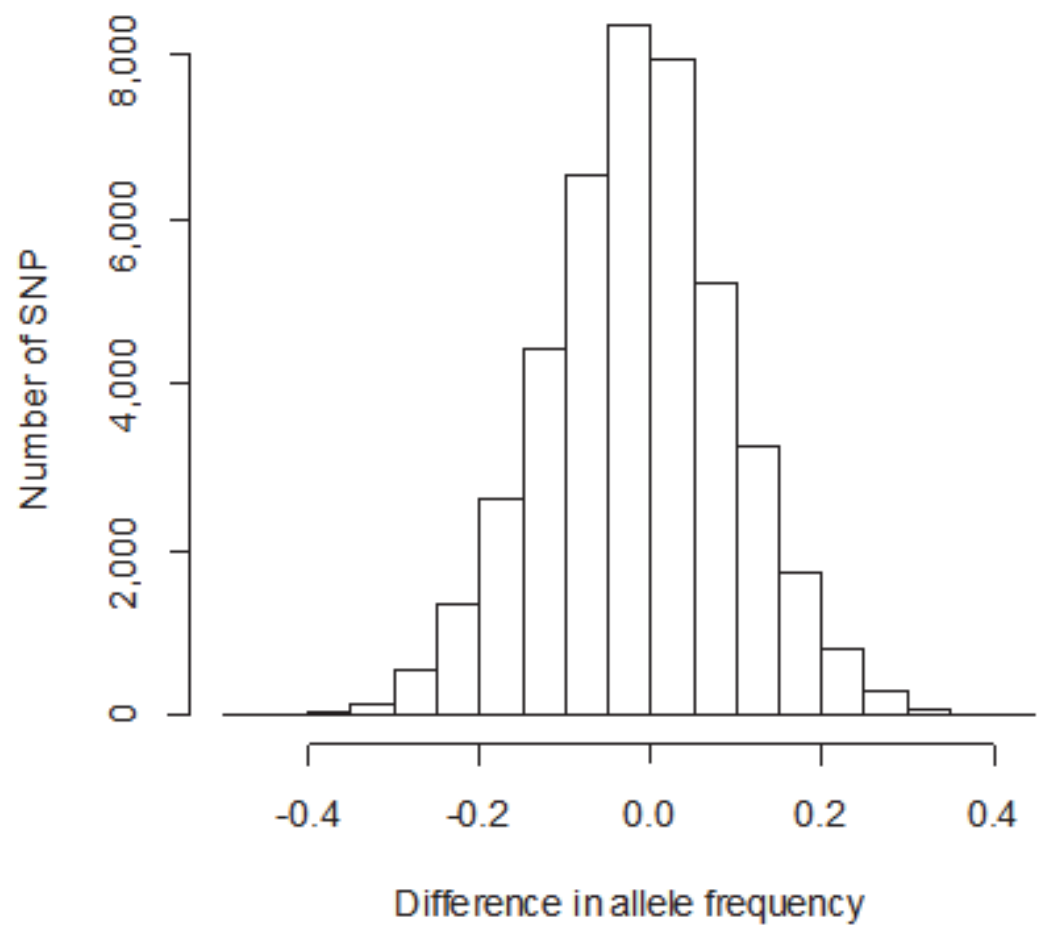

Figure 5.1. Distribution of the difference in allele frequency at each locus between Montbéliard x Charolais and Holstein x Charolais calves 


\subsubsection{Use of crossbred data to predict performance with BLUP and GBLUP}

When using pedigree information (BLUP), accuracies obtained for the different scenarios and traits ranged between 0.197 and 0.452 (Table 5.2). When using genomic information (GBLUP), accuracies obtained for the different scenarios and traits ranged between 0.281 and 0.473 . Increase in accuracy was observed for all traits and all scenarios when genomic information was used instead of pedigree information. Smallest increase was for muscular development in scenario $2 b$ with an accuracy of 0.452 with BLUP and 0.460 with GBLUP which represented $2 \%$ increase in accuracy. Largest increase was for bone thinness in scenario 3 with an accuracy of 0.203 with BLUP and 0.332 with GBLUP which represented $64 \%$ increase in accuracy. Standard errors of the estimated accuracy were lower in scenario 1 and 2a (between 0.018 and 0.032) than in scenario $2 b$ and 3 (between 0.024 and 0.063 ). It was due to larger validation population in scenarios 1 and $2 \mathrm{a}$ as compare to scenarios $2 \mathrm{~b}$ and 3. For muscular development, bias of EBV or GEBV was limited in all scenarios and for BLUP and GBLUP, ranging between 0.852 and 1.094 (Table 5.3). For bone thinness and height, bias was observed in scenario $2 \mathrm{~b}$ and 3 with BLUP ranging between 0.555 and 0.771 , but bias was limited with GBLUP ranging between 0.750 and 0.908 .

Table 5.2. Accuracy of breeding values $\left(r_{a, a}\right)$, averaged over ten replicates, estimated with BLUP and GBLUP for different combinations of crossbred populations

\begin{tabular}{|c|c|c|c|c|c|c|c|}
\hline \multirow[b]{2}{*}{ Scenario } & & \multicolumn{3}{|c|}{ BLUP } & \multicolumn{3}{|c|}{ GBLUP } \\
\hline & & Bone thin. & Height & Musc. dev & Bone thin. & Height & Mus. dev \\
\hline \multirow{2}{*}{1} & $r_{a, a ̂}$ & 0.374 & 0.333 & 0.431 & 0.455 & 0.395 & 0.473 \\
\hline & (SE) & $(0.022)$ & $(0.021)$ & (0.019) & (0.019) & $(0.027)$ & $(0.020)$ \\
\hline \multirow{2}{*}{$2 a$} & $r_{a, a ̂}$ & 0.382 & 0.312 & 0.433 & 0.464 & 0.350 & 0.462 \\
\hline & (SE) & (0.020) & $(0.029)$ & $(0.018)$ & $(0.022)$ & $(0.032)$ & (0.019) \\
\hline \multirow{2}{*}{$2 b$} & $r_{a, a ̂}$ & 0.234 & 0.259 & 0.452 & 0.299 & 0.371 & 0.460 \\
\hline & (SE) & $(0.024)$ & $(0.042)$ & (0.059) & (0.039) & $(0.033)$ & $(0.048)$ \\
\hline \multirow{2}{*}{3} & $r_{a, a ̂}$ & 0.203 & 0.197 & 0.380 & 0.332 & 0.281 & 0.409 \\
\hline & (SE) & $(0.030)$ & $(0.042)$ & $(0.063)$ & $(0.031)$ & $(0.041)$ & $(0.048)$ \\
\hline
\end{tabular}

Bone thin.= bone thinness, Mus. dev= muscular development, SE= standard error of the accuracy 
Table 5.3. Regression of phenotypes on the EBV, averaged over 10 replicates, estimated with BLUP and GBLUP for different combinations of crossbred populations

\begin{tabular}{lccccccc}
\hline & \multicolumn{3}{c}{ BLUP } & & \multicolumn{3}{c}{ GBLUP } \\
\cline { 2 - 4 } \cline { 7 - 8 } Scenario & $\begin{array}{c}\text { Bone } \\
\text { thinness }\end{array}$ & Height & $\begin{array}{c}\text { Muscular } \\
\text { development }\end{array}$ & & $\begin{array}{c}\text { Bone } \\
\text { thinness }\end{array}$ & Height & $\begin{array}{c}\text { Muscular } \\
\text { development }\end{array}$ \\
\hline 1 & 0.984 & 1.065 & 1.044 & & 1.010 & 0.919 & 0.924 \\
$2 \mathrm{a}$ & 1.056 & 0.977 & 1.086 & & 1.067 & 0.797 & 0.943 \\
$2 \mathrm{~b}$ & 0.691 & 0.771 & 1.094 & & 0.809 & 0.908 & 0.916 \\
3 & 0.555 & 0.586 & 0.890 & & 0.877 & 0.750 & 0.852 \\
\hline
\end{tabular}

\subsubsection{Accuracy of prediction within and across crossbred populations}

When the reference and validation populations were from the same crossbred population (scenario 1), accuracies tended to be highest for all three traits, with BLUP and GBLUP (Table 5.2). When the reference and validation populations consisted of different crossbred (scenario 3), accuracies tended to be lower, especially for bone thinness and height. Decrease in accuracy from scenario 1 to scenario 3 tended to be higher for BLUP than for GBLUP. This decrease was more pronounced for bone thinness and height. For bone thinness, the decrease in accuracy between scenario 1 and 3 was $-46 \%$ with BLUP and $-27 \%$ with GBLUP. For height, the decrease in accuracy was $-41 \%$ with BLUP and $-29 \%$ with GBLUP. For muscular development, the decrease in accuracy was $-12 \%$ with BLUP and $-14 \%$ with GBLUP.

\subsubsection{Accuracy of prediction combining crossbred populations into one reference population}

When reference population combined Montbéliard $x$ Charolais (in majority) and Holstein $x$ Charolais (in minority), accuracies tended to be larger when the validation population consisted of Montbéliard $x$ Charolais (scenario 2a) as compare to Holstein $x$ Charolais (scenario 2b) (Table 5.2). Accuracy tended to increase from prediction across populations (scenario 3 ) to scenario $2 b$, ranging between $13 \%$ and $32 \%$, with the exception of bone thinness with GBLUP. The difference in accuracy from prediction within one population (scenario 1 ) to scenario $2 a$ was limited and ranged between -0.045 and +0.008 . 


\subsection{Discussion}

\subsubsection{Use of crossbred data to predict performance}

The present study investigated the accuracy of genomic prediction by combining different crossbred populations. Reference and validation populations shared halfsibs from the same paternal families. This will result in higher accuracies as compared to using unrelated individuals in the reference and in the validation populations (Daetwyler et al., 2013). However, it is expected to affect the different scenarios to the same extend. Size of the reference population was kept constant for all scenarios to allow comparison of accuracy between scenarios. Smaller size of the validation population in scenario $2 b$ and 3 , as compared to scenarios 1 and $2 a$, affected the standard errors of the accuracies.

Accuracy was higher for GBLUP than for BLUP for all traits and all scenarios. Results illustrated the benefit of using genomic information of crossbred animals for prediction of breeding values. This possibility was initially suggested by Dekkers (2007) and then also studied by Ibanez-Escriche et al. (2009) and Toosi et al (2010). They used simulated data, with crossbred animals into the reference population to predict purebred candidates for their crossbred performance. They all concluded that breeding value for performance on crossbred can be accurately predicted using genomic information from crossbred animals. Ibanez-Escriche et al. (2009) and Toosi et al (2010) reported that using genomic information from crossbreds or purebreds tended to give slightly similar level of accuracy of prediction for crossbred performance. Despite of sufficient genomic data on purebreds in the current study, accuracies of genomic prediction using a single crossbred population (scenario 1) were compared to accuracies theoretically predicted by the formula of Daetwyler et al. (2010). The formula was applied on a Charolais purebred population with a genome length of 30 Morgans and an effective population size of 250. Accuracies theoretically obtained were lower than accuracies estimated using real crossbred genomic information. It was 0.313 for bone thinness (as compare to 0.455 in the present study), 0.371 for height (as compare to 0.395 in the present study), and 0.396 for muscular development (as compare to 0.473 in the present study). This could be explained by the tight relationship which benefit to the accuracy as compared to a situation with less strong family relationships modeled by the formula of Daetwyler et al. (2010). 


\subsubsection{Prediction of performance across crossbred populations}

5.4.2.1 Genetic correlation between crossbred populations

Higher loss in accuracy was observed for bone thinness and height compared to muscular development when prediction was performed across rather than within crossbred population. A previous study using partly the same data revealed that the estimated genetic correlation between bone thinness in Montbéliard $x$ Charolais and in Holstein $x$ Charolais was $0.70,0.80$ for height, and 0.99 for muscular development (Vallée et al., 2013). Based on these results, it can be concluded that bone thinness and height were genetically different traits between Montbéliard $x$ Charolais population and Holstein $x$ Charolais population but not muscular development. This explains why accuracy decreased when prediction was across populations as compared to within one population. This also explains higher bias observed for bone thinness and height when prediction was across populations as compared to within one population. The present results showed the concordance between genetic correlation and accuracy of prediction across populations. Using simulated data, Wientjes et al. (unpublished data) demonstrated that the accuracy across populations was proportional to the genetic correlation; if genetic correlation was 0.8 , accuracies of genomic prediction were $80 \%$ of the accuracies based on a genetic correlation of 1 . However, this was not clearly reported on real purebred data where genomic information was used to calculate genetic correlation (Karoui et al., 2012 and Olson et al., 2012). The current study confirmed the conclusions from Wientjes et al. (unpublished data). For bone thinness, with a genetic correlation between populations of 0.70 (Vallée et al, 2013), accuracy of genomic prediction across populations (scenario 3 ) was $73 \%$ of the accuracy within the same population (scenario 1). For height, with a genetic correlation between populations of 0.80 , accuracy of genomic prediction across populations was $71 \%$ of the accuracy within the same population.

Bone thinness and height being genetically different traits implies that the Charolais genes have different effect when the dam is Montbéliard or Holstein. The allele substitution effect of Charolais on Montbéliard $\mathrm{x}$ Charolais or Holstein $\mathrm{x}$ Charolais crossbreds is equal to $a+d\left(1-2 p_{d}\right)$ where $p_{d}$ is the allele frequency in the dam breed and $\mathrm{a}$ and $\mathrm{d}$ are the additive and dominance effects (Dekkers and Chakraborty, 2004). Difference in allele frequencies existed between dam breeds and therefore can result in difference in Charolais allele substitution effect between the crossbred populations. Modeling dominance effect (Zeng et al. 2013) with specifying dam allele frequency might better fit the situation and improve accuracy of prediction. The magnitude of additive effect (a) and dominance effect (d) of the Charolais alleles could also differ depending upon the dam breed. It could 
involve genotype by environment interaction where the genotype inherited from the Charolais sire could interact differently with the maternal environment provided by Montbéliard dams or Holstein dams (Cowley et al., 1989, Barker, 1998, Rhees et al., 1999). It could also involve epistatic interaction where the genotype inherited from the Charolais sire could interact differently with the genotype inherited from the Montbéliard dams or Holstein dams (Spelman et al., 2002, Thaller et al., 2003).

\subsubsection{Contribution of the maternal alleles in genomic prediction}

In GBLUP, alleles from Montbéliard and Holstein were used to establish relationships and they might affect genomic prediction. Previous studies reported that different purebred populations showed differences in allele substitution effects and differences in linkage disequilibrium (LD) between markers and genes. This lead to lower accuracy when prediction was across breeds as compare to within the same breed (Hayes et al., 2009, Pryce et al., 2011, Weber et al. 2012, and Chen et al., 2013). These differences could exist between Montbéliard and Holstein dam breeds and could lead to a decrease in accuracy when prediction was across crossbred populations as compare to within the same crossbred population. In BLUP, relationships on the Montbéliard and Holstein side were not used. Therefore, genetic difference between Montbéliard and Holstein dam breeds did not affect genetic prediction. Larger decrease in accuracy from prediction within to prediction between crossbred populations was not observed for GBLUP as compared to BLUP. Therefore, limited contribution of dam relationship on prediction of crossbred phenotypes is suggested.

Allele frequencies used to construct the genomic relationship matrix were estimated based on genotypes from different populations: 1,764 Montbéliard $x$ Charolais, 447 Holstein x Charolais and 88 purebred Charolais animals. Allele frequencies differ between Montbéliard $x$ Charolais and Holstein $x$ Charolais crossbreds and therefore we do not use the appropriate allele frequencies to construct the genomic relationship matrix. This might distort the within breed genetic variance (Erbe et al, 2012). Distortion could be avoided by scaling $\mathrm{G}$ but it was not expected to affect accuracy (Harris and Johnson, 2010, Erbe et al., 2012, and Makgahlela et al., 2013).

\subsubsection{Combining crossbred populations in the reference population}

The study showed that for bone thinness and height, combining the two crossbred populations in one reference population was beneficial as compare to prediction across populations, although the crossbred present in the validation was 
represented in minority in the reference population. Studies on dairy and beef purebreds also reported a benefit of combining reference populations as compare to across breed predictions because it increased LD phase persistence, similarity in allele effect and genetic correlation between reference and validation populations. (Hayes et al., 2009; Toosi et al., 2010; Pryce et al., 2011 ; Chen et al., 2013). In the present situation where size of the reference population was kept constant, combining crossbred populations into one reference population tended to give similar accuracy to prediction within one crossbred population. Combining crossbred populations will allow to increase the size of the reference population and therefore to increase the accuracy of prediction (Daetwyler et al., 2010). Improvement of the accuracy was assessed by using all Montbéliard $x$ Charolais calves $(n=1,764)$ and the Holstein $x$ Charolais calves $(n=402)$ to predict phenotype of Holstein $x$ Charolais calves $(n=45)$. Accuracy increased up to $9 \%$ for bone thinness, $25 \%$ for height, and $12 \%$ for muscular development, compare to scenario 3. Muscular development being genetically identical between the two crossbreds, combining the two crossbred populations will lead to a maximum gain of accuracy. Bone thinness and height being genetically different between the two crossbreds, increasing the reference size by combining the two crossbred populations will also give higher accuracy than prediction within one population; in a lower extend than for muscular development. The increase in accuracy will depend on the proportion of animals in the validation represented into the reference population.

\subsubsection{Implications}

Having crossbred populations with one parental breed in common offers the opportunity to estimate genetic correlation using pedigree relationships from the common breed, without the need of genotyping information. This scenario also occurs in pig, poultry or sheep breeding. Genetic correlation indicates the expected gain in accuracy of prediction when combining different crossbred populations into one reference population. The larger the genetic correlation is, the larger the benefit is to combine populations for genomic prediction.

\subsection{Acknowledgements}

This study was funded by Gènes Diffusion. The authors thank members of Gènes Diffusion's staff involved in providing the phenotype and genotype data, particularly Vincent Colas, Matthieu Duban, Thomas Gouby, and Sophie Merlin. Weijia Gong is acknowledged for his help in data manipulation and programming. 


\subsection{References}

Barker, D. J. P. 1998. Mothers, Babies, and Health in Later Life. 2nd edition. Churchill Livingstone, Edinburgh, UK.

Chen, L., F. Schenkel, M. Vinsky, D. H. Crews Jr., and C. Li. 2013. Accuracy of predicting genomic breeding values for residual feed intake in Angus and Charolais beef cattle. J. Anim. Sci. 91:4669-4678.

Cowley, D. E., D. Pomp, W. R. Atchley, E. J. Eisen, and D. Hawkins-Brown. 1989. The impact of maternal uterine genotype on postnatal growth and adult body size in mice. Genetics. 122:193-203.

Daetwyler, H. D., B. Villanueva, J. A. Woolliams. 2008. Accuracy of predicting the genetic risk of disease using a genome-wide approach. PLoS ONE. 3:e3395.

Daetwyler, H. D., R. Pong-Wong, B. Villanueva, and J. A. Woolliams. 2010. The impact of genetic architecture on genome-wide evaluation methods. Genetics. 185:1021-1031.

Daetwyler, H. D., M. P. L. Calus, R. Pong-Wong, G. de los Campos, and J. M. Hickey. 2013. Genomic prediction in animals and plants: simulation of data, Validation, reporting, and benchmarking. Genetics. 193:347-365.

Dekkers, J. C. M., R. Chakraborty. 2004. Optimizing purebred selection for crossbred performance using QTL. Genet Sel Evol. 36:297-324.

Dekkers, J. C. M. 2007. Marker-assisted selection for commercial crossbred performance. J. Anim. Sci. 85:2104-2114.

Erbe, M., B. J. Hayes, L. K. Matukumalli, S. Goswami, P. J. Bowman, C. M. Reich, B. A. Mason, and M. E. Goddard. 2012. Improving accuracy of genomic predictions within and between dairy cattle breeds with imputed highdensity single nucleotide polymorphism panels. J. Dairy Sci. 95 :41144129.

FASS. 2010. Guide for the care and use of agricultural animals in research and teaching. http://www.fass.org/docs/agguide3rd/Ag_Guide_3rd_ed.pdf.

Goddard, M. E. 2009. Genomic selection: prediction of accuracy and maximisation of long-term response. Genetica. 136:245-257. 
Harris, B. L., and D. L. Johnson. 2010. Genomic predictions for New Zealand dairy bulls and integration with national genetic evaluation. J. Dairy Sci. 93:1243-1252.

Hayes, B. J., P. J. Bowman, A. J. Chamberlain, and M. E. Goddard. 2009. Invited review: genomic selection in dairy cattle: progress and challenges. J. Dairy Sci. 92:433-443.

Hayes, B. J, J. Pryce, A. J. Chamberlain, P. J. Bowman, M. E. Goddard. 2010. Genetic architecture of complex traits and accuracy of genomic prediction: coat colour, milk-fat percentage, and type in Holstein cattle as contrasting model traits. PLoS Genet. 6(9):e1001139.

Ibanez-Escriche, N., R. L. Fernando, A. Toosi, and J. C. Dekkers. 2009. Genomic selection of purebreds for crossbred performance. Genet. Sel. Evol. 41:12-29.

Karoui, S., M. Carabaño, C. Díaz, and A. Legarra. 2012. Joint genomic evaluation of French dairy cattle breeds using multiple-trait models. Genet. Sel. Evol. 44: 39.

Makgahlela, M. L., I. Strandén, U. S. Nielsen, M. J. Sillanpää, and E. A. Mäntysaari. 2013. The estimation of genomic relationships using breedwise allele frequencies among animals in multibreed populations. J. Dairy Sci. 96 :5364-5375.

Meuwissen, T. H. E. 2009. Accuracy of breeding values of 'unrelated' individuals predicted by dense SNP genotyping. Genet. Sel. Evol. 41:35.

Misztal, I., S. Tsuruta, T. Stabel, B. Auvray, T. Druet, and D. H. Lee. 2002. BLUPF90 and related programs (BGF90). Commun. No. 28-07 in Proc. 7th World. Congr. Genet. Appl. Livest. Prod., Montpellier, France. INRA, CastanetTolosan, France. 28:1-2.

Olson, K. M, P. M. VanRaden, and M. E. Tooker. 2012. Multibreed genomic evaluations using purebred Holsteins, Jerseys, and Brown Swiss. J. Dairy Sci. 95:5378-5383.

Pryce, J. E., B. Gredler, S. Bolormaa, P. J. Bowman, C. Egger-Danner, C. Fuerst, R. Emmerling, J. Sölkner, M. E. Goddard, and B. J. Hayes. 2011. Short communication: Genomic selection using a multi-breed, across-country reference population. J. Dairy Sci. 94:2625-2630. 
Rhees, B. K., C. A. Ernst, C. H. Miao, and W. R. Atchley. 1999. Uterine and postnatal maternal effects in mice selected for differential rate of early development. Genetics. 153:905-917.

Spelman, R. J, C. A. Ford, P. McElhinney, G. C. Gregory, and R. G. Snell. 2002. Characterization of the DGAT1 gene in the New Zealand dairy population. J. Dairy Sci. 85:3514-3517.

Thaller, G., W. Krämer, A. Winter, B. Kaupe, G. Erhardt, and R. Fries. 2003. Effects of DGAT1 variants on milk production traits in German cattle breeds. J. Anim. Sci. 81:1911-1918.

Toosi, A., R. L. Fernando, and J. C. M. Dekkers. 2010. Genomic selection in admixed and crossbred populations. J. Anim. Sci. 88:32-46.

Vallée, A., J. A. M. van Arendonk, and H. Bovenhuis. 2013. Genetic parameters for calving and conformation traits in Charolais $\times$ Montbéliard and Charolais $\times$ Holstein crossbred calves. J. Anim. Sci. 91:5582-5588.

VanRaden, P. M. 2008. Efficient methods to compute genomic predictions. J. Dairy Sci. 91:4414-4423.

Weber, K. L., R. M. Thallman, J. W. Keele, W. M. Snelling, G. L. Bennett, T. P. L. Smith, T. G. McDaneld, M. F. Allan, A. L. Van Eenennaam, and L. A. Kuehn. 2012. Accuracy of genomic breeding values in multibreed beef cattle populations derived from deregressed breeding values and phenotypes. J. Anim. Sci. 90:4177-4190.

Zeng, J., A. Toosi, R. L. Fernando, J. C. M. Dekkers, and D. J. Garrick. 2013. Genomic selection of purebred animals for crossbred performance in the presence of dominant gene action. Genet. Sel. Evol. 45:11. 


\section{6}

General discussion 



\subsection{Introduction}

Beef and dairy farmers can mate their cows to beef sires to produce calves for beef production. Thus, two broad categories of mating for beef production exist; (i) beef sires mated to beef dams to produce purebred animals and (ii) beef sires mated to dairy dams to produce crossbred animals as terminal cross. Currently, two distinct Charolais breeding programs exist to select the best purebred beef sires for each of these categories. In one breeding program, Charolais sires are selected for purebred performance and in the other breeding program, Charolais sires are selected for crossbred performance.

The breeding program dedicated to improve performances of purebred animals, so-called "purebred breeding program", is focused on beef traits, maternal ability, and - more recently- on functional traits. Opportunities to use new functional traits for selection such as behavior and type traits in the purebred Charolais breeding program were studied in chapters 2 and $\mathbf{3}$.

The breeding program dedicated to select the best Charolais sires for terminal crossing with dairy cows, so-called "crossbred breeding program", is focused on improving the performance of the crossbred calves for direct calving ease and meat production. Charolais sires for terminal crossing are generally mated to Montbéliard and Holstein cows. In chapter 4, genetic parameters were estimated within the Montbéliard $x$ Charolais and within the Holstein $x$ Charolais population, and genetic correlations between traits in the two populations were calculated. In chapter 5, genomic breeding values were estimated within and across the two crossbred populations. The results from chapters 4 and 5 raised the question whether ranking of Charolais sires was identical for mating with Montbéliard or Holstein cows.

The same breeding organization might run one breeding program for purebred performances and one for crossbred performances. This implies selecting the best sires for purebred and for crossbred beef production. The breeding goals for these two beef production systems differ. Combining selection for purebred and crossbred performance in one combined breeding program will reduce the cost of selection but might affect genetic progress.

The aim of the general discussion is to discuss the advantages and disadvantages of separate and combined selection for purebred and crossbred performance. In 6.2, the purebred and the crossbred breeding programs will be described, using the current organization applied by a breeding company. In 6.3, the parameters for purebred and crossbred breeding programs that affect the relative performance of separate and combined breeding programs will be discussed. I will also discuss how 
the implementation of genomic evaluation might affect the decision of combining both breeding programs. To conclude, recommendations to optimize the actual breeding organization will be discussed in 6.4 .

\subsection{Description of the breeding programs}

Purebred and crossbred breeding programs will be described as implemented by the French breeding company Gènes Diffusion. In section 6.2.1, the structure of the purebred breeding program will be presented and in section 6.2.2 the crossbred breeding program. The genetic relationship between the two breeding programs will be described in section 6.2.3.

\subsubsection{Purebred breeding program}

The structure of the breeding program selecting Charolais sires for purebred performance and used by the French breeding company Gènes Diffusion is described in Figure 6.1. In this scheme, Charolais sires for purebred performance are selected through multi-stage selection using independent culling. From the French Charolais population of about 127,000 cows registered at the herd book; 1,500 are chosen to become dams of future Al sires (bull dams) and are mated to 15 top sires (bull sires). Offspring from the test matings are performance recorded on farm for direct calving difficulty, weight at birth, weight at 120 days, weight at 210 days, and for muscular and skeletal development at weaning. The best males are selected based on pedigree information and own performance records. Each year, out of 700 male calves, 65 are selected and bought at weaning by the breeding company. Young bulls enter the evaluation station at 210 days of age and during a testing period of one month, individual growth, muscular and skeletal development, and feed intake is recorded. At the end of the test, the best bulls are selected and semen quality is assessed before progeny testing. Each year, about 20 bulls go on to be progeny tested for beef traits recorded on male offspring and maternal ability recorded on female offspring. Each progeny tested bull is randomly mated to about 250 cows in second or higher parity from commercial herds. All 200 progeny born are recorded for direct calving difficulty, birth weight, weaning weight, and are scored for muscular and skeletal development at weaning. Carcass weight, dressing percentage, and carcass conformation are recorded on about 70 male progeny slaughtered at 18 mo. Growth, muscular development and skeletal development at 2 years, heifer reproductive performance, indirect calving difficulty, and suckling ability are recorded on about 50 female progeny. Sires with 
the best breeding values for growth, morphology, carcass quality, reproduction traits, and maternal traits are selected to become Al sires. Each year, 8 new sires are chosen and sires are 6 years old when the final selection takes place. The use of Al in Charolais purebred herds is low (about $11 \%$ of the Charolais cows inseminated by $\mathrm{Al}$ in France; UNCEIA, 2013) which determines the size of the breeding program.

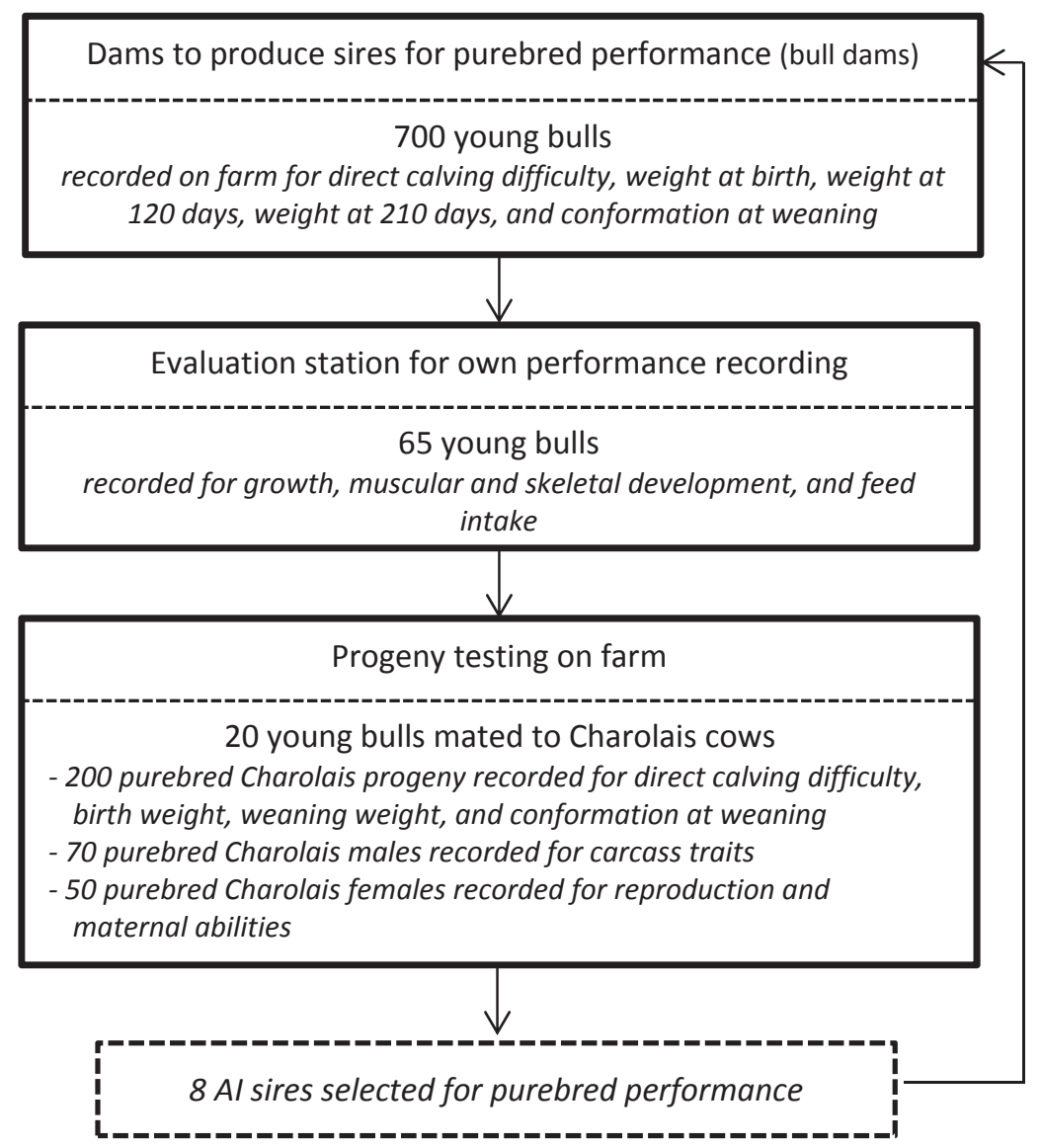

Figure 6.1. Structure of the purebred breeding program used by the French breeding company Gènes Diffusion (numbers refer to numbers per year) 


\subsubsection{Crossbred breeding program}

The structure of the breeding program selecting Charolais sires for crossbred performance and used by the French breeding company Gènes Diffusion is described in Figure 6.2. Similarly to the purebred breeding program, Charolais sires for Charolais $x$ dairy calves performance are selected at multiple time points (multistage selection). Each year, 5 Charolais cows are chosen to become dams of future Al sires (bull dams) and are mated to 5 top Charolais sires (bull sires) using multiple ovulation and embryo transfer. Offspring from the test matings are performance recorded on farm for direct calving difficulty, weight at birth, weight at 120 days, weight at 210 days, and for muscular development at weaning. The best males are selected based on pedigree information and own performance records. Bulls selected should carry the causal mutation Q204X in the myostatin gene GDF8 (Allais et al., 2010). Selected bulls are bought by the breeding company at weaning and assessed for semen quality before progeny testing. Each year, out of 20 male calves born and recorded, about 10 bulls go on to be progeny tested for crossbred performance. Selected bulls are randomly mated to about 220 cows in parity two or higher from dairy breeds; essentially Montbéliard (62\%) and Holstein (33\%). Direct calving difficulty, birth weight, and height, bone thinness, and muscular development at 3 weeks of age are recorded on about 110 crossbred calves. Each year, 3 sires with the best breeding values for direct calving difficulty, birth weight, and conformation at 3 weeks of age are selected to become Al sires using independent culling.

The crossbred breeding program has a smaller size than the purebred breeding program. The size of the crossbred breeding program is determined by the use of terminal crossbreeding in French dairy herds, which is directly related to the economy of the dairy sector. The use of terminal crossbreeding in France has declined by 33\% between 2005 and 2013 (Bouyssiere et al., 2013). This decline was explained by the announcement of the end of milk quotas where dairy farmers anticipated the expansion of their farms or selling heifers. So, mating of dairy cows was more orientated to produce purebred dairy heifers than to produce crossbred calves for meat production. Nevertheless, since the end of 2015, the situation of the dairy sector has changed and the use of terminal crossbreeding is again increasing. This is due to the size of dairy farms that has now stabilized. Another important factor is the current low milk price that reduces income for farmers. In reaction, farmers use terminal crossbreeding to increase their income by selling crossbred calves and to reduce cost of raising heifer for replacement. 


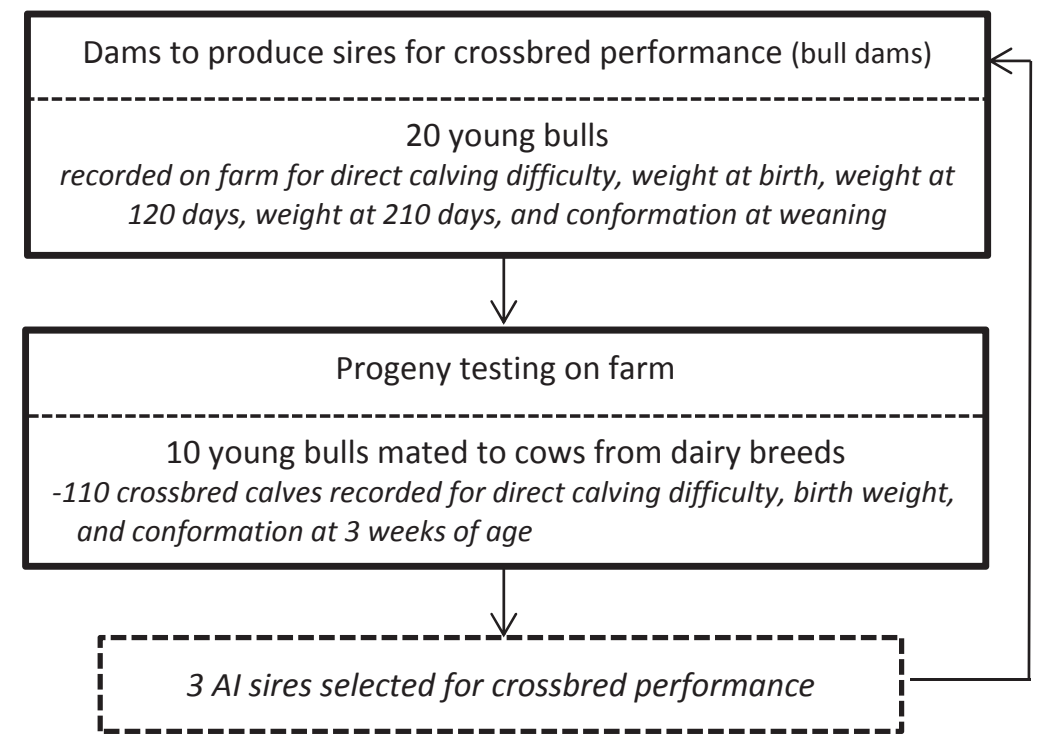

Figure 6.2. Structure of the crossbred breeding program used by the French breeding company Gènes Diffusion (numbers refer to numbers per year)

\subsubsection{Genetic relationship between the two breeding programs}

The purebred and the crossbred breeding programs are seen as distinct breeding programs. Selection of bulls is carried out within two distinct groups of tested bulls and selection is based on different criteria. Bull sires selected for purebred performance are different than bull sires selected for crossbred performance. However, as the number of bull dams in the crossbred breeding program is rather small, some females from the purebred breeding program, but not used as bull dams in the purebred program, are used as bull dams in the crossbred breeding program. This contributes to an increase in the genetic base and reduces the rate of inbreeding within the crossbred breeding program. Each year about one female from the purebred breeding program is used to be part of the five bull dams for the crossbred breeding program.

Genetic relationships between the two breeding programs are further maintained by the use of the "reference sire design" where three sires produce both purebred and crossbred offspring. These sires are no candidates for selection and each four years, one sire of the reference set is replaced by a new one. The use of reference sires, or so-called "connection sires", is an historical procedure established to provide statistical links between both breeding programs which enables the 
comparisons of breeding values for purebred and crossbred performance (Foulley and Sapa, 1982). However, genetic correlations between purebred and crossbred have never been published. As separated selection and separated breeding value estimation have been carried out for decades, maintaining the use of a reference sires design is not relevant.

\subsection{Combining purebred and crossbred breeding programs}

In the current situation there are two separate breeding programs; part of the tested sires are selected for purebred performance and another part is selected for crossbred performance. If breeding programs would be combined, the test resources would increase resulting in a higher selection intensity, and possibly in higher genetic gains (Smith, 1981; Goddard and Smith, 1990). Therefore combining the purebred and the crossbred breeding programs might allow greater response in each breeding program than when breeding programs are separate (Banos and Smith, 1991; Smith and Banos, 1991; Lohuis and Dekkers, 1998). However, superiority of one breeding program over two separate breeding programs has been shown to depend critically on the correlation between breeding objectives of both breeding programs. Furthermore, other parameters such as selection intensity, difference in level of genetic merit, and accuracy of selection might also affect the choice for one combined or two separate breeding programs. In addition, the recent implementation of genomic evaluation in beef breeding might also affect the choice for combining breeding programs or keeping them separate. Paragraph 6.3 discusses parameters that affect the choice for one combined or two separate breeding programs for purebred and crossbred performance.

\subsubsection{Correlation between breeding objectives}

The superiority of combining both breeding programs over keeping them separate largely relies on the correlation between breeding objectives for purebred and crossbred performance. When the correlation between both breeding objectives is high, one breeding program can successfully select animals suited for both breeding objectives. For a correlation of one, Smith and Banos (1991) reported between 5 to $15 \%$ higher genetic gain when combining selection as compared to within-population selection. This is because the same number of animals can be selected from a larger population of selection candidates, resulting in a higher selection intensity and genetic gain (Banos and Smith, 1991; Smith and Banos, 1991; Lohuis and Dekkers, 1998). However, the benefit from combining breeding 
programs decreases as the breeding objectives in the two breeding programs differ. Studies found that when the correlation between breeding objectives was lower than a threshold ranging from 0.75 to 0.90 , running a combined breeding program resulted in lower genetic gain than two separate breeding programs (Banos and Smith, 1991; Vargas and van Arendonk, 2004; Mulder et al., 2006). Below this threshold, the two breeding programs tend to select more of their own bulls and stop selecting bulls from the other breeding program after a few generations (Smith and Banos, 1991; Mulder et al., 2006).

A low correlation between breeding objectives can be due to; (i) different breeding objectives and (ii) genetic difference at the single trait level. Both aspects will be discussed in more detail.

\subsubsection{Difference in breeding objectives}

Difference in breeding objective for purebred and crossbred performance results from difference between traits and/or difference in economic weights for breeding goal traits. In the purebred breeding program, emphasis is on post-weaning traits related to growth, carcass quality, and maternal ability. In the crossbred breeding program, emphasis is on traits expressed earlier in life and related to direct calving ease and conformation of the calve. In chapter $\mathbf{3}$, new functional traits such as behavior and type traits were studied and these traits might be included in the breeding objective for the purebred breeding program. However, these traits have negligible interest for the crossbred breeding program because they do not currently determine the selling price of the crossbred calves by dairy farmers. Direct calving ease and birth weight are included in both breeding objectives but their relative economic weights are higher when selection is for crossbred performance than for purebred performance.

In practice, females from the purebred breeding program are used as bull dams in the crossbred breeding program. This suggests that breeding objectives for purebred and crossbred performance are not extremely different.

\subsubsection{Genetic differences at the trait level}

The same trait measured on purebreds and on crossbreds could be genetically different due to non-additive genetic effects (Wei et al., 1991; Baumung et al.,1997) or genotype by environment interaction (Morris et al., 1993).

Non-additive genetic effects include dominance, i.e. the fact that the alleles inherited from Charolais sire could interact with the alleles at the same locus inherited from Charolais dam or from dairy breed dam. The allele substitution effect of Charolais on purebreds or crossbreds is equal to $a+\left(1-2 p_{d a m}\right) d$ where $a$ is 
the additive genetic effect, $d$ is the dominance effect, and $p_{\text {dam }}$ is the allele frequency in the dam breed (i.e. Charolais breed or dairy breed) (Dekkers and Chakraborty, 2004). If a difference in allele frequencies $\left(p_{\text {dam }}\right)$ exists between Charolais and dairy breed, and $d$ is different from 0 , allele substitution effect for Charolais sires will differ for purebreds and crossbreds. Non-additive genetic effects also include epistasis, i.e. the interaction between alleles at two or more different loci. For more detail, I refer to the discussion in chapter 2.

Estimating non-additive genetic effects is difficult because accurate estimates need to be derived from large datasets of populations with several types of family relationships (Misztal and Lawlor, 1996; Misztal, 1997). Generally, data sets are too small and the familial structure does not allow to disentangle between nonadditive genetic effects and other effects such as common environment or maternal effects in beef cattle (reviewed by Misztal et al., 1996). Genomic information presents new opportunities to estimate non-additive effects. Few studies estimated non-additive genetic effects in livestock and reported a small but significant contribution to total variance (e.g., Van Tassell et al., 2000; Palucci et al., 2007; Su et al., 2012; Bolormaa et al., 2015). In beef cattle, dominance effects for birth weight ranged from 1 to $11 \%$ of the phenotypic mean (Arthur et al., 1999). For pre-weaning gain, non-additive genetic effects were between $-2.2 \%$ and $2.3 \%$ of the phenotypic mean (Roso et al, 2005). Thus, although limited information is available, reported results suggest that non-additive genetic effects might be small for purebred and crossbred.

Genetic difference between traits measured on purebreds and on crossbreds might also originate from genotype by environment interaction. Alleles inherited from Charolais sires could have different effect in the purebred and the crossbred environment (Falconer, 1952). One possible aspect that could contribute to genotype by environment interaction is that Charolais dams and dairy dams provide different maternal environment. For instance, Charolais dams and dairy dams have different body size and consequently provide different pre-natal conditions to their offspring. In mice, studies reported genetic-by-uterine interactions for postnatal growth and demonstrate progeny-specific effects of the prenatal uterine environment (Cowley et al., 1989; Rhees et al., 1999). See discussion in chapter 2.

Differences in postnatal environment also exist between purebreds and crossbreds and these might also cause genotype by environment interaction. Purebred animals are born and raised on specialized beef farms, under extensive conditions whereas crossbred animals are born on dairy farms and then sold to specialized 
fattening farms, under intensive conditions. Purebred calves stay with their dam until weaning (at 210 days on average), whereas crossbreds are immediately removed from their dams after birth to be placed in barns indoor. Purebreds are kept at pasture from spring to autumn and in open barn in winter, whereas crossbreds are kept in barn the whole year and are never kept on pasture. Purebreds are fed with maternal milk, grass, and creep feed whereas crossbreds are fed with milk replacer, concentrates and dry roughage. Charolais purebred animals are mainly born and raised in the mideastern and the western part of France (Bouquet, 2009). Crossbred calves are born in various regions in France and are mainly sold to fattening farms in the northeast region of Italy (Sarzeaud et al., 2007; Gallo et al., 2014). The mideastern and the western part of France have an oceanic climate and the northeast region of Italy has a Mediterranean climate. These climates differ in level of temperature, amount of rainfall, percentage of humidity, and days of sunshine.

The differences in housing, management, feeding, and in health, social and geographic conditions could result in genotype by environment interaction. Evidence of genotype by environment interaction in beef cattle has been reported by several studies with large range of genetic correlations between environments (Neser, 2002; Lopes et al., 2008; Neser et al., 2008; Espasandin et al., 2013).

6.3.1.3 Estimated genetic correlation between purebreds and crossbreds for birth weight

In this section, genetic correlation between birth weight recorded on purebreds and on crossbreds will be estimated. Birth weight is included in the breeding objective of the purebred and the crossbred breeding programs. These analyses will give further insight in the possibilities for combining the purebred and crossbred breeding programs.

Data was available on birth weight for 6,493 purebred calves and 7,946 Charolais $x$ Montbéliard calves. Pedigree information of the animals was traced back for three generations. For the crossbred calves, the pedigree on the maternal side (dairy cows) was not used as the interest is in the genetics transmitted by the Charolais breed. Purebred and crossbred calves originated from 447 purebred Charolais sires. Genetic links between the purebred and the crossbred calves are provided by some females from the purebred breeding program which are used as bull dams in the crossbred breeding program. In addition, for many years a reference sire design has been used where three sires produce both purebred and crossbred offspring (see section 6.2.3). From the animals present in the pedigree, 112 connected purebreds 
and crossbreds. In the current data set, the three "reference sires" had 491 purebred and 767 crossbred calves in total.

Birth weight of purebred and crossbred calves was estimated by the farmers immediately after calving and expressed in kilograms. Data was analyzed using a bivariate animal model with birth weight on purebred Charolais calves and birth weight on Charolais $\mathrm{x}$ Montbéliard calves as two distinct traits. Fixed effects included sex (only one class for purebreds as they were all females, 2 classes for crossbreds), and the combination of birth year (from 1995 to 2009 for purebreds and from 1999 to 2013 for crossbreds) and birth season defined as four classes where three-month periods were defined starting in December (44 classes for purebreds and 42 for crossbreds), parity ( 6 classes for purebreds and crossbreds), and herd (419 classes for purebreds and 2,418 for crossbreds). Random effects were the additive genetic effects and the error terms. Because the two traits are collected on different animals, a correlation between residuals was absent. To test if the genetic correlation was significantly different from 1, the Likelihood Ratio test was used. For this test, I used the likelihoods from the unconstrained model and from a model where the genetic correlation was fixed at 0.998. Significance levels were obtained from a chi-square distribution with 1 degree of freedom. Analysis was performed using ASREML (Gilmour et al., 2009).

Results of the genetic analysis of birth weight in purebred and crossbred are presented in Table 6.1.

Table 6.1. Genetic parameters for birth weight in purebred Charolais and in Charolais x Montbéliard calves (standard errors are given in parentheses)

\begin{tabular}{|c|c|c|}
\hline & $\begin{array}{c}\text { Purebred Charolais } \\
\text { calves }\end{array}$ & $\begin{array}{c}\text { Charolais } \mathrm{x} \\
\text { Montbéliard calves }\end{array}$ \\
\hline Genetic variance $\left(\sigma^{2}{ }_{a}\right)$ & 7.1 & 20.8 \\
\hline Residual variance $\left(\sigma_{\mathrm{e}}^{2}\right)$ & 13.8 & 32.3 \\
\hline Heritability $\left(h^{2}\right)$ & $0.34(0.06)$ & $0.24(0.05)$ \\
\hline Genetic correlation $\left(r_{\mathrm{g}}\right)$ & \multicolumn{2}{|c|}{$0.95(0.13)$} \\
\hline
\end{tabular}

Heritability for birth weight in purebreds $(0.34)$ is comparable with estimates from other studies (Phocas and Laloe, 2003; Eriksson et al., 2004). Heritability for birth weight in purebred Charolais (0.34) was higher than in Charolais $x$ Montbéliard (0.24). Additive genetic variance and residual variance are almost 3 times lower in purebreds than in crossbreds. 
The genetic correlation between birth weight in purebred and crossbred was 0.95. Standard error was high (0.13) which is most likely due to the limited number of genetic links between the two populations. Genetic correlation was not significantly different from $1(p=0.76)$. The data, therefore, does not provide evidence that the trait birth weight in purebred Charolais and in crossbred Charolais $x$ Montbéliard calves is genetically a different trait. The high genetic correlation suggests that for this trait non-additive genetic effects and genotype by environment interaction are relatively small.

Three sires had data available on purebred Charolais and Charolais x Montbéliard calves. Their breeding values for birth weight were estimated in purebred and in crossbred using an univariate model. Sires had the same ranking when estimated either on purebred or on crossbred, although possibilities for re-ranking of three animals are limited. As expected based on the genetic correlations, the sire with the lowest breeding value for birth weight in purebred also had the lowest breeding value in crossbred.

The genetic correlation (0.95) estimated for birth weight is higher than the threshold (from 0.75 to 0.90 ) suggested in some studies for splitting up breeding programs (Banos and Smith, 1991; Vargas and van Arendonk, 2004; Mulder et al., 2006). Thus, if selection of bulls was based on birth weight only, the purebred and the crossbred breeding programs should be combined.

Direct calving difficulty is also collected on purebreds and crossbreds and is included in both breeding objectives. However, data was not available to calculate genetic correlation between purebreds and crossbreds. In chapter 2, calving difficulty was found to be highly genetically correlated with birth weight. Thus, genetic correlation for calving difficulty between purebred and crossbred is expected to be in the same order of magnitude as for birth weight.

The correlation between the breeding objectives for purebred and crossbred performance will be lower than the genetic correlations for birth weight and calving difficulty. This is because of the difference in economic weights defining each breeding objective, as discussed in section 6.3.1.1.

\subsubsection{Difference in selection intensity}

The choice for one combined or two separate breeding programs is also affected by the selection intensity. When selection intensity is low within the breeding programs, the chance to achieve larger genetic gain is increased with one combined breeding program than with two separate breeding programs (Smith and Banos, 1991; Mulder et al., 2006). When selection intensities differ between breeding programs, having one breeding program instead of two separate breeding 
programs is expected advantageous for the smaller breeding program as for that program selection intensity is low (Banos and Smith, 1991; Smith and Banos, 1991; Lohuis and Dekkers, 1998; Mulder et al., 2006). Mulder and Bijma (2006) simulated two breeding programs, a small one with 100 test bulls and a large one with 300 test bulls. Both breeding programs selected an identical number of bulls. Combined selection increased the genetic gain of the small breeding programs by $34 \%$ as compared to selection within the small breeding program. In comparison, combined selection increased the genetic gain of the large breeding program by $7 \%$ as compared to a situation with two separate breeding programs.

When the purebred and the crossbred breeding programs are separate, out of the 700 male calves born each year from the purebred breeding program, 8 are selected to become Al sires. In the crossbred breeding program, out of the 20 male calves born each year, 3 are selected to become Al sires. Thus, the selection intensity estimated across all selection stages is higher for the purebred breeding program (2.62) than for the crossbred breeding program (1.55) (Table 6.2). When the breeding programs are combined, the numbers of male selection candidates can be added so the total number of selection becomes 720 . The selection intensity only slightly increases (2.63) for the purebred breeding program and dramatically increases up to 2.95 for the crossbred breeding program (Table 6.2), as compared to the situation with two separate breeding programs. These calculations indicate that, as the crossbred breeding program has lower selection intensity than the purebred breeding program, higher genetic progress is expected for the crossbred breeding program than for the purebred breeding program when breeding programs are combined.

Table 6.2. Selected fraction $(p)$ and selection intensity $(i)$ for the purebred and the crossbred breeding programs when selection is separate or combined

\begin{tabular}{lccccc}
\hline & \multicolumn{2}{c}{$\begin{array}{c}\text { Purebred breeding } \\
\text { program }\end{array}$} & & \multicolumn{2}{c}{$\begin{array}{c}\text { Crossbred breeding } \\
\text { program }\end{array}$} \\
\cline { 2 - 3 } \cline { 5 - 6 } & $p$ & $i$ & & $p$ & $i$ \\
\hline $\begin{array}{l}\text { Two separate breeding } \\
\text { programs }\end{array}$ & $8 / 700$ & 2.62 & & $3 / 20$ & 1.55 \\
$\begin{array}{l}\text { One combined breeding } \\
\text { program }\end{array}$ & $8 / 720$ & 2.63 & & $3 / 720$ & 2.95 \\
\hline
\end{tabular}




\subsubsection{Difference in genetic mean}

Studies reported that when there is an initial difference in genetic mean between populations, the population with the higher genetic merit will have more to contribute initially to the next generation of selected candidates when breeding programs are combined. The population with the lowest genetic merit benefits most from a combined breeding program. The high genetic merit population still benefits from combined breeding program, but initially less, when the low genetic merit population contributes little and gradually more as the two populations equalize (Banos and Smith, 1991; Vargas and van Arendonk, 2004).

Genetic means for birth weight in purebreds and crossbreds were assessed by the mean EBVs of the sires from the purebred and the crossbred breeding programs. EBVs were estimated using the data and the bivariate animal model described in 6.3.1.3. Means were calculated using EBVs of Charolais sires born after 1995 and with more than 20 purebred or crossbred calves with data. In total, EBVs of 33 selected Al sires from the purebred breeding program were used and sires had on average 132 purebred offspring. EBVs of 29 selected Al sires from the crossbred breeding program were used and sires had on average 59 crossbred offspring.

Standard error of the genetic mean was calculated as the standard deviation of the EBVs, divided by the square root of the number of sires with EBV calculated.

Results of the genetic means for birth weight in purebreds and crossbreds are presented in Table 6.3.

Table 6.3. Genetic means for birth weight in purebred and crossbred. Standard errors are given in parentheses

\begin{tabular}{lcc}
\hline & $\begin{array}{c}\text { Genetic mean for } \\
\text { birth weight in } \\
\text { purebred }\end{array}$ & $\begin{array}{c}\text { Genetic mean for } \\
\text { birth weight in } \\
\text { crossbred }\end{array}$ \\
\hline $\begin{array}{l}\text { Sires from the purebred } \\
\text { breeding program }\end{array}$ & $0.18(0.35)$ & $0.15(0.40)$ \\
$\begin{array}{l}\text { Sires from the crossbred } \\
\text { breeding program }\end{array}$ & $-0.63(0.29)$ & $-0.80(0.36)$ \\
\hline
\end{tabular}

Sires from the crossbred breeding program have lower genetic mean for birth weight in purebred $(-0.63)$ than sires from the purebred breeding program $(0.18)$, with a difference of 0.81 . Similarly, sires from the crossbred breeding program have lower genetic mean for birth weight in crossbred $(-0.80)$ than sires from the purebred breeding program (0.15), with a difference of 0.95 . Given the emphasis 
on low birth weight in the crossbred breeding program, it is expected that Charolais sires from the crossbred breeding program have lower breeding value for birth weight than the sires from the purebred breeding program. Thus, when breeding programs are combined, the difference in genetic level will negatively affect the contribution of the animals from the purebred breeding program.

The difference in genetic mean for birth weight at the crossbred level between sires from the purebred and the crossbred breeding program is 0.95 . This is equivalent to $0.36 \sigma_{a}$ ( $\sigma_{a}$ for birth weight in purebreds is 2.66 , see Table 6.1 ). This relatively small difference suggests that when breeding programs are combined and selection is for birth weight, there are sufficient possibilities to select within the purebred breeding program those sires which suit the requirements in crossbreds. This can also be illustrated by combining the $33 \mathrm{Al}$ sires from the purebred breeding program and the $29 \mathrm{Al}$ sires from the crossbred breeding program and selecting the 10 sires with the lowest EBV for birth weight in crossbred. From the 10 sires with the lowest EBV, 4 originated from the purebred breeding program and 6 originated from the crossbred breeding program. This indicates that difference in birth weight in crossbred is relatively small between the two breeding programs. Therefore, when both breeding programs are combined, it is still possible to identify sires which have a low EBV for birth weight and are thus suitable for crossbreeding with a dairy breed.

\subsubsection{Strategy for progeny testing}

The choice for one combined or two separate breeding programs also depends on the strategy used for progeny testing as it determines the level of accuracy of selection. If the accuracy of selection increases when breeding programs are combined, the chance to achieve larger genetic gain increases, as compared to separate breeding programs.

The progeny testing strategy is defined by the number of progeny per tested sire, the heritability of the trait measured, and the genetic correlation between the trait measured and the trait in the breeding goal.

When breeding programs are separate, 20 sires from the purebred breeding program are progeny tested on 200 purebreds and 10 sires from the crossbred breeding program are progeny tested on 110 crossbreds. I will assume that the total number of tested sires is fixed when breeding programs are combined, so 30 sires will be progeny tested. Furthermore, I will assume that the progeny testing capacity, i.e. the number of progeny produced for progeny testing, is fixed and that collecting data on purebreds and on crossbreds is equivalent in terms of effort and 
cost; so the number of progeny per tested sire will be 170 when breeding programs are combined (see Table 6.4).

When breeding programs are combined, one option is to progeny test all sires in one population only instead of two, as it offers the advantage to simplify organization. One strategy is to progeny test all sires by producing purebred offspring only. The other strategy is to progeny test all sires by producing crossbred offspring only. In this paragraph, I will compare the initial situation where breeding programs are separate to the situation where breeding programs are combined and all sires are progeny tested either based on purebred or on crossbred offspring. To compare genetic gain for each situation, selection for birth weight was considered and genetic parameters estimated in 6.3.1.3 were used.

When breeding programs are combined and progeny testing is on purebred only and the interest is in improving purebreds, the number of progeny per sire decreases from 200 to 170, as compared to separate breeding programs (see Table $6.4)$. The change in genetic gain due to a change in accuracy $(R)$ is assessed by:

$$
R=\sqrt{\left.\frac{\left\{\frac{1 / 2}{2} n_{\text {comb }} h_{B W_{-} P B}^{2}\right.}{1+\frac{1}{4} h_{B W_{-} P B}^{2}\left(n_{\text {comb }}-1\right)}\right\}}
$$

(Rutten et al., 2010)

where $n_{\text {sep }}$ and $n_{\text {comb }}$ are the number of purebred progeny per tested sire when breeding programs are separate (200) and when breeding programs are combined (170), and $h_{B W_{-} P B}^{2}$ is the heritability of birth weight measured on purebred progeny (0.34).

$R$ is equal to 1.00 , so the decrease in genetic gain due to a decrease in the number of purebred progeny per tested sire is negligible (less than 1\%) when breeding programs are combined, than when they are separate.

When the interest is now on improving crossbreds, the genetic gain when breeding programs are combined and progeny testing is on purebred only is compared to the situation when breeding programs are separate and progeny testing is on crossbreds. $R$ is now equal to: 


$$
R=\sqrt{\frac{\left\{\frac{1 / 2 n_{c o m b} r_{a}^{2} h_{B W \_P B}^{2}}{1+\frac{1}{4} h_{B W_{-} P B}^{2}\left(n_{c o m b}-1\right)}\right\}}{\left\{\frac{1 / 2 n_{\text {sep }} h_{B W_{-} C B}^{2}}{1+\frac{1}{4} h_{B W_{-} C B}^{2}\left(n_{\text {sep }}-1\right)}\right\}}}
$$

(Rutten et al., 2010)

where $n_{\text {sep }}$ is the number of crossbred progeny per tested sire when breeding programs are separate (110) and $n_{\text {comb }}$ is the number of purebred progeny per tested sire when breeding programs are combined (170), $h_{B W_{-} C B}^{2}$ is the heritability of birth weight on crossbred (0.24), and $r_{a}$ is the genetic correlation between birth weight measured on purebred progeny and birth weight on crossbreds (0.95).

Heritability for birth weight in purebred (0.34) is higher than in crossbred (0.24), which favors birth weights collected on purebreds as compared to crossbreds. $R$ is equal to 0.99 , so the change in genetic gain due to a change in accuracy is negligible (1\%) for crossbred when breeding programs are combined, than when they are separate.

When breeding programs are combined and progeny testing is now on crossbred only and the interest is in improving crossbreds, the number of crossbred progeny per sire increases from 110 to 170 , as compared to separate breeding programs. Applying the formula from Rutten et al. (2010), $R$ is equal to 1.02. Thus, the increase in genetic gain due to an increase in the number of crossbred progeny per tested sire is small (2\%) when breeding programs are combined, than when they are separate.

When the interest is now in improving purebreds, the genetic gain when breeding programs are combined and progeny testing is on crossbred only is compared to the situation when breeding programs are separate and progeny testing is on purebreds. Applying the formula from Rutten et al. (2010), $R$ is equal to 0.94. Thus, the genetic gain is slightly lower $(6 \%)$ when breeding programs are combined, than when they are separate.

In conclusion, the genetic gain for birth weight hardly changes due to a change in accuracy when breeding programs are combined and progeny testing is on purebreds, as compared to separate breeding programs. 


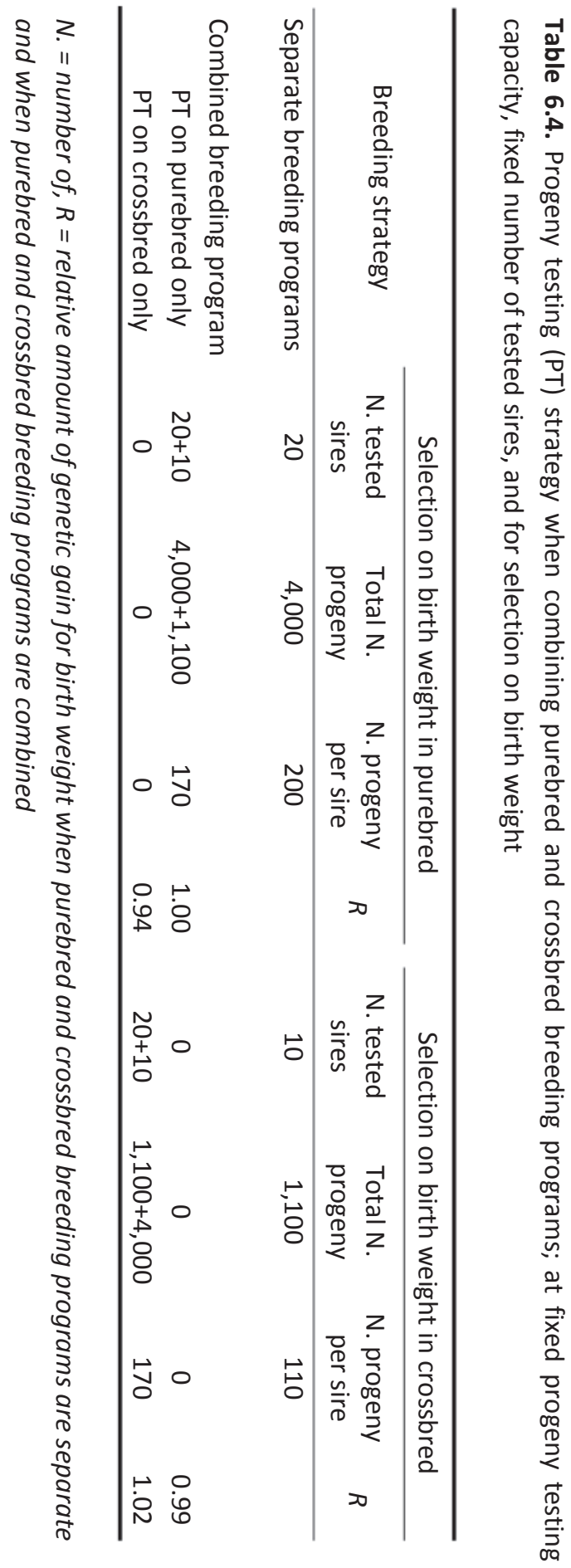


When selection is on other traits than birth weight, combining breeding programs might reduce the genetic gain, because of the reduction of the number of progeny per tested sire, as compared to separate breeding programs. Consider selection for fertility in purebreds which has a heritability of 0.02 (Phocas and Sapa, 2004). During progeny testing, only part of the progeny is recorded for fertility. When breeding programs are separate, 20 sires are progeny tested based on 50 purebreds. At fixed progeny testing capacity and fixed number of tested sires, when breeding programs are combined and progeny testing is on purebred only, 30 sires will be progeny tested based on 33 purebred offspring. Due to the reduction of the number of progeny per tested sires, $R$ is now 0.84 so the genetic gain for fertility is reduced by $16 \%$.

Some traits collected in one population (i.e. purebred or crossbred) are not collected in the other population. For instance, conformation traits at three weeks of age are collected and included in the breeding goal for crossbred but not for purebred. Conformation at weaning is highly correlated with conformation at other ages (Cardoso et al., 2004; Filho et al., 2010). Therefore, it is expected that conformation at weaning collected on purebreds could be used to accurately predict conformation at three weeks of age in crossbreds.

Growth and conformation at weaning, carcass traits, reproductive performance, and maternal ability are collected and included in the breeding goal for purebred but not for crossbred. Studies reported low genetic correlations between birth weight and carcass weight (Lopes et al, 2016), and between birth weight and fertility (Banerjee, 2002). Thus, traits collected on crossbred, such as birth weight might not be informative enough to accurately predict the traits on purebreds.

In conclusion, accuracy of progeny testing when breeding programs are combined is expected to have a small impact on genetic gain, as compared to progeny testing when breeding programs are separate. When breeding programs are combined, progeny testing on purebred is preferred because higher genetic gain is expected, as compared to progeny testing on crossbred. Moreover, progeny testing on crossbred would involve mating all Charolais sires to dairy cows. However, for some Charolais sires, severe risk of calving difficulty might exist when mated to dairy cows so progeny testing on crossbred might not be accepted by dairy farmers. 


\subsubsection{Implementation of genomic evaluation}

Recently, genomic evaluation (GEBV) became available in beef cattle. The implementation of genomic evaluation in the purebred and the crossbred breeding program could affect the choice to keep breeding programs separate or to combine them.

Some traits are collected in the purebred and the crossbred purebred breeding program. This is the case for birth weight. One can decide to have separate reference population for the evaluation of the trait collected on purebred and for the trait collected on crossbred. Alternatively, data collected on purebreds and on crossbreds could be combined to have one unique reference population. This approach allows enlarging the size of the reference population and might increase accuracy of prediction. Results from chapter $\mathbf{5}$ showed that accuracy of prediction when combining reference populations depends on the genetic correlation between traits in both reference populations. Genetic correlation between birth weight collected on purebred and on crossbred is high $(0.95$, estimated in paragraph 6.3.1.3) so there is benefit to have one reference population for purebred and crossbred. Consequently, young bulls from the purebred and the crossbred breeding program would be evaluated using one unique ranking.

Some traits are collected in one breeding program only. This is the case for carcass traits, reproductive performance, or maternal ability traits that are collected on purebred only. Studies reported than one reference population could be used to predict genetic performance in the other population without loss of accuracy; if populations are genetically close (Habier et al., 2007; Habier et al., 2010; Pryce et al., 2011, Weber et al. 2012, and Chen et al., 2013). Animals from the purebred and the crossbred breeding program are genetically related (see paragraph 6.2.3). Thus, genomic evaluation could be performed across breeding programs. Consequently, young bulls from both breeding program could have GEBV for all traits collected in the purebred and in the crossbred purebred breeding program.

In conclusion, if the reference populations for purebred and for crossbred are combined or if genomic evaluation is implemented across breeding programs, young bulls from the purebred and the crossbred breeding program could benefit from the same reference population. This offers the possibility to select young bulls from one breeding program which suit the requirement for the other breeding program and therefore to combine the purebred and the crossbred breeding program. 


\subsection{Recommendations}

In 6.3, I have discussed how several parameters for the purebred and crossbred breeding program individually affect the genetic gain and therefore the decision for combining the breeding programs or keeping them separate. These parameters are:

- the correlation between the breeding objective for the purebred and the crossbred breeding program. Breeding objectives are defined by a combination of traits. Birth weight is included in both breeding objectives and the genetic correlation between birth weight in purebred and in crossbred is high. Therefore, the correlation between breeding objectives is likely to be high and higher genetic gain is expected when combining breeding programs than when breeding programs are separate.

- the selection intensity. When breeding programs are combined, the selection intensity for the crossbred breeding program dramatically increases so higher genetic progress for the crossbred breeding program is expected, as compared to separate breeding programs. The selection intensity for the purebred breeding program only slightly changes.

- $\quad$ the difference in genetic mean between the purebred and the crossbred breeding program. The difference in genetic mean for birth weight is small between the two breeding programs so animals from both breeding programs can contribute to the genetic improvement of birth weight.

- $\quad$ the progeny testing strategy and the subsequent accuracy of selection. When breeding programs are combined and progeny testing is on purebreds, the change in accuracy for birth weight is expected to have a small impact on genetic gain, as compared to progeny testing when breeding programs are separate.

- the implementation of genomic evaluation. It might be possible to combine reference populations for purebred and for crossbred or to implement genomic evaluation across breeding programs.

These parameters are not independent; if one parameter changes, another one might also be affected. Therefore, to decide upon combining the breeding 
programs or keeping them separate, these parameters have to be considered together.

The genetic correlation at the single trait level between purebred and crossbred partly determines the correlation between breeding objectives. The genetic correlation at the single trait level between purebred and crossbred also determines the progeny testing accuracy when breeding programs are combined. When genetic correlation for birth weight between purebred and crossbred is 0.95 , the maximum decrease in genetic gain when breeding programs are combined is $6 \%$, as compared to separate breeding programs. Assuming a genetic correlation of 0.7 , the maximum decrease in genetic gain will be $31 \%$, as compared to separate breeding programs.

The genetic correlation at the single trait level between purebred and crossbred also determines the possibility to combine data into one reference population, which will increase the size of the reference population and the accuracy of genomic evaluation (see paragraph 6.3.5).

The difference in genetic mean between the purebred and the crossbred breeding program determines the possibility to selected sires suitable for both breeding programs. If some sires suit both breeding programs, the number of progeny tested sires might be decreased. As the progeny testing capacity might be distributed over a smaller number of sires, the number of progeny per tested sire might increase, so the accuracy of selection. Having less tested sires when combining breeding programs will also reduce cost associated with housing and semen production of sires.

Given the genetic links between both breeding programs where females from the purebred breeding program are used as bull dams in the crossbred breeding program, the genetic correlation at the single trait level between purebred and crossbred and the correlation between breeding objectives is likely to be high. Moreover, the difference in genetic mean between the purebred and the crossbred breeding program is likely to be small. High genetic correlation and low difference in genetic mean were confirmed for birth weight.

Considering all parameters affecting the choice for combining breeding programs, and assuming selection for birth weight reflects the selection for purebred and crossbred performance; the general discussion shows that higher genetic gain is expected when combining the purebred and the crossbred breeding programs, than when keeping them separate. Moreover, combining the breeding programs might simplify operating organization and reduce associated costs. Therefore I recommend combining the purebred and the crossbred breeding program. 


\subsection{Reference}

Allais, S., H. Levéziel, N. Payet-Duprat, J.-F. Hocquette, J. Lepetit, S. Rousset, C. Denoyelle, C. Bernard-Capel, L. Journaux, A. Bonnot, and G. Renand. 2010. The two mutations Q204X and nt821 of the myostatin gene affect carcass and meat quality in heterozygous young bulls of French beef breeds. J. Anim. Sci. 88:446-454.

Arthur, P. F., H. Hearshaw, and P. D. Stephenson. 1999. Direct and maternal additive and heterosis effect from crossing Bos indicus and Bos taurus cattle: Cow and calf performance in two environments. Livest. Prod. Sci. 57:231-241.

Banerjee, S. 2002. Correlation between body weights at different ages and some production and reproduction traits in HFxS crossbred cattle. Indian Vet. J. 79:1040 - 1043.

Banos, G., and C. Smith. 1991. Selecting bulls across countries to maximize genetic improvement in dairy cattle. J. Anim. Breed. Genet. 108:174-181.

Baumung, R., J. Sölkner, and A. Essl. 1997. Correlation between purebred and crossbred performance under a two-locus model with additive by additive interaction. J. Anim. Breed. Genet. 114:89-98.

Bolormaa, S., J. E. Pryce, Y. Zhang, A. Reverter, W. Barendse, B. J. Hayes, and M. E. Goddard. 2015. Non-additive genetic variation in growth, carcass and fertility traits of beef cattle. Genet. Sel. Evol. 47:26.

Bouquet, A. 2009. Amélioration de l'efficacité des programmes de sélection des bovins allaitants: de nouveaux modèles d'évaluation génétique. PhD thesis.

Bouyssiere, S., M. Carlier, and B. Lelyon. 2013. Le croisement viande en élevage laitier: état des lieux des pratiques et perspectives. Proc. Renc. Rech. Ruminants. 20:225-228.

Cardoso, F. F., R. A. Cardellino, and L. T. Campos. 2004. (Co)variance components and genetic parameters of post-weaning traits in Angus cattle. R. Bras. Zootec. 33:313-319.

Chen, L., F. Schenkel, M. Vinsky, D. H. Crews Jr., and C. Li. 2013. Accuracy of predicting genomic breeding values for residual feed intake in Angus and Charolais beef cattle. J. Anim. Sci. 91:4669-4678. 
Cowley, D. E., D. Pomp, W. R. Atchley, E. J. Eisen, and D. Hawkins-Brown. 1989. The impact of maternal uterine genotype on postnatal growth and adult body size in mice. Genetics. 122:193-203.

Dekkers, J. C. M., and R. Chakraborty. 2004. Optimizing purebred selection for crossbred performance using QTL. Genet. Sel. Evol. 36:297-324.

Eriksson, S., A. Näsholm, K. Johansson, and J. Philipsson. 2004. Genetic parameters for calving difficulty, stillbirth, and birth weight for Hereford and Charolais at first and later parities. J. Anim. Sci. 82:375-383.

Espasandin, A. C., J. I. Urioste, H. Naya, and M. M. Alencar. 2013. Genotype x production environment interaction for weaning weight in Angus populations of Brazil and Uruguay. Livest. Prod. Sci. 151:264-270.

Falconer, D. S., 1952. The problem of environment and selection. Am. Nat. 86: 293298.

Filho, W. K., L. G. de Albuquerque, S. Forni, J. A. de Vasconcelos Silva, M. J. Yokoo, and M. M. de Alencar. 2010. Genetic parameters estimates for visual scores and their association with body weight in beef cattle. R. Bras. Zootec. 39:1015-1022.

Foulley, J.-L., and J. Sapa. 1982. The French evaluation programme for natural service beef bulls using Al sire progeny as herd ties. Digest. 37:64-68.

Gallo, L., M. De Marchi, and G. Bittante 2014. A survey on feedlot performance of purebred and crossbred European young bulls and heifers managed under intensive conditions in Veneto, northeast Italy. Ital. J. Anim. Sci. 13:798-807.

Gilmour, A. R., B. J. Gogel, B. R. Cullis, and R. Thomson. 2009. ASREML Software Release 3.

Goddard, M. E., and C. Smith. 1990. Optimum number of bull sires in dairy cattle breeding. J. Dairy Sci. 73:1113-1122.

Habier, D., R. L. Fernando, and J. C. M. Dekkers. 2007. The impact of genetic relationship information on genome-assisted breeding values. Genetics 177:2389-2397.

Habier, D., J. Tetens, F. R. Seefried, P. Lichtner, and G. Thaller. 2010. The impact of genetic relationship information on genomic breeding values in German Holstein cattle. Genet. Sel. Evol. 42: 5. 
Lohuis, M. M., and J. C. M. Dekkers. 1998. Merits of borderless evaluations. Proc. 6th World Congr. Genet. Appl. Livest. Prod., Armidale, Australia. 26:169172.

Lopes, J. S., P. R. N. Rorato, T. Weber, A. A. Boligon, J. G. Comin, and M. A. Dornelles. 2008. Genotype and environment interaction effect on weights at birth, 205 and 550 day of age of Nellore cattle in the South Region of Brazil. R. Bras. Zootec. 37:54-60.

Lopes, F. B., M. C. da Silva, C. U. Magnabosco, M. G. Narciso, R. and D. Sainz. 2016. Selection indices and multivariate analysis show similar results in the evaluation of growth and carcass traits in beef cattle. PLoS One 11: e0147180.

Misztal, I., R. L. Fernando, M. Grossman, T. J. Lawlor, and M. Łukaszewicz. 1996. Dominance and epistatic effects in genetic evaluation. Anim. Sci. Papers Rep. 13:251.

Misztal, I., and T. J. Lawlor. 1996. Estimation of variance components and genetic evaluation with large-scale dominance models. Proc. Europ. Ass. Anim. Prod., Lillehammer, Norway.

Misztal, I. 1997. Estimation of variance components with large-scale dominance models. J. Dairy Sci. 80:965-974.

Morris, C. A., R. L. Baker, S. M. Hickey, D. L. Johnson, N. G. Cullen, and J. A. Wilson. 1993. Evidence of genotype by environment interaction for reproductive and maternal traits in beef cattle. Anim. Sci. 56:69-83.

Mulder, H. A., and P. Bijma. 2006. Benefits of cooperation between breeding programs in the presence of genotype by environment interaction. J. Dairy Sci. 89:1727-1739.

Mulder, H. A., R. F. Veerkamp, B. J. Ducro, J. A. M. van Arendonk, and P. Bijma. 2006. Optimization of dairy cattle breeding programs for different environments with genotype by environment interaction. J. Dairy Sci. 89:1740-1752.

Neser, F. W. C. 2002. A preliminary investigation into the use of cluster analyses in genotype $x$ environment interaction studies in beef cattle. Proc. 7th World Congr. Genet. Appl. Livest. Prod., Montpellier, France. 32:391393. 
Neser, F. W. C., G. J. Erasmus, and M. M. Scholtz. 2008. The use of a cluster analysis in across herd genetic evaluation for beef cattle. S. Afr. J. Anim. Sci. 38:51-57.

Palucci, V, L. R. Schaeffer, F. Miglior, and V. Osborne. 2007. Non-additive genetic effects for fertility traits in Canadian Holstein cattle. Genet. Sel. Evol. 39:181-93.

Phocas, F., and D. Laloe. 2003. Evaluation models and genetic parameters for calving difficulty in beef cattle. J. Anim. Sci. 81:933-938.

Phocas, F., and J. Sapa. 2004. Genetic parameters for growth, reproductive performance, calving ease and suckling performance in beef cattle heifers. Anim. Sci. 79:41-48.

Pryce, J. E., B. Gredler, S. Bolormaa, P. J. Bowman, C. Egger-Danner, C. Fuerst, R. Emmerling, J. Sölkner, M. E. Goddard, and B. J. Hayes. 2011 Short communication: Genomic selection using a multi-breed, across-country reference population. J. Dairy Sci. 94:2625-2630.

Rhees, B. K., C. A. Ernst, C. H. Miao, and W. R. Atchley. 1999. Uterine and postnatal maternal effects in mice selected for differential rate of early development. Genetics. 153:905-917.

Roso, V. M., F. S. Schenkel, S. P. Miller, and J. W. Wilton. 2005. Additive, dominance, and epistatic loss effects on preweaning weight gain of crossbred beef cattle from different Bos taurus breeds. J. Anim. Sci. 83:1780-1787.

Rutten, M. J. M., H. Bovenhuis, and J. A. M. van Arendonk. 2010. The effect of the number of observations used for Fourier transform infrared model calibration for bovine milk fat composition on the estimated genetic parameters of the predicted data. J Dairy Sci. 93:4872-4882.

Sarzeaud, P., F. Bécherel, and C. Perrot. 2007. Adaptations des systèmes bovins viande européens à la réforme de la PAC. Première analyse de la Beef Task Force. Proc. Renc. Rech. Ruminants. 14:445-448.

Smith, C. 1981. Levels of investment in testing and genetic improvement of livestock. Livest. Prod. Sci. 8:193-201.

Smith, C., and G. Banos. 1991. Selection within and across populations in livestock improvement. J. Anim. Sci. 69:2387-2394. 
Su, G., O. F. Christensen, T. Ostersen, M. Henryon, and M. S. Lund. 2012. Estimating additive and non-additive genetic variances and predicting genetic merits using genome-wide dense single nucleotide polymorphism markers. PLoS One. 7:e45293.

van Tassell, C. P., I. Misztal, and L. Varona. 2000. Method R estimates of additive genetic, dominance genetic, and permanent environmental fraction of variance for yield and health traits of Holsteins. J Dairy Sci. 83:18731877.

Vargas, B., and J. A. M. van Arendonk. 2004. Genetic comparison of breeding schemes based on semen importation and local breeding schemes: Framework and application to Costa Rica. J. Dairy Sci. 87:1496-1505.

Weber, K. L., R. M. Thallman, J. W. Keele, W. M. Snelling, G. L. Bennett, T. P. L. Smith, T. G. McDaneld, M. F. Allan, A. L. Van Eenennaam, and L. A. Kuehn. 2012. Accuracy of genomic breeding values in multibreed beef cattle populations derived from deregressed breeding values and phenotypes. J. Anim. Sci. 90:4177-4190.

Wei, M., H. A. M. van der Steen, J. H. J van der Werf, and E. W. Brascamp. 1991. Relationship between purebred and crossbred parameters. I. Variances and covariances under the one-locus model. J. Anim. Breed. Genet. 108:253-261. 
Summary 

Beef and dairy farmers can mate their cows to beef sires to produce calves for beef production. Thus, two broad categories of mating for beef production exist; (i) beef sires mated to beef dams to produce purebred animals and (ii) beef sires mated to dairy dams to produce crossbred animals as terminal cross for meat production. Currently, two distinct Charolais breeding programs exist. In one breeding program, so-called "purebred breeding program", purebred Charolais sires are selected for purebred performance. In the other breeding program, so-called "crossbred breeding program", purebred Charolais sires are selected for crossbred performance.

The purebred breeding program is mainly focused on improving production and reproduction traits. Nowadays, there is a growing interest to include behavior and type traits in the breeding goal. There is an interest in behavior as it is associated with human safety and workability, and in type traits as they might be associated with longevity of cows.

The objective of chapter $\mathbf{2}$ was to estimate the heritability for behavior and type traits in Charolais, and to estimate the genetic correlations among these traits. Behavior traits, including aggressiveness at parturition, aggressiveness during gestation period, and maternal care, were scored by farmers using a simple subjective recording system to enable large scale collection of phenotypes. Type traits, including udder traits $(n=3)$, teat traits (3), feet and leg traits (5), and locomotion (1), were scored by ten trained classifiers. Data was available on 6,649 cows. Aggressiveness at parturition has higher heritability (0.19) than aggressiveness during gestation (0.06) and maternal care (0.02). Heritabilities for udder traits $(0.14$ to 0.20$)$ and teat traits $(0.17$ to 0.35$)$ are higher than for feet and leg traits (0.02 to 0.19). Strong genetic correlations between behavior traits (with absolute values from 0.71 to 0.98 ) indicate that it is difficulty to simultaneously improve maternal care and reduce aggressiveness. To conclude, there are good opportunities to implement selection for improved udder and teat traits and against aggressiveness at parturition using a simple on-farm recording system of behavior.

Information on genes involved in behavior and type traits might provide valuable insight in the genetic background of these traits and might be used in genomic selection. In chapter $\mathbf{3}$ a genome-wide association study (GWAS) was performed for the three behavior traits and the twelve type traits in Charolais cattle. Data used in the GWAS consisted of 3,274 cows with phenotypic records and genotyping information. When SNP had a false discovery rate (FDR) smaller than 0.05 , they were referred as significant. When SNP had a FDR between 0.05 and 0.20 , they 
were referred as suggestive. Four significant and 12 suggestive regions were detected for aggressiveness during gestation, maternal care, udder balance, teat thinness, teat length, foot angle, foot depth, and locomotion. These 4 significant and 12 suggestive regions were not supported by other significant SNP in close proximity. No SNP with major effects was detected for behavior and type traits and SNP associations for these traits were spread across the genome suggesting that behavior and type traits are influenced by many genes each explaining a small part of genetic variance.

The crossbred breeding program is focused on improving the performance of the crossbred calves for direct calving ease and meat production. In France, the two main dairy breeds mated to Charolais sires are Montbéliard and Holstein. The same trait measured on Montbéliard $x$ Charolais and on Holstein x Charolais crossbred calves is not necessarily genetically identical. Thus, the estimated breeding value of Charolais sires might differ depending on the dam breed they are mated to.

In chapter 4 , heritability and genetic correlation between traits within Montbéliard $x$ Charolais and within Holstein x Charolais population were estimated. Genetic correlations between traits in the two populations were calculated. Traits studied were calving difficulty, birth weight, height, bone thinness, and muscular development. Data included 22,852 Montbéliard x Charolais and 16,012 Holstein x Charolais crossbred calves. Heritabilities estimated separately within each crossbred population are similar. Stronger genetic correlations are observed in Holstein $x$ Charolais population compared with Montbéliard $x$ Charolais between calving difficulty and height $(0.67$ vs. 0.54$)$, calving difficulty and bone thinness (0.42 vs. 0.27 ), birth weight and bone thinness ( 0.52 vs. 0.20 ), and between birth weight and muscular development (0.41 vs. 0.18). Birth weight and muscular development are genetically identical traits between crossbred populations, with genetic correlations of 0.96 and 0.99 . Genetic correlations are 0.91 for calving difficulty, 0.80 for height, and 0.70 for bone thinness, and they are significantly different from 1 ( $p \leq 0.01$ ). Results show evidence for re-ranking of Charolais sires for calving difficulty, height, and bone thinness depending on whether they are mated to Montbéliard or Holstein cows.

Selection of Charolais bulls for crossbred performance could benefit from genomic selection. To implement genomic selection, one could build a reference population with the Montbéliard $x$ Charolais calves and a reference population with the Holstein $x$ Charolais calves independently. An alternative could be to combine both crossbred populations into a single reference population to increase size and accuracy of prediction. The objective of chapter $\mathbf{5}$ was to investigate the accuracy 
of genomic prediction by combining different crossbred populations. Three scenarios were considered: (1) using one crossbred population as reference to predict phenotype of animals from the same crossbred population, (2) combining the two crossbred populations into one reference to predict phenotype of animals from one crossbred population, and (3) using one crossbred population as reference to predict phenotype of animals from the other crossbred population. To allow fair comparison between scenarios, size of the reference population was kept constant for all scenarios. Traits studied were bone thinness, height and muscular development. Accuracies tend to be highest when prediction is within one crossbred population, intermediate when populations are combined into the reference population, and lowest when prediction is across populations. Decrease in accuracy from a prediction within one population to a prediction across populations is more pronounced for bone thinness $(-27 \%)$ and height $(-29 \%)$ than for muscular development (-14\%). Genetic correlation between the two crossbred populations estimated in chapter 4 using pedigree relationships is 0.70 for bone thinness, 0.80 for height and 0.99 for muscular development. Genetic correlation indicates the expected gain in accuracy of prediction when combining different populations into one reference population. The larger the genetic correlation is, the larger the benefit is to combine populations for genomic prediction.

The selection of Charolais sires to produce purebred or crossbred animals is made through distinct breeding programs. The same breeding organization might run one breeding program for purebred performances and one for crossbred performances. Combining selection for purebred and crossbred in one breeding program will simplify the organization of selection but might affect genetic gain. The genetic gain is affected by or keeping them separate is affected by several parameters that were discussed in chapter 6 .

One important parameter is the correlation between the breeding objective for the purebred and the crossbred breeding program. When the correlation between the breeding objectives is high, higher genetic gain can be obtained by combining breeding programs, as compared to separate breeding programs. Breeding objectives are defined by a combination of traits. Birth weight is included in the breeding objective for the purebred and the crossbred breeding program. The genetic correlation between birth weight in purebred and in crossbred is high (0.95). Therefore, the correlation between breeding objectives is likely to be high.

Other parameters such as selection intensity, difference in level of genetic merit, accuracy of selection, and the recent implementation of genomic evaluation also affect the relative performance of combined and separate breeding programs. 
When breeding programs are combined, the selection intensity for the crossbred breeding program dramatically increases (from 1.55 to 2.95 ) so higher genetic progress is expected, as compared to separate breeding programs. The difference in genetic mean for birth weight is relatively small between the two breeding programs so both breeding programs can contribute to the genetic improvement of birth weight when breeding programs are combined. When breeding programs are combined and progeny testing is on purebreds, the change in accuracy is expected to have a small impact on genetic gain, as compared to progeny testing when breeding programs are separate. When genomic evaluation is implemented and it is possible to combine the reference populations for purebred and for crossbred or to predict across populations, it allows combining breeding programs.

These parameters are not independent; if one parameter changes, another one might also be affected. The genetic correlation at the single trait level between purebred and crossbred partly determines the correlation between breeding objectives, but also the progeny testing accuracy when breeding programs are combined and the possibility to combine reference populations. Given the genetic links between both breeding programs, the genetic correlation at the single trait level and the correlation between breeding objectives for purebred and crossbred are likely to be high. Furthermore, the difference in genetic mean between purebred and the crossbred is likely to be small. High genetic correlation and low difference in genetic mean were confirmed with the estimations for birth weight.

Considering all parameters affecting the choice for combining breeding programs together, and assuming selection for birth weight reflects the selection for purebred and crossbred performance; higher genetic gain is expected when combining the purebred and the crossbred breeding programs, than when keeping them separate. Moreover, combining the breeding programs might simplify operating organization and reduce associated costs. Therefore I recommend combining the purebred and the crossbred breeding program. 
Curriculum vitae 



\section{About the author}

Amélie Vallée-Dassonneville was born on the $16^{\text {th }}$ of December 1983 in Reims France, and grew up in the Ardennes region. From 2001 to 2005, she completed a master's level study in agriculture science at ISA Group in Lille - France. In 2005, she started a double-degree MSc program in Animal Breeding and Genomics at Wageningen University. In 2007, she graduated both from ISA Group and Wageningen University. During her studies, she did a three-months internship at the dairy farm EARL Leborgne in Clais - France, a six-months internship at the corn seed breeding company AgReliant Genetics in Ames - USA, a four-months internship at the pig breeding company PenArLan in Maxent - France, and a fourmonths internship at the INRA research center in Petit-Bourg, Guadeloupe - French West Indies. She did her MSc thesis on molecular genetic in poultry at the Animal Breeding and Genomics Center of Wageningen University. Her MSc thesis contributed to confirm the role of the partial duplication of two genes in the late feathering phenotype in chicken. In 2007, she started working as an engineer at the cattle breeding company Gènes Diffusion, Douai - France. Since then, she has been involved in the implementation of genomic information into the Holstein and Charolais breeding programs. In 2011, she initiated the scientific collaboration between Gènes Diffusion and the Animal Breeding and Genomics Center of Wageningen University, and took the opportunity to start a PhD project in combination to her current work. The results of her PhD project are presented in this thesis. Amélie is married and has one son.

\section{Peer reviewed publications}

Vallée, A., J. Daures, J. A. M. van Arendonk, and H. Bovenhuis. 2016. Genome-wide association study for behavior, type traits, and muscular development in Charolais beef cattle. J. Anim. Sci. 94:1-10.

Vallée, A., I. Breider, J. A. M. van Arendonk, and H. Bovenhuis. 2015. Genetic parameters for large-scale behavior traits and type traits in Charolais beef cows. J. Anim. Sci. 93:4277-4284.

Vallée, A., J. A. M. van Arendonk, and H. Bovenhuis. 2014. Accuracy of genomic prediction when combining two related crossbred populations. J. Anim. Sci. 92:4342-4348. 
Vallée, A., J. A. M. van Arendonk, and H. Bovenhuis. 2013. Genetic parameters for calving and conformation traits in Charolais $\times$ Montbéliard and Charolais $\times$ Holstein crossbred calves. J. Anim. Sci. 91:5582-5588.

van der Spek, D., J. A. M. van Arendonk, A. A. A. Vallée, and H. Bovenhuis. 2013. Genetic parameters for claw disorders and the effect of preselecting cows for trimming. J. Dairy Sci. 96:6070-6078.

Elferink, M. G., A. A. A. Vallée, A. P. Jungerius, R. P. M. A. Crooijmans, and M. A. M. Groenen. 2008. Partial duplication of the PRLR and SPEF2 genes at the late feathering locus in chicken. BMC Genomics, 9:391-400.

\section{Submitted manuscript}

Vallée, A., I. Breider, J. A. M. van Arendonk, and H. Bovenhuis. 2016. Amélioration génétique du comportement des vaches Charolaises. Submitted to the review Viandes \& Produits Carnés.

\section{Conference proceedings}

Vallée, A., J. A. M. van Arendonk, and H. Bovenhuis. 2015. Genetic parameters for large scale behavior traits in Charolais beef cows. $66^{\text {th }}$ annual meeting of the European Association for Animal Production. Warsaw, Poland.

Vallée, A., J. A. M. van Arendonk, and H. Bovenhuis. 2014. Accuracy of genomic prediction when combining two related crossbred populations. $10^{\text {th }}$ World Congress on Genetics Applied to Livestock Production. Vancouver, Canada.

Vallée, A., J. A. M. van Arendonk, and H. Bovenhuis. 2013. Genetic parameters for calving and conformation traits in Charolais $\times$ Montbéliard and Charolais $\times$ Holstein crossbred calves. $64^{\text {th }}$ annual meeting of the European Association for Animal Production. Nantes, France.

van der Spek, D., J. A. M. Van Arendonk, A. A. A. Vallée, and H. Bovenhuis. 2013. Claw disorder genetics and the effect of preselecting cows for trimming. $9^{\text {th }}$ International Conference on Lameness in Ruminants. Bristol, United Kingdom.

van der Spek, D., J. A. M. van Arendonk, A. A. A. Vallée, and H. Bovenhuis. 2012. Genetic parameters of hoof lesions in French Holstein dairy cattle. $63^{\text {rd }}$ annual meeting of the European Association for Animal Production. Bratislava, Slovakia. 


\section{Training and supervision plan (TSP)}

The basic package

3 ECTS

Ethics and philosophy in life sciences

2013

WIAS introduction course

2012

Scientific exposure

13 ECTS

International conferences

$66^{\text {th }}$ EAAP, Warsaw, Poland

2015

$10^{\text {th }}$ WCGALP, Vancouver, Canada

2014

$64^{\text {th }}$ EAAP, Nantes, France

2013

$9^{\text {th }}$ WCGALP, Liepzig, Germany

2010

$41^{\text {st }}$ BIF, Sacramento, USA

2009

Seminars and workshops

WIAS science day, Wageningen, the Netherlands

2014

Seminar on genomics and animal breeding, Wageningen, the Netherlands

2011

Interbull workshop, Paris, France

2010

Seminar on genomic selection, Paris, France

2010

Seminar on epigenetic, Paris, France

2010

Presentations

$66^{\text {th }}$ EAAP, Warsaw, Poland (oral)

2015

$10^{\text {th }}$ WCGALP, Vancouver, Canada (poster)

2014

WIAS science day, Wageningen, the Netherlands (oral)

2014

$64^{\text {th }}$ EAAP, Nantes, France (oral)

In-depth studies

6.7 ECTS

Introduction to theory and implementation of genomic selection, Wageningen, the Netherlands

Advanced statistical and genetic analysis of complex data using ASReml4, Wageningen, the Netherlands 2014

Social genetic effects: theory and genetic analysis, Wageningen, the Netherlands

Advanced methods and algorithms in animal breeding with focus on genomic selection, Wageningen, the Netherlands

Computer algorithms in animal breeding with special focus on genomic selection, Padova, Italy

Genetic variability, Paris, France 
Professional skills support courses

3.1 ECTS

Mobilizing your scientific network

2016

Voice matters - Voice and presentation skills training

2014

Project management and methods to write a proposal

2014

Stress identification and management

2014

Techniques for writing and presenting a scientific paper

2012

Research skills training

4.9 ECTS

Introduction to $\mathrm{R}$ for statistical analyses

2012

Getting started in ASReml

2011

Preparing own PhD research proposal

2011

Didactic skills training

11 ECTS

Supervising theses

MSc thesis, Ecole d'Ingénieur, Purpan, France

2015

MSc thesis, WUR, Wageningen, The Netherlands

2014

MSc thesis, WUR, Wageningen, The Netherlands

2013

MSc thesis, Institut Supérieur d'Agriculture, Lille, France

MSc thesis, AgroParisTech, Paris, France

2012

MSc thesis, PolyTech, Lille, France

2011 
Acknowledgements 

Doing a PhD is like trekking. Although the trekker is the only one capable to put his foot in front of the other to move forward, he needs help of many persons to reach the summit. Here I would like to express my gratitude to those who have contributed to successfully complete my trek.

When I asked Johan van Arendonk for a meeting to present him my company Gènes Diffusion, our objective to run our own research, and our need for scientific support; he turned out to be an excellent tour-operator. He quickly and perfectly understood our expectations and indicated the best path to a fruitful collaboration between Gènes Diffusion and Wageningen University. Johan, thank you for giving me the golden opportunity to do a PhD at the ABGC group. I appreciated your "cool head" and "talk less, say more" attitude, and your efforts in making a win-win project.

This collaboration would have been impossible without the input of Claude Grenier. Claude, thank you for immediately understanding the interest of this collaboration and my willingness to do a PhD. Thank you for putting Gènes Diffusion's crampons on and making sure they stay well attached. I am grateful to you for your support, your constant trust and your loyalty that made me believe I add so little to lose but far more to prove. Our talks during the long drives to Wageningen were a real breath of fresh air.

I would like to deeply thank Henk Bovenhuis for being an outstanding guide during my trek. Thank you Henk for your valuable supervision made of insightful suggestions, motivating discussions and room for self-initiative. Alike an experienced Sherpa, you adapted your rhythm to mine; thank you for your patience and for never putting me under pressure. I appreciated your attentiveness on the issues and concerns of Gènes Diffusion.

From the rope of Gènes Diffusion, I would like to thank the director François Desmons and the head manager of the Charolais division Michel Fouchet for making this research project possible. I would like to strongly thank the managers of the Charolais breeding programs Sébastien Landemaine and Vincent Colas. Sébastien and Vincent, thank you for sharing with me your knowledge on Charolais breeding and your practical vision. I sincerely appreciated working with you. Special thanks to Vincent for your rigor, your humor, and your friendship. Also thanks to all Charolais technicians for your attendance in providing me information. I am grateful to my colleagues from the Holstein breeding program for your support. Thank you to Sylvie Patey and Frédéric Lepoint for sharing with me your rational and down-to-earth vision and for showing me that breeding is far more than 
statistics and numbers. Thanks for understanding what this trek represented to me. I would like to especially thank Dany Fauqueux and Solène Rault. Dany and Solène, all your help and kindness constituted a significant input to me.

From the rope of Wageningen University, I would like to thank all members of the $A B G C$ group for the nice and friendly atmosphere. You contributed to my acclimatization to the difference in altitude between Gènes Diffusion and Wageningen University. I would like to particularly thank Dianne van der Spek, and also Anouk Schurink and Sonia Eynard for kindly accepting to be my paranymphs.

At some stages of the trek, a stop in a shelter is needed to rest, to talk about the itinerary, to repair the equipment, but also to laugh out loud next to the fireplace. Thanks to all my working mates, my friends and relatives for making my shelter so warm and cozy. I would like to particularly thank Adeline, Fanny, Matthieu, Sébastien; and Anne, Anne-Constance, Cécilia, Christophe, Emilie, Guillaume, Justin, Lucille, Manu, Sandrine, Stéphanie, Thibault; and also Brigitte, Camille, Chantal, Garance, Julien, Louis, Olivier, Pauline, Sixtine for your attentiveness and for helping me to put things into perspective.

My base camp; my parents. Never swept away by an avalanche, you are the place where I can always come back when the climbing is too hard, when the cliff appears to be way steeper than expected beforehand. Thank you for your careful listening, the right of your understanding and your infinite support that helped me to push my own limits.

I did my whole trek firmly tied to my rope partner; my husband. Thank you Henri for always supporting the direction I took, joining my enthusiasm and for being my compass when the signs were unclear. We got on top together.

After reaching the summit, trekkers always speculate about what their next ascent would be. Mine will be with my son Victor in my back carrier and I will make sure to show him the most gorgeous viewpoints. 
Remerciements 

Faire une thèse c'est comme faire un trek. Même si le trekkeur est le seul à pouvoir mettre son pied devant l'autre pour avancer, il a besoin de l'aide nombreuse personnes pour atteindre le sommet. Ici, je souhaiterais exprimer ma gratitude à ceux qui ont contribué à accomplir mon trek.

Quand j'ai sollicité Johan van Arendonk pour une rencontre afin de lui présenter mon entreprise Gènes Diffusion, notre objectif de mener nos propres projets de recherche et notre besoin d'avoir une expertise scientifique; il s'est avéré être un excellent tour-opérateur. II a rapidement et parfaitement compris nos attentes et indiqua le meilleur sentier vers une fructueuse collaboration entre Gènes Diffusion et l'université de Wageningen. Johan, merci de m'avoir donné cette opportunité en or de faire une thèse au sein du groupe ABGC. J'ai apprécié ton attitude sereine, efficace et tes efforts pour rendre le projet gagnant-gagnant.

Cette collaboration aurait été impossible sans la contribution de Claude Grenier. Claude, merci d'avoir immédiatement compris l'intérêt de cette collaboration et ma volonté de faire une thèse. Merci d'avoir mis les crampons à Gènes Diffusion et de t'être assuré qu'ils restaient bien fixés. Je te suis reconnaissante pour ton soutien, ta confiance constante et ta loyauté qui m'ont montrée que j'avais si peu à perdre mais bien plus à prouver. Nos discussions lors de nos longs trajets jusqu'à Wageningen étaient un vrai bol d'air frais.

J'aimerais profondément remercier Henk Bovenhuis pour avoir été un guide horspair pendant mon trek. Merci Henk pour ta précieuse supervision faite de suggestions perspicaces, de discussions motivantes et de place à l'initiative personnelle. Tel un Sherpa expérimenté, tu as adapté ton rythme au mien ; merci pour ta patience et pour ne jamais m'avoir mise sous pression. J'ai apprécié ton attention portée aux enjeux et aux préoccupations de Gènes Diffusion.

De la cordée de Gènes Diffusion, j'aimerais remercier le directeur François Desmons et le responsable de la section Charolaise Michel Fouchet pour avoir permis ce projet de recherche. J'aimerais exprimer ma vive reconnaissance aux responsables des schémas de sélection Charolais Sébastien Landemaine et Vincent Colas. Sébastien et Vincent, merci d'avoir partagé avec moi vos connaissances sur la sélection charolaise et votre vision pratique. J'ai sincèrement apprécié de travailler avec vous. Vincent, un merci tout particulier pour ta rigueur, ton humour et ton amitié. Merci également à tous les techniciens génétiques Charolais pour votre assiduité à me fournir des informations. Je suis reconnaissante envers mes collègues du schéma de sélection Holstein pour leur soutien. Merci à Sylvie Patey et à Frédéric Lepoint pour avoir partagé avec moi votre vision rationnelle et terre-à- 
terre et pour m'avoir montré que la génétique est bien plus que des statistiques et des chiffres. Merci d'avoir compris ce que ce trek représentait pour moi. J'aimerais spécialement remercier Dany Fauqueux et Solène Rault. Dany et Solène, merci pour toute votre aide et votre bienveillance.

De la cordée de l'université de Wageningen, j'aimerais remercier tous les membres du groupe $A B G C$ pour cette atmosphère si agréable et sympathique. Vous avez contribué à mon acclimatation à la différence d'altitude entre Gènes Diffusion et l'université de Wageningen. Je tiens à remercier particulièrement Dianne van der Spek, et également Anouk Schurink et Sonia Eynard pour avoir gentiment accepté d'être mes paranymphs.

A certaines étapes du trek, s'arrêter dans un refuge est nécessaire pour se reposer, raconter son itinéraire, réparer son matériel, mais aussi pour rire aux éclats au coin de la cheminée. Merci à tous mes potes de bureau, mes amis et mes proches pour avoir rendu mon refuge si chaleureux et confortable. J'aimerais particulièrement remercier Adeline, Fanny, Matthieu, Sébastien; et Anne, Anne-Constance, Cécilia, Christophe, Emilie, Guillaume, Justin, Lucille, Manu, Sandrine, Stéphanie, Thibault; et aussi Brigitte, Camille, Chantal, Garance, Julien, Louis, Olivier, Pauline, Sixtine pour votre prévenance et pour m'avoir aidée à relativiser.

Mon camp de base; mes parents. Jamais emportés par une avalanche, vous êtes l'endroit où je peux toujours revenir quand l'ascension est trop difficile, quand la pente s'avère être bien plus raide que prévue au départ. Merci pour votre écoute attentive, pour la justesse de votre compréhension et pour votre infini soutien qui mºnt aidée à dépasser mes limites.

J'ai fait tout mon trek fermement attachée à mon compagnon de cordée; mon mari. Merci, Henri, d'avoir toujours soutenu la direction que j'ai prise, d'avoir partagé mon enthousiasme et d'avoir été ma boussole quand le balisage était flou. Tu as été mon appel d'air durant toute l'ascension.

Après avoir atteint le sommet, les trekkeurs pensent toujours à ce que pourrait être leur prochaine ascension. La mienne se fera avec mon fils Victor dans le porte-bébé et je m'assurerai de lui montrer les plus beaux points de vue.

Amélie 
Colophon 

The research described in this thesis was financially supported by the French breeding company Gènes Diffusion. The Al cooperatives Apis Diffusion, Ain Génétique Service, CECNA, CIA Gènes Diffusion, COOPELIA, COOPEL, and ELVA NOVIA; their technicians and farmers are acknowledged for their effort in collecting the data and biological samples. Institut de l'Elevage is acknowledged for making the historical crossbred data available.

The cover of this thesis and the invitation were designed by Sébastien Tricart.

This thesis was printed by Digiforce | Proefschriftmaken.nl, De Limiet 26, 4131NC, Vianen, the Netherlands. 